\title{
Synthesis and Biological Evaluation of Fingolimod Derivatives
}

\section{as Antibacterial Agents}

\section{Zore, Matej}

2021-07-09

Zore , M , Gilbert-Girard , S, Reigada , I, Patel , J , Savijoki , K, Fallarero , A \& Yli-Kauhaluoma , J 2021 , ' Synthesis and Biological Evaluation of Fingolimod Derivatives as

Antibacterial Agents ' , ACS Omega , vol. 6 , no. 28 , pp. 18465-18486 . https://doi.org/10.1021/acsomega.1c02591

http://hdl.handle.net/10138/332955

https://doi.org/10.1021/acsomega.1c02591

cc_by

publishedVersion

Downloaded from Helda, University of Helsinki institutional repository.

This is an electronic reprint of the original article.

This reprint may differ from the original in pagination and typographic detail.

Please cite the original version. 


\title{
Synthesis and Biological Evaluation of Fingolimod Derivatives as Antibacterial Agents
}

\author{
Matej Zore, ${ }^{\S}$ Shella Gilbert-Girard ${ }^{\S}$ Inés Reigada, Jayendra Z. Patel, Kirsi Savijoki, Adyary Fallarero, \\ and Jari Yli-Kauhaluoma*
}

Cite This: ACS Omega 2021, 6, 18465-18486

Read Online

ABSTRACT: We recently identified fingolimod as a potent antibiofilm compound by screening FDA-approved drugs. To study if the antibacterial activity of fingolimod could be further improved and to explore in-depth structure-activity relationships, we synthesized 28 novel fingolimod derivatives and evaluated their efficacy against Staphylococcus aureus grown in planktonic/single cell and biofilms. The most effective derivatives were tested on preformed $S$. aureus biofilms and against Gram-negative bacteria Acinetobacter baumannii and Pseudomonas aeruginosa, using fingoli-

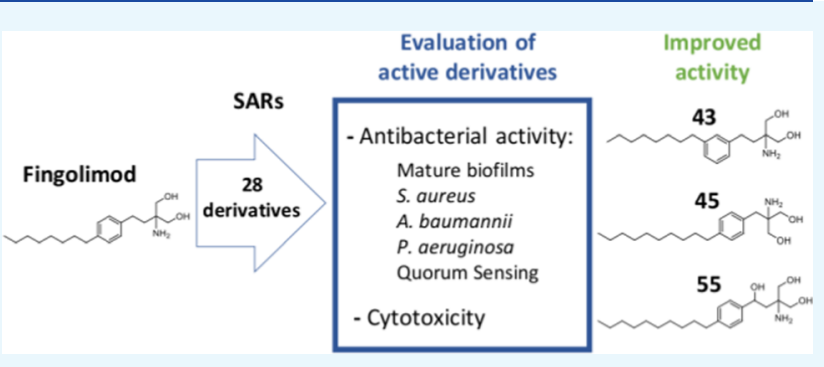
mod as the reference compound. Seven derivatives were more effective against $S$. aureus, while five other derivatives showed improved activity against $P$. aeruginosa and/or A. baumannii, with no apparent change in cytotoxicity on human cells. The most interesting derivatives, compounds 43 and 55, displayed a broader spectrum of antibacterial activity, possibly exerted by the change of the para-hydrocarbon chain to a meta position for $\mathbf{4 3}$ and by an additional hydroxyl group for $\mathbf{5 5}$.

\section{INTRODUCTION}

Bacterial infections are one of the most important challenges of modern medicine, as the emergence of multidrug-resistant strains increasingly reduces the options of antibiotic treatment. ${ }^{1}$ In particular, biofilm-forming organisms are responsible for an important number of recalcitrant infections. ${ }^{2,3}$ Biofilms, defined as multicellular communities protected by a selfproduced matrix, are the most common phenotype of bacteria and are well known for their high tolerance to antibiotic treatments. ${ }^{4}$ They are particularly prevalent in device-related infections, which are increasing in numbers alongside the augmenting use of medical devices, and frequently cause the removal of the device. ${ }^{5,6}$ For these reasons, bacterial biofilms represent a large burden on the health care system and lead to significant morbidity and considerable costs.

Great efforts have been made in recent years to develop new treatment strategies and identify new antimicrobial compounds among natural and synthetic products as well as approved drugs. Sphingosine (Figure 1), a sphingoid base naturally found in mammalian cells, has a well-reported antimicrobial<smiles>CCCCCCCCCC=C[C@@H](O)[C@H](N)CO</smiles>
Sphingosine<smiles>CCCCCCCCc1ccc(CCC(N)(CO)CO)cc1</smiles>
Fingolimod activity. This molecule plays a role in the immune protection of the skin and the airways, with its depletion contributing to infection. $^{7-9}$ Sphingosine, along with other sphingolipids, has been tested against various bacterial species and its potential as an antibacterial treatment has been under evaluation in recent years. ${ }^{10-13}$ Treatment with sphingosine by inhalation or as a coating on endotracheal catheters has demonstrated a protective effect against Pseudomonas aeruginosa infection in vivo. ${ }^{14,15}$

Repurposing drugs as antimicrobials is an approach with many advantages, namely, that a large amount of information about the drug's activity, pharmacokinetics, and safety is already available, facilitating its development for a new purpose. ${ }^{16}$ Recently, we identified fingolimod as an antibacterial compound in a screening of a library of FDAapproved drugs. ${ }^{17}$ Fingolimod is a sphingosine structural analogue that was initially synthesized from the natural fungal product myriocin. ${ }^{18}$ It was approved for the treatment of relapsing multiple sclerosis in view of its immunomodulatory activity that causes a redistribution of the lymphocyte population. ${ }^{19}$ Fingolimod's antibacterial activity has been

Received: May 18, 2021

Accepted: June 29, 2021

Published: July 9, 2021

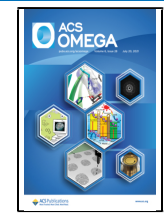

Figure 1. Structures of sphingosine and fingolimod. 
Scheme 1. Synthesis of Fingolimod Derivatives $10-16$ and $42-45^{a}$
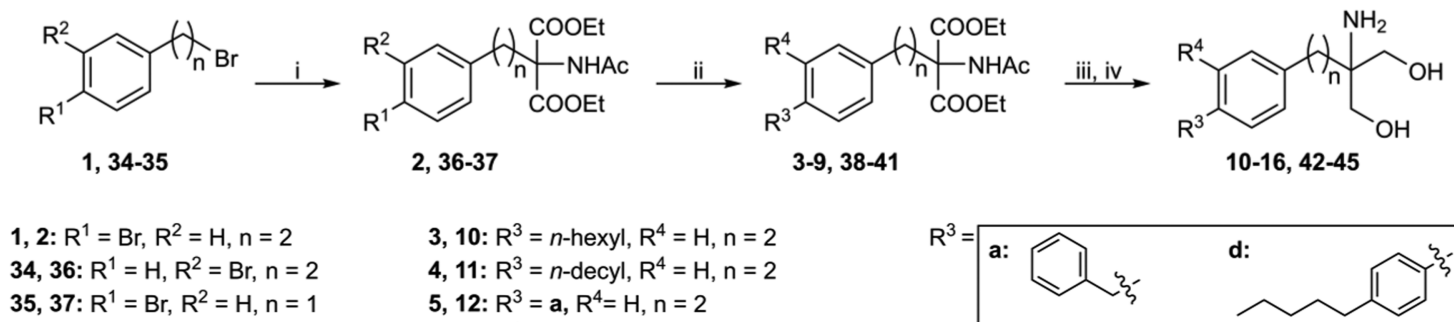

3, 10: $\mathrm{R}^{3}=n$-hexyl, $\mathrm{R}^{4}=\mathrm{H}, \mathrm{n}=2$

4, 11: $\mathrm{R}^{3}=n$-decyl, $\mathrm{R}^{4}=\mathrm{H}, \mathrm{n}=2$

5, 12: $R^{3}=a, R^{4}=H, n=2$

6, 13: $R^{3}=b, R^{4}=H, n=2$

7, 14: $R^{3}=c, R^{4}=H, n=2$

8, 15: $R^{3}=d, R^{4}=H, n=2$

9, 16: $R^{3}=e, R^{4}=H, n=2$

38, 42: $\mathrm{R}^{3}=$ trans-1-octen-1-yl, $\mathrm{R}^{4}=\mathrm{H}, \mathrm{n}=2$

39, 43: $\mathrm{R}^{3}=\mathrm{H}, \mathrm{R}^{4}=n$-octyl, $\mathrm{n}=2$

40, 44: $\mathrm{R}^{3}=n$-octyl, $\mathrm{R}^{4}=\mathrm{H}, \mathrm{n}=1$

41, 45: $\mathrm{R}^{3}=n$-decyl, $\mathrm{R}^{4}=\mathrm{H}, \mathrm{n}=1$

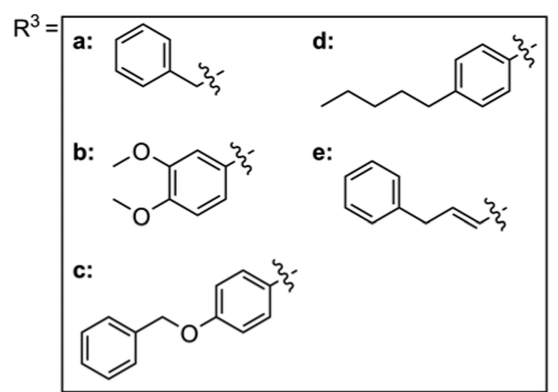

${ }^{a}$ Reagents and conditions: (i) diethyl acetamidomalonate, $\mathrm{Cs}_{2} \mathrm{CO}_{3}, \mathrm{MeCN}, \mathrm{MW}, 130{ }^{\circ} \mathrm{C}, 1 \mathrm{~h}$; (ii) $\mathrm{R}^{3}-\mathrm{B}(\mathrm{OH})_{2}$ or $\mathrm{R}^{4}-\mathrm{B}(\mathrm{OH})_{2}, \mathrm{Pd}_{2}(\mathrm{dba})_{3}, \mathrm{SPhos}$, $\mathrm{K}_{2} \mathrm{CO}_{3}$, toluene/water (4:1), $\mathrm{MW}, 110^{\circ} \mathrm{C}, 1.5-2 \mathrm{~h}$; (iii) $\mathrm{NaBH}_{4}, \mathrm{CaCl}_{2}, \mathrm{EtOH} /$ water (4:1), rt, overnight; and (iv) $2 \mathrm{M} \mathrm{LiOH}$ (aq.), $\mathrm{MeOH} /$ tetrahydrofuran (THF) (1:1), reflux, $5 \mathrm{~h}$.

Scheme 2. Synthesis of Phenyl Ether Derivatives 25-29, 48, and $49^{a}$

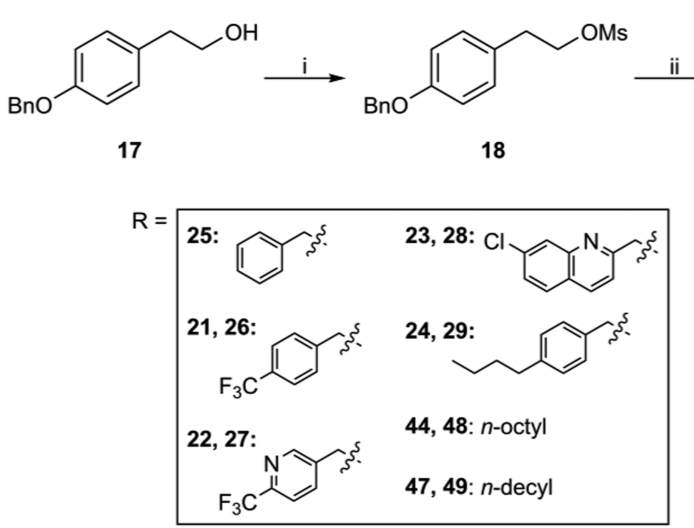

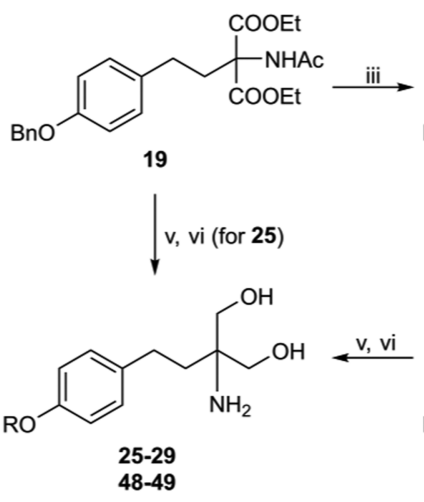<smiles>CCOC(=O)C(CCc1ccc(O)cc1)(C(=O)OCC)C(=O)OCC</smiles>

20

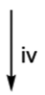

27:

${ }^{a}$ Reagents and conditions: (i) $\mathrm{MsCl}, \mathrm{Et}_{3} \mathrm{~N}$, dichloromethane $(\mathrm{DCM}), 0{ }^{\circ} \mathrm{C}, 2 \mathrm{~h}$; (ii) diethyl acetamidomalonate, $\mathrm{Cs}_{2} \mathrm{CO}_{3}, \mathrm{MeCN} \mathrm{MW}, 130{ }^{\circ} \mathrm{C}, 1$ h; (iii) $\mathrm{H}_{2}, 10 \% \mathrm{Pd} / \mathrm{C}$, EtOH/THF (1:1), rt, $5 \mathrm{~h}$; (iv) R-Br, $\mathrm{K}_{2} \mathrm{CO}_{3}, \mathrm{~N}, \mathrm{~N}$-dimethylformamide (DMF), $0{ }^{\circ} \mathrm{C}$ to rt, overnight; $(\mathrm{v}) \mathrm{NaBH}_{4}, \mathrm{CaCl}_{2}$, EtOH/water (4:1), rt, overnight; (vi) $2 \mathrm{M} \mathrm{LiBH}_{4}$, THF, rt, overnight (for 25 and 27); and (vii) $2 \mathrm{M} \mathrm{LiOH} \mathrm{(aq.),} \mathrm{MeOH/THF} \mathrm{(1:1),} \mathrm{reflux,} 5$ h.

reported against a few bacterial species and, like sphingosine, it has shown a protective effect against $P$. aeruginosa in vivo. ${ }^{14,17,20}$ As fingolimod and structurally similar compounds have strong activity against different bacterial species, we set out to synthesize fingolimod derivatives and evaluate their antibacterial effects, with a focus on their activity against biofilms. Fingolimod has been the focus of optimization efforts as a potential anticancer drug, ${ }^{21,22}$ but to our knowledge, this is the first report of the synthesis and evaluation of fingolimod derivatives as antibacterial compounds. The derivatives were first tested against Staphylococcus aureus grown in planktonic and biofilm states, and then the active compounds were further tested against preformed $S$. aureus biofilms and other pathogenic and clinically prevalent microorganisms such as Acinetobacter baumannii and $P$. aeruginosa. We studied the cytotoxicity effects of the most promising derivatives as well as their ability to interfere with the bacterial central cell-to-cell communication system (quorum sensing), a key mediator of biofilm formation and antibacterial resistance. Finally, we evaluated the effect of fingolimod on $S$. aureus biofilms formed in the presence of human neutrophils to emulate the in vivo conditions of an infection following the implantation of a medical device.

\section{RESULTS AND DISCUSSION}

Chemistry. We designed and synthesized a library of 28 fingolimod derivatives by chemical modification of the aromatic ring, the eight-carbon chain, and the 2 -amino-1,3diol polar head. For the first set of derivatives (10-16, 25-29, 33 ), we focused mainly on the modification of the hydrocarbon chain and left the rest of the structure intact. We replaced the chain with additional aromatic structures bearing various substituents. The exceptions in this set are compounds 10 and 11, which compared to fingolimod have shorter and longer carbon chains, respectively. Based on the screening of the first set of 13 derivatives, we designed a second set (42$45,48-49,54-55,61-62,79-83)$, and in this step, we focused on the modifications of the aromatic ring and the ethylene linker connecting the aromatic ring and polar head. Again, we left the amino diol moiety intact. All compounds in this set have a hydrocarbon chain, consisting of either eight or ten carbons. 
Scheme 3. Synthesis of Derivatives 54-55 (A), Pyridine Derivatives 61-62 (B), and Quinoline and Naphthalene Derivatives 33 and $79-83(\mathrm{C})^{a}$

A<smiles>O=C(CBr)c1ccc(Br)cc1</smiles><smiles>CC1CC1CC1CC1</smiles>

B<smiles>COCCc1ccc(Br)cn1</smiles>

C<smiles>[R]c1cc2[c]c(C([Y])C)ccc2cc1[R]</smiles>
$31,63,67-69$

31: $R^{1}=H, R^{2}=H, Z=N, X=O M s, n=2$ 63: $\mathrm{R}^{1}=\mathrm{Br}, \mathrm{R}^{2}=\mathrm{H}, \mathrm{Z}=\mathrm{CH}, \mathrm{X}=\mathrm{Br}, \mathrm{n}=1$ 67: $\mathrm{R}^{1}=\mathrm{Br}, \mathrm{R}^{2}=\mathrm{H}, \mathrm{Z}=\mathrm{N}, \mathrm{X}=\mathrm{OMs}, \mathrm{n}=2$ 68: $R^{1}=H, R^{2}=C l, Z=N, X=B r, n=1$ 69: $R^{1}=B r, R^{2}=H, Z=N, X=B r, n=1$<smiles>[R]c1ccc(C(O)CC(N)(CO)CO)cc1</smiles>

55: $\mathrm{R}=n$-decyl<smiles>[R]c1ccc(CCC(N)(CO)CO)nc1</smiles>

62: $\mathrm{R}=n$-decyl<smiles>[R]c1cc2[Z]c(CC(N)(CO)CO)ccc2cc1[R3]</smiles>

$33,79-83$
33: $R^{3}=H, R^{4}=H, Z=N, n=2$

79: $\mathrm{R}^{3}=n$-octyl, $\mathrm{R}^{4}=\mathrm{H}, \mathrm{Z}=\mathrm{CH}, \mathrm{n}=1$

80: $\mathrm{R}^{3}=n$-octyl, $\mathrm{R}^{4}=\mathrm{H}, \mathrm{Z}=\mathrm{N}, \mathrm{n}=2$

81: $\mathrm{R}^{3}=n$-decyl, $\mathrm{R}^{4}=\mathrm{H}, \mathrm{Z}=\mathrm{N}, \mathrm{n}=2$

82: $R^{3}=H, R^{4}=n$-octyl, $Z=N, n=1$

83: $\mathrm{R}^{3}=n$-decyl, $\mathrm{R}^{4}=\mathrm{H}, \mathrm{Z}=\mathrm{N}, \mathrm{n}=1$

${ }^{a}$ Reagents and conditions: (i) diethyl acetamidomalonate, $\mathrm{Cs}_{2} \mathrm{CO}_{3}, \mathrm{MeCN}$, or DMF, MW, $130{ }^{\circ} \mathrm{C}, 1 \mathrm{~h}$; (ii) $n$-octylboronic acid or $n$-decylboronic acid, $\mathrm{Pd}_{2}(\mathrm{dba})_{3}$, SPhos, $\mathrm{K}_{2} \mathrm{CO}_{3}$, toluene/water (4:1), MW, $110^{\circ} \mathrm{C}, 1.5-8 \mathrm{~h}$; (iii) $\mathrm{NaBH}_{4}, \mathrm{CaCl}_{2}, \mathrm{EtOH} /$ water $(4: 1)$, rt, overnight or $1 \mathrm{M} \mathrm{LiAlH}$, THF, $0{ }^{\circ} \mathrm{C}$ to rt, $2 \mathrm{~h}$ (for 80 and 81); and (iv) $2 \mathrm{M} \mathrm{LiOH}$ (aq.), $\mathrm{MeOH} / \mathrm{THF}(1: 1)$, reflux, $5 \mathrm{~h}$.

The four to six-step synthesis of all derivatives is presented in Schemes 1-3. A crucial step in the synthesis was the nucleophilic substitution of halide or mesylate with diethyl acetamidomalonate in the presence of cesium carbonate to obtain para-bromo $\mathrm{N}$-acetylated diester intermediates 2, 3637, 51, 58, and 70-73, or $\mathrm{N}$-acetylated diester phenol intermediate 20. ${ }^{23}$ Bromo intermediates were later used for microwave-assisted Suzuki coupling with an appropriate boronic acid and palladium catalyst (Schemes 1 and 3), while a phenol intermediate was used for O-alkylation with appropriate alkyl bromide in the presence of potassium carbonate (Scheme 2). The last step in the synthesis of all derivatives was a reduction of the corresponding diester with sodium borohydride and calcium chloride, or lithium aluminum hydride to obtain $\mathrm{N}$-acetylated diol intermediates, which were further hydrolyzed with lithium hydroxide (aq.) to give the desired compounds. ${ }^{24}$

Screening of the Derivatives for Their Antibacterial Activity against $S$. aureus. The antibacterial activity of the synthesized compounds was first evaluated against $S$. aureus at a concentration of $50 \mu \mathrm{M}$ (Supporting Information, Figure S1). Compounds that inhibited both the planktonic cells (turbidity and viability) and the biofilm formation (viability and biomass) by at least $60 \%$ were considered active. From the screening of the first set of 13 compounds (Figure S1A), we identified only two active compounds (11 and 15), which were then selected for further characterization. Compound $\mathbf{1 1}$ had the strongest inhibitory activity and was also the most structurally similar to fingolimod, with only two carbons added to its hydrocarbon chain. As opposed to the other derivatives with two aromatic rings, compounds 15 and 29 both possessed a short hydrocarbon chain. Yet, only 15 displayed high enough activity to be considered active. These results demonstrated the importance of the hydrocarbon chain for the antibacterial and antibiofilm activity, and its replacement led to decreased or lost inhibitory activity even at the concentration of $50 \mu \mathrm{M}$. In addition, the length of the alkyl chain proved important. Compound $\mathbf{1 0}$ had a shorter, sixcarbon chain and possessed only limited activity against $S$. aureus biofilms. As the only derivatives with a measurable antibacterial activity were the ones with a hydrocarbon chain, and since fingolimod and 11, the two compounds with the longest chains, displayed the highest inhibitory activity, the second step of optimization focused on derivative structures with this feature.

The antibacterial activity of the second set of derivatives was also first studied against $S$. aureus at $50 \mu \mathrm{M}$ (Figure S2B). Among these, only pyridine derivative $\mathbf{6 1}$ did not show an inhibitory activity comparable to fingolimod and was therefore discarded. This finding was intriguing, as $\mathbf{6 2}$ had an identical structure, with a longer hydrocarbon chain, and yet displayed a higher activity. Including the two derivatives selected from the first screening (11 and 15), a total of 16 derivatives active against $S$. aureus were selected for further characterization.

Concentration-Response of the Active Derivatives. To determine the minimal inhibitory concentration (MIC), 
(A) $5 \mu \mathrm{M}$

$\square 10 \mu \mathrm{M}$

$15 \mu \mathrm{M}$

$25 \mu \mathrm{M}$

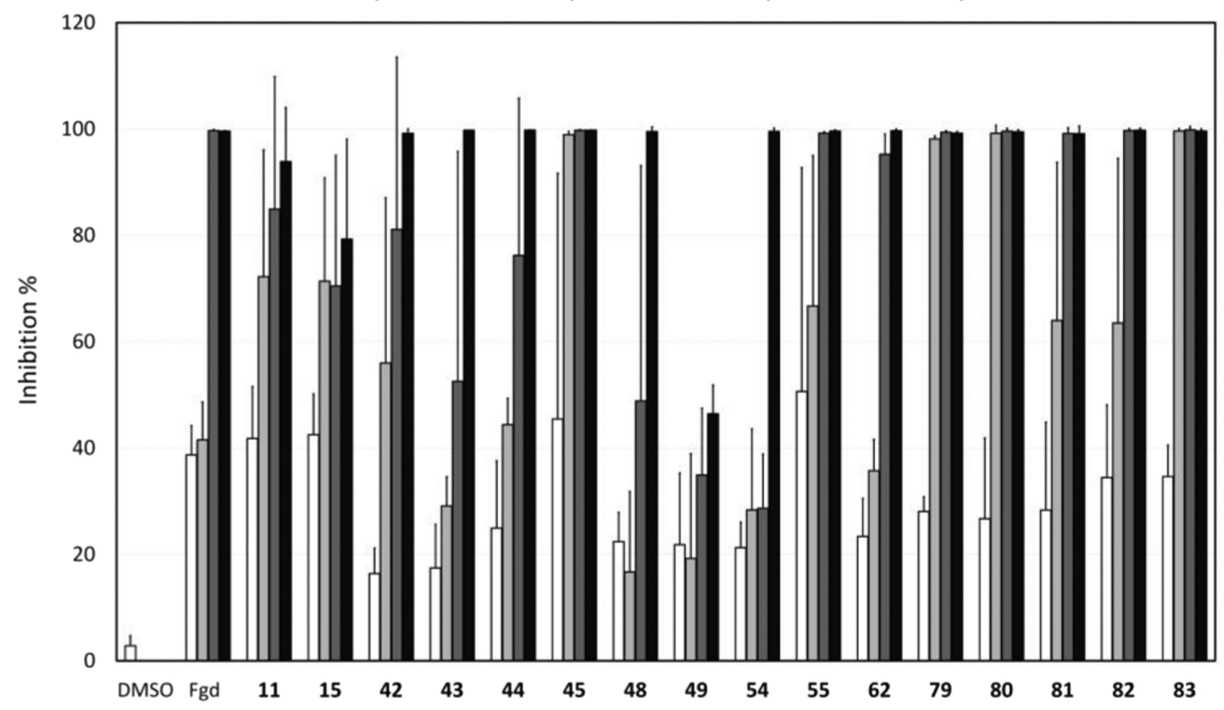

(B)

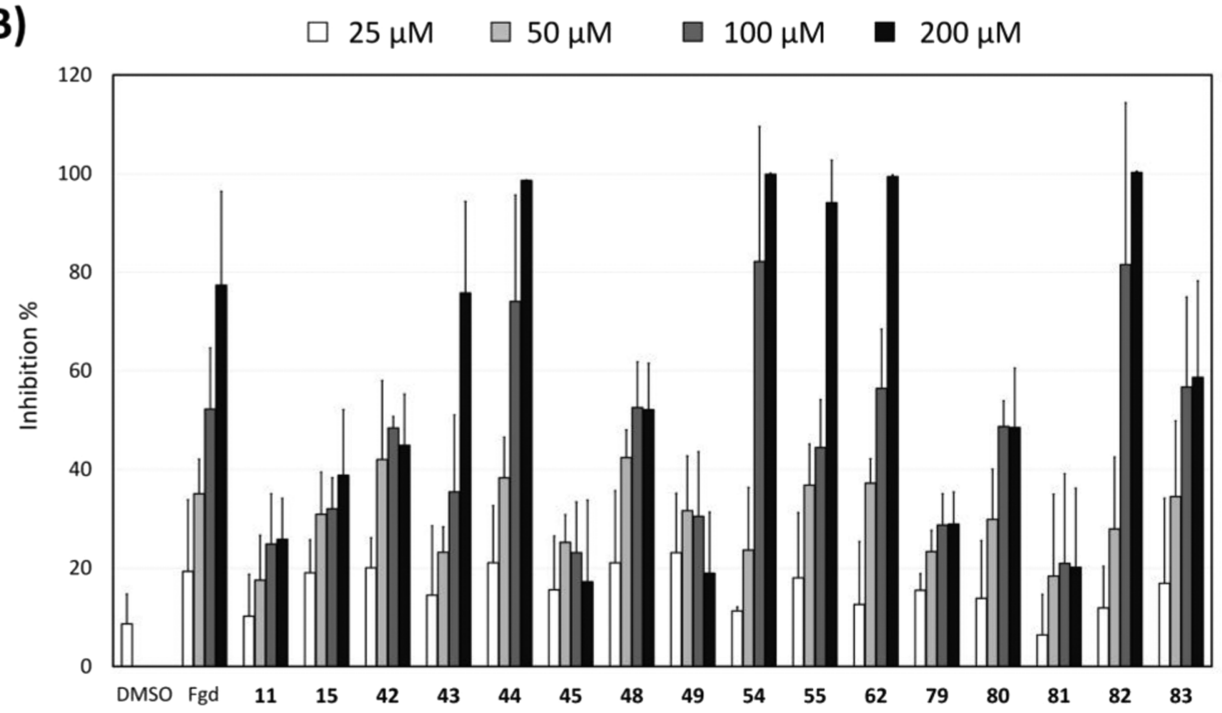

Figure 2. Inhibition of the viability of S. aureus ATCC 25923 biofilms in pre-exposure (A) and post-exposure (B) after exposure to fingolimod (Fgd) derivatives. The results are expressed as the inhibition percentage \pm SD in comparison to the untreated control. The experiment was repeated three times, each with two replicates per concentration.

the active derivatives were tested at different concentrations against $S$. aureus ATCC 25923. Here, the MIC is defined as the lowest concentration where no growth was visible (resulting in over $90 \%$ inhibition of turbidity and viability of the planktonic cells) after $18 \mathrm{~h}$ of incubation. In addition, the compounds were tested in post-exposure for their capacity to affect a preformed biofilm (compounds added to 18-h-old biofilms and incubated for $24 \mathrm{~h}$ ). Fingolimod was previously found to have an MIC of $15 \mu \mathrm{M}$ in pre-exposure with some activity also against preformed biofilms. ${ }^{17}$ The same combination of four measurements used for the initial screening rounds (planktonic turbidity, planktonic viability, biofilm viability, and biofilm total biomass) was used in both pre- and post-exposure studies. Figure 2 shows the inhibition of the viability of $S$. aureus biofilms by the derivatives in either pre-exposure at $5-25 \mu \mathrm{M}$ or post-exposure at $25-200 \mu \mathrm{M}$. The viability of the biofilms is shown as a representative parameter, and the other three measurements lead to similar conclusions regarding the activity of the derivatives. The inhibition percentages and standard deviation (SD) obtained for all measurements (viability and turbidity of the planktonic cells, viability, and biomass of the biofilms) are available as the Supporting Information (Table $\mathrm{S} 1$ ). In pre-exposure (Figure 2A), seven derivatives displayed higher inhibitory activity than fingolimod. Four derivatives, 45, $\mathbf{7 9}, \mathbf{8 0}$, and 83 , had an MIC of $10 \mu \mathrm{M}$, and for some replicates, the MIC of $\mathbf{4 5}$ and $\mathbf{5 5}$ was as low as $5 \mu \mathrm{M}$. The derivatives 11 and 81 displayed an MIC varying from 10 to $15 \mu \mathrm{M}$ (depending on the replicate), and $\mathbf{6 2}$ and $\mathbf{8 2}$ had the same MIC as fingolimod. Interestingly, wide variations in the antibacterial activity were observed between very similar structures, and in some cases, small structural changes led to a very drastic change of activity.

Generally, a longer hydrocarbon chain seemed beneficial as all derivatives with a 10-carbon chain $(11,45,49,55,62,81$, and 83) had an MIC either equal or lower than fingolimod, except for 49. As an example, derivatives 44 and 45, which structurally differ only in the length of the chain, had an MIC of $15-25$ and 5-10 $\mu \mathrm{M}$, respectively. However, this did not 
Table 1. Minimum Inhibitory Concentration (MIC) of the 16 Selected Active Fingolimod Derivatives against all Strains Tested $^{d}$

\begin{tabular}{|c|c|c|c|c|c|c|}
\hline & & \multicolumn{5}{|c|}{$\operatorname{MIC}(\mu \mathrm{M})^{a}$} \\
\hline Compound & Structure & $\begin{array}{c}\text { S. aureus } \\
\text { ATCC } 25923\end{array}$ & $\begin{array}{c}\text { S. aureus } \\
\text { ATCC } 12598\end{array}$ & $\begin{array}{l}\text { S. aureus } \\
\text { P2 }\end{array}$ & $\begin{array}{l}\text { A. baumannii } \\
\text { NCTC } 13423\end{array}$ & $\begin{array}{c}\text { P. aeruginosa } \\
\text { ATCC } 9027\end{array}$ \\
\hline Fgd & & 15 & 15 & 15 & 25 & $>200^{b}$ \\
\hline 11 & & $10-15$ & $-c$ & - & Inactive $^{\mathrm{d}}$ & Inactive \\
\hline 15 & & $25-100$ & - & - & Inactive & Inactive \\
\hline 42 & & $15-25$ & - & - & $>50$ & Inactive \\
\hline 43 & & $15-25$ & - & - & 15 & $50-100$ \\
\hline 44 & & $15-25$ & - & - & $25-50$ & $>200$ \\
\hline 45 & & $5-10$ & $5-10$ & $5-10$ & Inactive & Inactive \\
\hline 48 & & $15-25$ & - & - & $>50$ & $>200$ \\
\hline 49 & & $50-100$ & - & - & Inactive & Inactive \\
\hline 54 & & 25 & - & - & 50 & 100 \\
\hline 55 & & $5-15$ & 10 & 10 & 15 & Inactive \\
\hline 62 & & 15 & - & - & 15 & $>200$ \\
\hline 79 & & 10 & $5-10$ & 10 & Inactive & Inactive \\
\hline 80 & & 10 & 10 & 10 & $15-25$ & Inactive \\
\hline 81 & & $10-15$ & - & - & Inactive & Inactive \\
\hline 82 & & 15 & 10 & 10 & 15 & $>200$ \\
\hline 83 & & 10 & 10 & 10 & $>50$ & Inactive \\
\hline
\end{tabular}

${ }^{a}$ The MIC is defined as the lowest concentration where no growth was visible ( $>90 \%$ inhibition of turbidity and viability of the planktonic cells). The experiment was repeated three times with two replicates per concentration. ${ }^{b}$ When some inhibitory activity was observed, but no MIC was reached, the MIC is indicated to be over the highest concentration tested. ${ }^{c} \mathrm{~A}$ dash indicates that the compound was not tested on the strain. $d$ "Inactive" indicates that no activity was observed up to the highest concentration tested $(50 \mu \mathrm{M}$ with A. baumannii and $200 \mu \mathrm{M}$ with $P$. aeruginosa). 
apply to all comparable structures, as $\mathbf{8 0}$ and $\mathbf{8 1}$ had very similar activity and the compound with the shorter chain was slightly more potent. Compound 81, like fingolimod, was not fully soluble in dimethyl sulfoxide (DMSO), which is likely to decrease its activity. Replacing the phenyl ring in fingolimod with quinoline or naphthalene seemed to either improve the activity or leave it unchanged. All derivatives with bicyclic aromatic rings performed the same as fingolimod ( 81 and $\mathbf{8 2}$ ) or better $(\mathbf{7 9}, \mathbf{8 0}$, and 83$)$. On the other hand, replacing the phenyl ring with pyridine negatively affected the inhibitory activity of derivative 61. However, the longer chain of compound $\mathbf{6 2}$ compensated for this modification since the MIC was similar to fingolimod. A shorter carbon linker between the aromatic ring and the polar head did not seem to positively affect the activity in itself ( 44 has lower activity than fingolimod), while not necessarily being correlated with a lower activity as some of the most potent derivatives harbored this modification (45, 79, and 83). Addition of another hydroxyl group next to the polar head decreased the inhibitory activity (54), although a longer hydrocarbon chain seems to compensate for this modification (55). Phenyl ether derivatives 48 and 49 had lower activity, indicating that the oxygen on the para position negatively affects the antibacterial activity. The meta-isomer (43) had slightly lower activity (MIC of $15-25 \mu \mathrm{M})$, suggesting that the position of the hydrocarbon chain plays a minor role against $S$. aureus. A combination of different structural changes in some derivatives might also affect the antibacterial activity in a more complex way that would be difficult to directly correlate to one or another change. In the case of $\mathbf{8 2}$ and $\mathbf{8 3}$, several modifications were made compared to fingolimod; yet, the activity remained unchanged or even improved (83).

Very different results were obtained in post-exposure (Figure $2 \mathrm{~B})$, as the derivatives $\mathbf{4 4}, \mathbf{5 4}$, and 82 were the strongest inhibitors, affecting both the viability (Figure $2 \mathrm{~B}$ ) and total biomass (Table S1) of preformed biofilms by at least $70 \%$ at $100 \mu \mathrm{M}$. Considering that preformed biofilms display a greater tolerance to chemical agents, such a reduction is not negligible. Other derivatives showed activity comparable to fingolimod $(43,48,55,62,80$, and 83) and caused an important inhibition of the preformed biofilms. As opposed to preexposure, a longer hydrocarbon chain did not improve the post-exposure activity. On the contrary, many derivatives with this feature that showed potent activity in pre-exposure had an important loss of activity in post-exposure. In addition, when comparing similar compounds with shorter and longer chains, the compounds with the shorter chain always performed better (e.g., fingolimod vs 11, 44 vs 45 , etc.). A shorter linker to the polar head also appeared a positive change (fingolimod vs 44), while a bicyclic aromatic ring did not seem to change the postexposure activity. The addition of a hydroxyl group $(54,55)$ also appeared to positively influence the activity. Interestingly, the derivatives that performed best in pre-exposure were quite different from those that did best in post-exposure, underlining how each setting's conditions are greatly important in what type of structures will prove efficient.

Activity of the Active Derivatives on Other Bacterial Strains. To verify if the derivatives that performed best against S. aureus ATCC 25923 could also show activity against other clinical strains, we tested six of the most effective derivatives $(\mathbf{4 5}, \mathbf{5 5}, \mathbf{7 9}, \mathbf{8 0}, \mathbf{8 2}$, and 83) against S. aureus ATCC 12598 (pathogenic septic arthritis isolate) and P2 (penicillin-resistant hip prosthetic implant isolate) at $5-10-15-25 \mu \mathrm{M}$ as described above for planktonic and biofilm cells. The MIC values obtained for these derivatives against each $S$. aureus strain are shown in Table 1 . All of the inhibition results against the clinical strains of $S$. aureus are available as the Supporting Information in Table S2. All six derivatives and fingolimod showed a similar and even increased activity in some cases against the clinical strains compared to $S$. aureus ATCC 25923. The derivatives $\mathbf{4 5}$ and $\mathbf{7 9}$ were the most potent, with an MIC between 5 and $10 \mu \mathrm{M}$, which exceeds MIC detected with the parent compound.

In addition, we previously reported that fingolimod shows strong activity against $A$. baumannii (MIC $25 \mu \mathrm{M}$ ) and modest activity against $P$. aeruginosa. ${ }^{17}$ These bacteria belong to the ESKAPE pathogens (Enterococcus faecium, S. aureus, Klebsiella pneumoniae, A. baumannii, $P$. aeruginosa, and Enterobacter species), causing a majority of nosocomial infections and having a great ability to evade treatment. ${ }^{25}$ Here, we tested the 16 derivatives selected from the initial screening against $A$. baumannii at $10-15-25-50 \mu \mathrm{M}$ and against $P$. aeruginosa at 50-100-150-200 $\mu \mathrm{M}$ using the same protocol as above with necessary modifications, taking into account the Gramnegative nature of the tested species. A. baumannii NCTC 13423 is a multidrug-resistant $\operatorname{strain}^{26}$ and $P$. aeruginosa ATCC 9027 is a nonvirulent antibiotic-sensitive clinical strain. ${ }^{27}$ Fingolimod had previously shown the strongest activity against this strain out of a few P. aeruginosa strains. ${ }^{17}$ Derivatives were tested in pre-exposure, and Table 1 shows the MIC measured for each derivative. Where no MIC could be obtained, the results for the highest concentration tested are shown. All inhibition results are available as the Supporting Information in Table S3. Four derivatives $(43,55,62$, and 82$)$ displayed a clearly increased activity with an MIC of $15 \mu \mathrm{M}$ against $A$. baumannii. The derivatives that were found the most effective against $A$. baumannii were not correlated to those detected as most effective against $S$. aureus in pre-exposure. The derivatives 55,80 , and 82 performed well on both strains, whereas 43 and 62 displayed improved activity only against $A$. baumannii. On the other hand, 11, 45, and 79, compounds with high efficacy against $S$. aureus, were inactive at concentrations up to $50 \mu \mathrm{M}$ against $A$. baumannii. Interestingly, 43 and 82, which have the hydrocarbon chain at a different position compared to fingolimod, showed an improved activity. While a longer chain seemed beneficial against $S$. aureus, this was not necessarily the case against $A$. baumannii, and only two compounds with a 10-carbon chain (55 and 62) showed an improved activity. Other structural changes either did not affect the activity or did so negatively.

The activity of the derivatives against $P$. aeruginosa was also different from what was observed against $S$. aureus and $A$. baumannii. Two derivatives, 43 and 54, displayed a clearly improved activity with an MIC of 50-100 $\mu \mathrm{M}$, while fingolimod was not able to completely inhibit the bacteria at a concentration up to $200 \mu \mathrm{M}$. The reported activity of fingolimod and sphingosine against $P$. aeruginosa has been strongly variable depending on the strains tested and the experimental conditions, ${ }^{10,14,17}$ but as inhalation of fingolimod itself was shown to rescue susceptible mice from a $P$. aeruginosa lung infection, the derivatives $\mathbf{4 3}$ and $\mathbf{5 4}$ might be interesting compounds for similar use. ${ }^{14}$ For this species, a longer hydrocarbon chain has systemically led to a lower activity, as exemplified by $\mathbf{1 1}, \mathbf{4 5}$, and 55, in comparison with fingolimod, 44 and 54, respectively. A bicyclic aromatic ring has similarly reduced the activity. As observed with A. baumannii, meta- 
isomer (43) also performed better against $P$. aeruginosa, suggesting that meta-substitution is preferable against Gramnegative species. The addition of a hydroxyl group next to the polar head (54) also improved the inhibitory activity against $P$. aeruginosa, a modification that also improved the activity against $S$. aureus in post-exposure. Other modifications did not seem to visibly affect the activity of the compounds.

When comparing the activity of the derivatives against different species, very different conclusions can be made between the Gram-positive and Gram-negative species. Compounds with a longer hydrocarbon chain, bicyclic aromatic ring, and/or shorter carbon linker on the right side seem to increase the activity against $S$. aureus. Changing the position of the hydrocarbon chain or an additional hydroxyl group next to the polar head seems to broaden the spectrum of activity, as some of the derivatives bearing these modifications have a good activity also against Gram-negative species. The derivative $\mathbf{8 2}$ displayed similar activity compared to fingolimod against $S$. aureus in pre-exposure and better activity against $S$. aureus in post-exposure and against A. baumannii. Also, 43, while having good activity against $S$. aureus in pre-exposure, was among the most active against the Gram-negative strains.

In a recent work, the mode of action of sphingosine as an antibacterial compound against $S$. aureus and $P$. aeruginosa was suggested to involve an interaction between sphingosine's protonated amino group and a negatively charged protein, cardiolipin, in the bacterial membrane, causing clustering of the protein and thus compromising membrane's permeability. ${ }^{13}$ The presence of the amino group in the structure was proven necessary for the antibacterial activity of sphingosine. Considering the structural similarity between fingolimod and sphingosine, it is likely that fingolimod uses the same mechanism, although our results also suggest that other parts of the structure, particularly the long hydrocarbon chain, are important for these molecules' antibacterial activity.

Activity of Selected Derivatives on Quorum Sensing. Quorum sensing (QS) is a community-based communication system that is activated when bacteria reach a high enough density, at which point QS induces community behaviors, such as the formation of a biofilm. ${ }^{28}$ Inhibiting QS is therefore a potential antivirulence approach to prevent biofilm formation and keep bacteria in their more susceptible planktonic state. ${ }^{29}$ The QS system molecules vary from species to species, and in Gram-negative bacteria, they are generally acyl-homoserine lactones (AHLs). ${ }^{28}$ Chromobacterium violaceum can be used as a reporter for QS activation as its QS induces the production of a violet pigment, violacein. ${ }^{30} \mathrm{We}$ previously reported that fingolimod could inhibit QS in C. violaceum. ${ }^{17}$ To test whether some of the derivatives here would show an improved QS inhibitory activity, we tested selected derivatives that performed well on various strains using $C$. violaceum as previously described. ${ }^{17,31}$

The derivatives were tested against both the wild-type strain (ATCC 31532) and the CV026 mutant strain that needs the addition of AHL to activate QS. ${ }^{30}$ The use of both strains allows indicating if the $\mathrm{QS}$ inhibition takes place upstream or downstream of the AHL synthesis, for instance, in the case of quorum quenchers via binding to the AHL outside of the cells or by affecting the AHL diffusion through the cell wall/ membrane. The viability of the bacteria was measured in parallel with a resazurin staining to assess if the inhibitory activity resulted from genuine anti-QS effects rather than bactericidal activity (Supporting information, Figure S2).
Quercetin was used as a control for QS inhibition (QSI), as its activity has been reported previously, ${ }^{32}$ and azithromycin was used as a bactericidal control. Figure 3 shows the
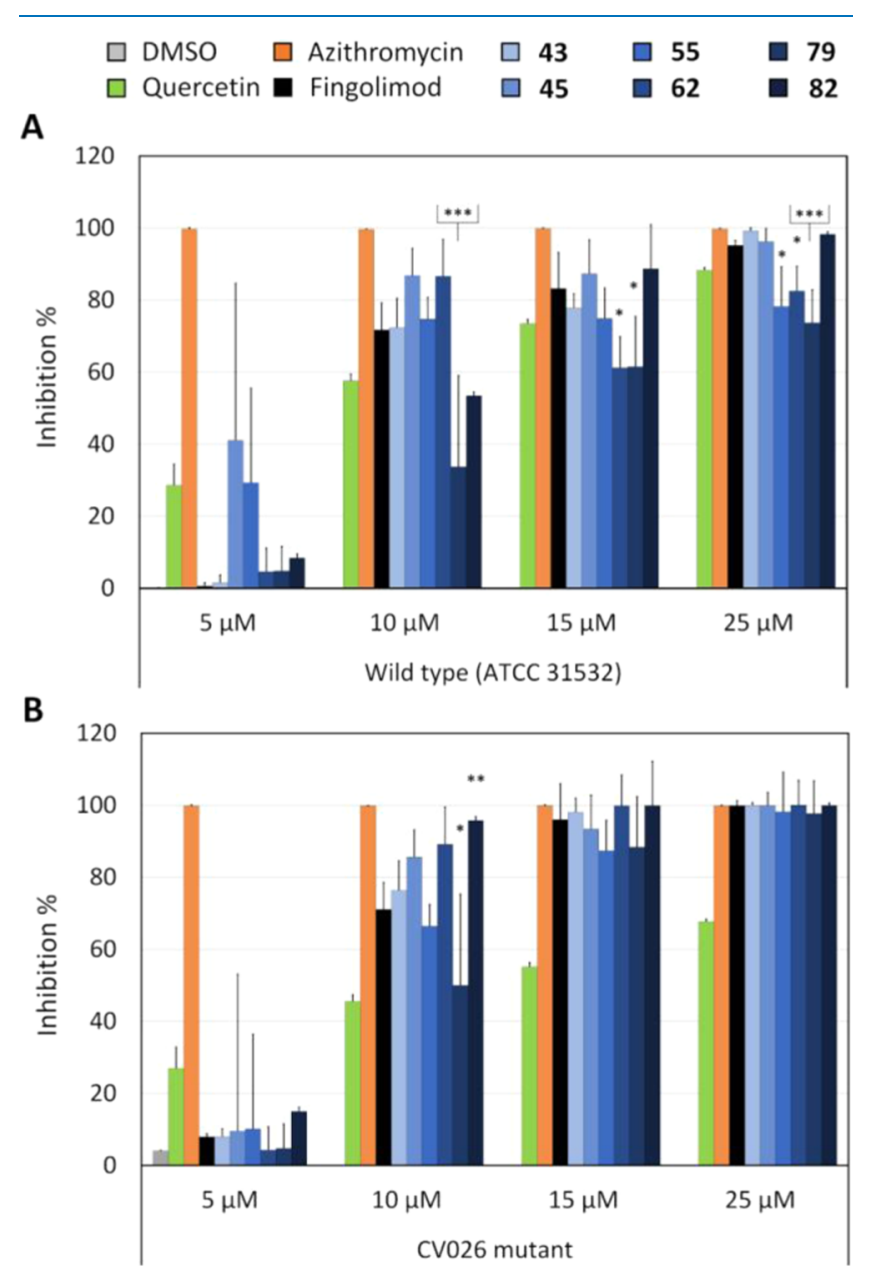

Figure 3. Quorum sensing inhibitory activity of selected fingolimod (Fgd) derivatives at various concentrations against (A) C. violaceum ATCC 31532 (wild type) and (B) C. violaceum CV026 (AHLdeficient mutant). The results are expressed as the inhibition percentage $\pm \mathrm{SD}$ as compared to the untreated control. The experiment was repeated twice with two replicates per concentration. The stars indicate the significance of the difference between the derivatives and fingolimod, $*: p<0.05, * *: p<0.01,{ }^{* * *}: p<0.001$.

inhibitory effects of the selected derivatives and the controls on both the wild-type and the mutant strains. None of the derivatives displayed a bactericidal effect on either strain of $C$. violaceum (Figure S2). On the other hand, they promoted strong anti-QS effects with at least $60 \%$ inhibition at $15 \mu \mathrm{M}$ on both strains. This indicates that the QS signal is inhibited downstream of the release of the AHL, potentially by quenching the signal or by competition with the AHL's receptor. The inhibitory profile of the derivatives did not differ significantly from that detected with fingolimod. Intriguingly, 82 had a significantly better QSI activity against the mutant strain $(p=0.006)$. Derivative 79 was found to be an effective QSI, but displayed significantly lower QSI activity than fingolimod against the mutant strain at $10 \mu \mathrm{M}(p=0.021)$ and the wild-type strain at $10 \mu \mathrm{M}(p<0.001), 15 \mu \mathrm{M}(p=$ $0.018)$, and $25 \mu \mathrm{M}(p<0.001)$. Although having a seemingly strong QSI activity against the wild-type strain at $10 \mu \mathrm{M}, 62$ 
performed significantly worse than fingolimod at 15 and 25 $\mu \mathrm{M}(p=0.016$ and 0.036 , respectively). Since the QSI activity profiles of each derivative are highly similar, clear conclusions as to what structural changes benefit the QSI activity are hard to make.

Cytotoxicity of Selected Derivatives. Fingolimod has been reported to have cytotoxic effects on various cancer cell lines with a $\mathrm{CC}_{50}$ value in the range of 5-20 $\mu \mathrm{M}^{33,34}$ To see if some of the structural changes made on the derivatives could ameliorate this, the same six derivatives selected for the QSI experiment were also tested on three cell lines, A549, HEp-2, and HL-60. Table 2 shows the $\mathrm{CC}_{50}$ values obtained for each

Table 2. $\mathrm{CC}_{50}$ of Fingolimod and Six Derivatives on Three Human Cell Lines (A549, HEp-2, and HL-60), after a 24 h Incubation

\begin{tabular}{lllc} 
& \multicolumn{3}{c}{$\mathrm{CC}_{50}(\mu \mathrm{M})^{a}$} \\
\cline { 2 - 4 } fingolimod & \multicolumn{1}{c}{ A549 } & \multicolumn{1}{c}{ HEp-2 } & HL-60 \\
43 & $>40$ & $>40$ & $36.1 \pm 13.4$ \\
45 & $27.4 \pm 15.1$ & $>40$ & $23.4 \pm 3.2$ \\
55 & $35.3 \pm 5.1$ & $33.9 \pm 1.2$ & $3.2 \pm 1$ \\
62 & $27.6 \pm 6.4$ & $30.9 \pm 6.2$ & $3.6 \pm 6.9$ \\
79 & $>40$ & $>40$ & $26.9 \pm 1.6$ \\
82 & $27.5 \pm 3$ & $28.8 \pm 1.8$ & $6.5 \pm 0.8$
\end{tabular}

${ }^{a}$ Calculated from the results of four experiments with each two technical replicates per concentration (two experiments for HL-60).

cell line after exposure to the compounds. In contrast with previous reports, fingolimod had a $\mathrm{CC}_{50}$ value above or close to the highest concentration tested $(40 \mu \mathrm{M})$, possibly due to different incubation times and poor solubility. None of the derivatives displayed reduced cytotoxicity in comparison to fingolimod, but $\mathbf{4 3}$ and 79 both displayed a lesser cytotoxic activity than the other derivatives and were quite similar to fingolimod. All compounds, including fingolimod, had $\mathrm{CC}_{50}$ at a higher concentration than their MIC against $S$. aureus and $A$. baumannii, offering a potential therapeutic window for antibacterial treatment. While many derivatives have shown an increased antibacterial activity, fingolimod also remains an interesting potential antibacterial compound as it is less cytotoxic. In addition, it has been reported that only the nonphosphorylated form of fingolimod is cytotoxic, while the phosphorylated compound might even have a cytoprotective effect. $^{35,36}$ As fingolimod, and possibly some of its derivatives, become phosphorylated in vivo, it is possible that they would prove a safe treatment option, something that could be confirmed by future in vivo studies.

Effect of Fingolimod on S. aureus in Coculture with Human Neutrophils. As biofilms are particularly prevalent in device-associated infection, a potential application for fingolimod and its derivatives could be the protection of medical devices against biofilm formation. Many factors can affect the activity of a drug in vivo, for instance, the presence of human cells and their by-products as well as inflammation and tissue damage following the insertion of a medical device. The placement of endotracheal tubes results in tissue injuries that induce the influx of neutrophils, increasing their number by up to 10 -fold in the trachea after intubation. ${ }^{37,38}$ This acute inflammatory response may lead to the ineffectiveness of the innate immune system to clear out planktonic bacteria, giving a perfect opportunity for biofilm formation. ${ }^{39}$ Fingolimod being the least cytotoxic compound in our study, we used it in a proof-of-concept model to show how it would protect a catheter made of clinically relevant material, low-density polyethylene (LDPE), from biofilm formation in a less simplified environment. We used a coculture system that includes HL-60 cells differentiated into neutrophils and $S$. aureus ATCC 25923 . $^{40}$

Figure 4 shows the effects of fingolimod $(25 \mu \mathrm{M})$ on the prevention of $S$. aureus ATCC 25923 attachment on LDPE

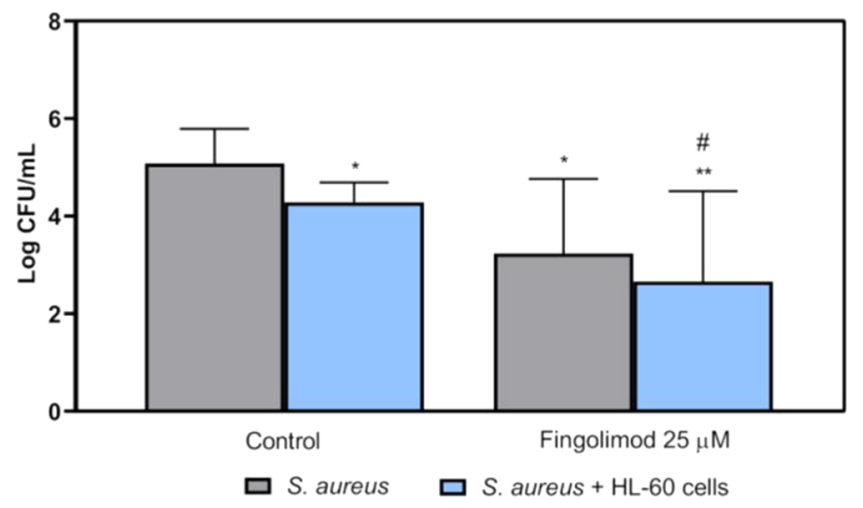

Figure 4. Viable counts of adhered S. aureus ATCC 25923 on LDPE tubes, grown alone or in coculture with differentiated HL-60 cells and exposed for $24 \mathrm{~h}$ to fingolimod at $25 \mu \mathrm{M}$. The results are expressed as mean + SD of three technical replicates in experiments repeated three times. * Indicates differences with the monoculture control, \# indicates differences with the coculture control $(*: p<0.05$, **: $p<$ $0.01, \#: p<0.05)$.

tubes after a $24 \mathrm{~h}$ incubation. Fingolimod alone (in the absence of HL-60 cells) significantly reduced the numbers of attached viable $S$. aureus $(p=0.013)$. Adding the HL-60 cells to the system resulted in a significant reduction of attached $S$. aureus $(p=0.023)$. The addition of fingolimod in combination with HL-60 cells also caused a significant reduction of the bacterial attachment in comparison with the coculture control $(p=$ 0.042). Fingolimod and the neutrophils seemed to act in synergy against the bacteria as the combination of the two had a slightly stronger effect than fingolimod or the cells alone. This showed that fingolimod, and quite probably its derivatives, are still active against $S$. aureus and has a protective activity on the catheter even in the presence of cells.

\section{CONCLUSIONS}

In this work, we developed a library of 28 fingolimod derivatives and evaluated their antibacterial and antibiofilm activities. Compared to fingolimod, seven compounds displayed a better activity against $S$. aureus, with an MIC below $15 \mu \mathrm{M}$. Five derivatives were also more active against preformed $S$. aureus biofilms. On the other hand, five derivatives showed improved activity against $P$. aeruginosa and/or A. baumannii. Some of the most interesting compounds in our study include 43, the meta-isomer of fingolimod, which was the most active against the Gram-negative species and was one of the least cytotoxic derivatives. Derivative $\mathbf{5 5}$ had an increased activity against $S$. aureus in both pre- and postexposure and against $A$. baumannii. The derivative 45 was the most active against $S$. aureus in pre-exposure while showing poor activity in other conditions. By contrast, compound 54, while having a lower MIC of $25 \mu \mathrm{M}$ against $S$. aureus, had improved activity in post-exposure and good activity against $P$. 
aeruginosa. This study presents many modifications of the structure of fingolimod that affected its antibacterial activity in many interesting ways. While none of the tested derivatives displayed lower cytotoxicity than fingolimod, many optimization efforts generally do not lead to both an improvement of the desired activity and reduced cytotoxicity. Nevertheless, the information gathered in this work can guide further optimization toward less cytotoxic and more potent antibacterial molecules. This family of structures, which have gained more and more attention in recent years, have promising antibacterial and QSI activities, among other potential therapeutic uses.

\section{EXPERIMENTAL SECTION}

Chemistry. All reagents used in the synthesis were acquired from Merck (Darmstadt, Germany), Fluorochem (Hadfield, United Kingdom), Combi-Blocks (San Diego), and TCI (Tokyo, Japan) and used without further purification. Moisture-sensitive reactions were conducted using dry solvents in oven-dried $\left(120^{\circ} \mathrm{C},>24 \mathrm{~h}\right)$ glassware under an inert argon atmosphere. The progress of chemical reactions was monitored by thin-layer chromatography (TLC) on $0.2 \mathrm{~mm}$ Silica gel 60 $\mathrm{F}_{254}$ aluminum plates (Merck, Darmstadt, Germany) and visualized by UV light $(254 / 366 \mathrm{~nm})$. Microwave reactions were conducted with a Biotage Initiator + SP Wave Microwave Synthesizer (Uppsala, Sweden). Column chromatography was carried out on automated Biotage Isolera Spektra Systems with $\mathrm{ACI}$ and Assist (ISO-1SW Isolera One) equipped with a variable UV-VIS (200-800 $\mathrm{nm}$ ) photodiode array (Uppsala, Sweden), using preloaded Biotage SNAP and Sfär columns, and the indicated mobile phase gradient. Nuclear magnetic resonance spectra $\left({ }^{1} \mathrm{H},{ }^{13} \mathrm{C}\right.$, and ${ }^{19} \mathrm{~F}$ NMR $)$ were recorded on a Bruker Ascend $400 \mathrm{MHz}$-Avance III HD NMR spectrometer (Bruker Corporation, Billerica, MA). Chemical shifts $(\delta)$ are reported in parts per million (ppm) relative to the residual NMR solvent signals: $\mathrm{CDCl}_{3} 7.26$ and $77.16 \mathrm{ppm}, \mathrm{CD}_{3} \mathrm{OD}$ 3.31 and $49.00 \mathrm{ppm}, \mathrm{DMSO}-d_{6} 2.50$ and $39.52 \mathrm{ppm}$, $\left(\mathrm{CD}_{3}\right)_{2} \mathrm{CO} 2.05$ and $29.84 / 206.26$ for ${ }^{1} \mathrm{H}$ and ${ }^{13} \mathrm{C} \mathrm{NMR}$, respectively. When necessary, two-dimensional NMR spectra (HSQC, HMBC, COSY) were recorded to support structure determination. Multiplicities of peaks are represented as $s$ ( singlet), d (doublet), $\mathrm{t}$ (triplet), $\mathrm{q}$ (quartet), $\mathrm{p}$ (pentet), dd (doublet of doublets), m (multiplet), and bs (broad singlet). Coupling constants $J$ are quoted in hertz $(\mathrm{Hz})$. All spectra were processed for recorded FID files with MestReNova 12.0.1 software (Mestrelab Research, Santiago de Compostela, Spain). The exact mass and purity (>95\%) of all tested compounds were confirmed by liquid chromatography-mass spectrometry (LC-MS) analyses with a Waters Acquity1 UPLC system (Waters, Milford, MA) equipped with an Acquity UPLC1 BEH C18 column $(1.7 \mu \mathrm{m}, 50 \mathrm{~mm} \times 2.1 \mathrm{~mm}$, Waters, Ireland), an Acquity PDA detector, and a Waters Synapt G2 HDMS mass spectrometer (Waters, Milford, MA) via an electrospray ionization (ESI) ion source in a positive mode. High-resolution mass spectrometry (HRMS-ESI) data were reported for the molecular ions $[\mathrm{M}+\mathrm{H}]^{+}$.

General Procedure A: Diethyl acetamidomalonate Alkylation. To a solution of diethyl acetamidomalonate (DEAM) and bromide or mesylate (typically $1.2-2$ equiv) in anhydrous MeCN or DMF (0.1-0.2 M) was added cesium carbonate $\left(\mathrm{Cs}_{2} \mathrm{CO}_{3}, 1.5\right.$ or 2.0 equiv), and the reaction mixture was irradiated in a microwave reactor for $1 \mathrm{~h}$ at $130{ }^{\circ} \mathrm{C}$. The progress of the reaction was monitored by TLC using $50 \%$
EtOAc in $n$-heptane as a mobile phase. The mixture was filtered and concentrated on a rotary evaporator. The crude product was purified by silica gel column chromatography with an increasing gradient of EtOAc (starting with 10-30\%) in $n$ heptane to afford the desired $\mathrm{N}$-acetylated diester.

General Procedure B: Suzuki Coupling. Aryl bromide or aryl chloride, boronic acid (1.2 equiv), $5 \mathrm{~mol} \%$ of tris(dibenzylideneacetone) dipalladium $(0)\left(\mathrm{Pd}_{2}(\mathrm{dba})_{3}\right)$, and 10 mol \% of 2-dicyclohexylphosphino-2',6'-dimethoxybiphenyl (SPhos) were dissolved under argon in toluene/water (4:1; 0.1-0.2 M). When the starting material did not dissolve completely, a few drops of DMF were added. The reaction mixture was bubbled with argon for $1 \mathrm{~min}$. Then, potassium carbonate $\left(\mathrm{K}_{2} \mathrm{CO}_{3}, 3.0\right.$ equiv) was added, and the reaction mixture was irradiated in a microwave reactor for $1.5-8 \mathrm{~h}$ at $110{ }^{\circ} \mathrm{C}$. The progress of the reaction was monitored by TLC using 50\% EtOAc in $n$-heptane as a mobile phase. The mixture was filtered through Celite and concentrated on a rotary evaporator. The crude product was purified by silica gel column chromatography with an increasing gradient of EtOAc in $n$-heptane, starting with 10 or $30 \%$ of EtOAc.

General Procedure C: O-Alkylation of Diethyl 2Acetamido-2-(4-hydroxyphenethyl)malonate (20). To a cooled solution of diethyl 2-acetamido-2-(4hydroxyphenethyl)malonate (20) in anhydrous DMF was added anhydrous $\mathrm{K}_{2} \mathrm{CO}_{3}$ (2.0 equiv), and the mixture was stirred for $30 \mathrm{~min}$ on an ice bath. Appropriate bromide (1.2 equiv) was dissolved in anhydrous DMF, and the resulting solution was added dropwise to the reaction at $0{ }^{\circ} \mathrm{C}$. Stirring was continued for $30 \mathrm{~min}$, after which the reaction mixture was allowed to warm up to room temperature and stirred overnight. The progress of the reaction was monitored by TLC using 50\% EtOAc in $n$-heptane as a mobile phase. The reaction was quenched with water and extracted with EtOAc. Combined organic layers were washed with brine, dried over anhydrous sodium sulfate $\left(\mathrm{Na}_{2} \mathrm{SO}_{4}\right)$, filtered, and concentrated on a rotary evaporator. The crude product was purified by silica gel column chromatography with an increasing gradient of EtOAc in $n$-heptane, starting with $20 \%$ of EtOAc.

General Procedure D: Diester Reduction and the Subsequent Amide Hydrolysis. To a solution of diester in EtOH/water (4:1), sodium borohydride $\left(\mathrm{NaBH}_{4}, 5.0\right.$ equiv) and calcium chloride $\left(\mathrm{CaCl}_{2}, 2.5\right.$ equiv) were added in portions over $1 \mathrm{~h}$, and the reaction mixture was stirred at room temperature overnight. The progress of the reaction was monitored by TLC- $\mathrm{NH}_{2}$ using $5 \% \mathrm{MeOH}$ in DCM as a mobile phase. If needed, excess quantities of $\mathrm{NaBH}_{4}$ (5.0 equiv) and $\mathrm{CaCl}_{2}$ (2.5 equiv) were added and the mixture was stirred for an additional $2-4 \mathrm{~h}$. The reaction was quenched with water or a $0.1 \mathrm{M}$ solution of $\mathrm{HCl}$ in water and extracted with either EtOAc or DCM. Combined organic layers were washed with brine, dried over anhydrous $\mathrm{Na}_{2} \mathrm{SO}_{4}$, filtered, and concentrated on a rotary evaporator to give an $\mathrm{N}$-acetylated diol intermediate, which was used in the next step without further purification. To a solution of $\mathrm{N}$-acetylated diol intermediate in $\mathrm{MeOH} / \mathrm{THF}$ (1:1), a $2 \mathrm{M}$ solution of lithium hydroxide $(\mathrm{LiOH})$ in water was added and the reaction mixture was refluxed $4-7 \mathrm{~h}$. The progress of the reaction was monitored by TLC- $\mathrm{NH}_{2}$ using $5 \% \mathrm{MeOH}$ in DCM as a mobile phase. The mixture was cooled to room temperature and portioned between water and EtOAc or DCM. The layers were separated, and the aqueous layer was extracted with either EtOAc or DCM. The combined organic layers were washed with brine, 
dried over anhydrous $\mathrm{Na}_{2} \mathrm{SO}_{4}$, filtered, and concentrated on a rotary evaporator. Silica gel column chromatography was performed with a Biotage SNAP KP-NH column and an increasing gradient of $\mathrm{MeOH}$ in $\mathrm{DCM}$, starting with $2 \%$ of $\mathrm{MeOH}$, to afford the desired amino diol compounds.

Diethyl 2-Acetamido-2-(4-bromophenethyl)malonate (2). General procedure A was followed using 4-bromophenethyl bromide (1) ( $2.00 \mathrm{~g}, 7.58 \mathrm{mmol}, 1.5$ equiv), DEAM (1.10 g, $5.05 \mathrm{mmol}), \mathrm{Cs}_{2} \mathrm{CO}_{3}(2.47 \mathrm{~g}, 7.58 \mathrm{mmol}, 1.5$ equiv), and anhydrous $\mathrm{MeCN}(20 \mathrm{~mL})$. Compound 2 was obtained as a light yellow solid (1.16 g, 58\%). $\left.{ }^{1} \mathrm{H} \mathrm{NMR} \mathrm{(400} \mathrm{MHz}, \mathrm{CDCl}_{3}\right)$ : $\delta 7.40-7.35(\mathrm{~m}, 2 \mathrm{H}), 7.04-6.99(\mathrm{~m}, 2 \mathrm{H}), 6.75(\mathrm{bs}, 1 \mathrm{H})$, 4.27-4.15 (m, 4H), 2.69-2.62 (m, 2H), 2.47-2.40 (m, 2H), $1.99(\mathrm{~s}, 3 \mathrm{H}), 1.24(\mathrm{t}, J=7.1 \mathrm{~Hz}, 6 \mathrm{H}) .{ }^{13} \mathrm{C} \mathrm{NMR}(101 \mathrm{MHz}$, $\left.\mathrm{CDCl}_{3}\right): \delta 169.2,168.1,139.7,131.5,130.3,120.0,66.4,62.8$, $33.4,29.7,23.1,14.1$. HRMS-ESI $(\mathrm{m} / z)$ : calcd for $\mathrm{C}_{17} \mathrm{H}_{23} \mathrm{NO}_{5} \mathrm{Br}[\mathrm{M}+\mathrm{H}]^{+} 400.0760$, found: 400.0760 .

Diethyl 2-Acetamido-2-(4-hexylphenethyl)malonate (3). General procedure B was followed using 2 (0.100 g, 0.250 $\mathrm{mmol}), n$-hexylboronic acid $(39.0 \mathrm{mg}, 0.300 \mathrm{mmol}, 1.2$ equiv), $\mathrm{Pd}_{2}(\mathrm{dba})_{3}$ (11.4 mg, $0.0125 \mathrm{mmol}, 0.05$ equiv), SPhos (10.3 $\mathrm{mg}, 0.0250 \mathrm{mmol}, 0.1$ equiv), $\mathrm{K}_{2} \mathrm{CO}_{3}(0.104 \mathrm{~g}, 0.750 \mathrm{mmol}$, 3.0 equiv), and toluene/water $(4: 1,2 \mathrm{~mL})$. Compound 3 was obtained as a white solid (65 mg, 64\%). ${ }^{1} \mathrm{H}$ NMR (400 MHz, $\left.\mathrm{CDCl}_{3}\right): \delta 7.11-7.01(\mathrm{~m}, 4 \mathrm{H}), 6.75(\mathrm{~s}, 1 \mathrm{H}), 4.28-4.11(\mathrm{~m}$, $4 \mathrm{H}), 2.72-2.64(\mathrm{~m}, 2 \mathrm{H}), 2.55(\mathrm{t}, J=7.6 \mathrm{~Hz}, 2 \mathrm{H}), 2.49-2.41$ $(\mathrm{m}, 2 \mathrm{H}), 1.97(\mathrm{~s}, 3 \mathrm{H}), 1.63-1.51(\mathrm{~m}, 2 \mathrm{H}), 1.36-1.20(\mathrm{~m}$, $12 \mathrm{H}), 0.94-0.84(\mathrm{~m}, 3 \mathrm{H}) .{ }^{13} \mathrm{C} \mathrm{NMR}\left(101 \mathrm{MHz}, \mathrm{CDCl}_{3}\right): \delta$ 169.1, 168.2, 140.9, 137.8, 128.5, 128.4, 66.6, 62.7, 35.7, 33.5, 31.9, 31.7, 29.8, 29.1, 23.1, 22.7, 14.2, 14.1. HRMS-ESI $(\mathrm{m} / z)$ : calcd for $\mathrm{C}_{23} \mathrm{H}_{36} \mathrm{NO}_{5}[\mathrm{M}+\mathrm{H}]^{+}$406.2593, found: 406.2594.

Diethyl 2-Acetamido-2-(4-decylphenethyl)malonate (4). General procedure B was followed using 2 (0.100 g, 0.250 $\mathrm{mmol}), n$-decylboronic acid (46.9 mg, $0.300 \mathrm{mmol}, 1.2$ equiv), $\mathrm{Pd}_{2}(\mathrm{dba})_{3}$ (11.4 mg, $0.0125 \mathrm{mmol}, 0.05$ equiv), SPhos (10.3 $\mathrm{mg}, 0.0250 \mathrm{mmol}, 0.1$ equiv), $\mathrm{K}_{2} \mathrm{CO}_{3}(0.104 \mathrm{mg}, 0.750 \mathrm{mmol}$, 3.0 equiv), and toluene/water $(4: 1,2 \mathrm{~mL})$. Compound 4 was obtained as a white solid (68 mg, 59\%). ${ }^{1} \mathrm{H}$ NMR (400 MHz, $\left.\mathrm{CDCl}_{3}\right): \delta 7.11-7.01(\mathrm{~m}, 4 \mathrm{H}), 6.74(\mathrm{bs}, 1 \mathrm{H}), 4.26-4.12(\mathrm{~m}$, $4 \mathrm{H}), 2.72-2.64(\mathrm{~m}, 2 \mathrm{H}), 2.54(\mathrm{t}, J=7.6 \mathrm{~Hz}, 2 \mathrm{H}), 2.49-2.41$ $(\mathrm{m}, 2 \mathrm{H}), 1.97(\mathrm{~s}, 3 \mathrm{H}), 1.56(\mathrm{~m}, 2 \mathrm{H}), 1.31-1.20(\mathrm{~m}, 20 \mathrm{H})$, 0.92-0.84 (m, 3H). ${ }^{13} \mathrm{C}$ NMR (101 MHz, $\left.\mathrm{CDCl}_{3}\right): \delta 169.0$, $168.1,140.8,137.7,128.4,128.3,66.4,62.5,35.5,33.3,31.9$, 31.6, 29.7, 29.64, 29.61, 29.5, 29.3, 23.0, 22.7, 14.1, 14.0. HRMS-ESI $(m / z)$ : calcd for $\mathrm{C}_{27} \mathrm{H}_{44} \mathrm{NO}_{5}[\mathrm{M}+\mathrm{H}]^{+}$462.3219, found: 462.3222 .

Diethyl 2-Acetamido-2-(4-benzylphenethyl)malonate (5). General procedure B was followed using $2(0.100 \mathrm{~g}, 0.250$ $\mathrm{mmol})$, benzylboronic acid pinacol ester $(65.4 \mathrm{mg}, 0.300$ mmol, 1.2 equiv), $\mathrm{Pd}_{2}(\mathrm{dba})_{3}(11.4 \mathrm{mg}, 0.0125 \mathrm{mmol}, 0.05$ equiv), SPhos (10.3 mg, $0.0250 \mathrm{mmol}, 0.1$ equiv), $\mathrm{K}_{2} \mathrm{CO}_{3}$ (0.104 mg, $0.750 \mathrm{mmol}, 3.0$ equiv), and toluene/water (4:1, 2 $\mathrm{mL})$. Compound 5 was obtained as a white solid $(65 \mathrm{mg}$, 64\%). ${ }^{1} \mathrm{H}$ NMR (400 MHz, $\left.\mathrm{CDCl}_{3}\right): \delta 7.30-7.23(\mathrm{~m}, 2 \mathrm{H})$, 7.21-7.14 (m, 3H), 7.11-7.03 (m, 4H), $6.73(\mathrm{~s}, 1 \mathrm{H}), 4.25-$ $4.09(\mathrm{~m}, 4 \mathrm{H}), 3.93(\mathrm{~s}, 2 \mathrm{H}), 2.72-2.63(\mathrm{~m}, 2 \mathrm{H}), 2.49-2.41$ $(\mathrm{m}, 2 \mathrm{H}), 1.95(\mathrm{~s}, 3 \mathrm{H}), 1.22(\mathrm{t}, J=7.1 \mathrm{~Hz}, 6 \mathrm{H}) .{ }^{13} \mathrm{C}$ NMR $(101$ $\left.\mathrm{MHz}, \mathrm{CDCl}_{3}\right): \delta 169.1,168.2,141.4,139.1,138.4,129.03$, 128.97, 128.7, 128.6, 126.2, 66.5, 62.7, 41.7, 33.4, 29.8, 23.1, 14.1. HRMS-ESI $(m / z)$ : calcd for $\mathrm{C}_{24} \mathrm{H}_{30} \mathrm{NO}_{5}[\mathrm{M}+\mathrm{H}]^{+}$ 412.2124, found: 412.2124 .

Diethyl 2-Acetamido-2-[2-(3',4'-dimethoxy-[1,1'-biphenyl]-4-yl)ethyl]malonate (6). General procedure B was followed using 2 (0.100 g, $0.250 \mathrm{mmol})$, (3,4-dimethoxyphenyl)boronic acid (54.6 mg, $0.300 \mathrm{mmol}, 1.2$ equiv), $\mathrm{Pd}_{2}(\mathrm{dba})_{3}(11.4 \mathrm{mg}$, $0.0125 \mathrm{mmol}, 0.05$ equiv), SPhos ( $10.3 \mathrm{mg}, 0.025 \mathrm{mmol}, 0.1$ equiv), $\mathrm{K}_{2} \mathrm{CO}_{3}$ (103.7 $\mathrm{mg}, 0.750 \mathrm{mmol}, 3.0$ equiv), and toluene/water $(4: 1,1.5 \mathrm{~mL})$. Compound 6 was obtained as a yellow solid (0.10 g, 87\%). ${ }^{1} \mathrm{H}$ NMR (400 $\left.\mathrm{MHz} \mathrm{CDCl}_{3}\right): \delta$ $7.48-7.43(\mathrm{~m}, 2 \mathrm{H}), 7.23-7.17(\mathrm{~m}, 2 \mathrm{H}), 7.11(\mathrm{dd}, J=8.3,2.1$ $\mathrm{Hz}, 1 \mathrm{H}), 7.07(\mathrm{~d}, J=2.1 \mathrm{~Hz}, 1 \mathrm{H}), 6.93(\mathrm{~d}, J=8.3 \mathrm{~Hz}, 1 \mathrm{H})$, $6.78(\mathrm{~s}, 1 \mathrm{H}), 4.28-4.16(\mathrm{~m}, 4 \mathrm{H}), 3.94(\mathrm{~s}, 3 \mathrm{H}), 3.91(\mathrm{~s}, 3 \mathrm{H})$, $2.76-2.68(\mathrm{~m}, 2 \mathrm{H}), 2.56-2.48(\mathrm{~m}, 2 \mathrm{H}), 1.99(\mathrm{~s}, 3 \mathrm{H}), 1.26(\mathrm{t}$, $J=7.1 \mathrm{~Hz}, 6 \mathrm{H}) .{ }^{13} \mathrm{C} \mathrm{NMR}\left(101 \mathrm{MHz}, \mathrm{CDCl}_{3}\right): \delta 169.2,168.2$, $149.3,148.7,139.4,139.1,134.1,129.0,126.9,119.3,111.6$, $110.5,66.5,62.7,56.12,56.07,33.5,29.9,23.1,14.1$. HRMSESI $(m / z)$ : calcd for $\mathrm{C}_{25} \mathrm{H}_{32} \mathrm{NO}_{7}[\mathrm{M}+\mathrm{H}]^{+} 458.2179$, found: 458.2180.

Diethyl 2-Acetamido-2-[2-[4'-(benzyloxy)-[1,1'-biphenyl]4-yl]ethyl]malonate (7). General procedure B was followed using 2 ( $50.0 \mathrm{mg}, 0.125 \mathrm{mmol}$ ), [4-(benzyloxy)phenyl]boronic acid (34.2 mg, $0.150 \mathrm{mmol}, 1.2$ equiv), $\mathrm{Pd}_{2}(\mathrm{dba})_{3}(5.7 \mathrm{mg}$, $0.0063 \mathrm{mmol}, 0.05$ equiv), SPhos $(5.1 \mathrm{mg}, 0.013 \mathrm{mmol}, 0.1$ equiv), $\mathrm{K}_{2} \mathrm{CO}_{3}$ ( $51.8 \mathrm{mg}, 0.375 \mathrm{mmol}, 3.0$ equiv), and toluene/ water $(4: 1,2 \mathrm{~mL})$. Compound 7 was obtained as a yellowwhite solid (52 mg, 82\%). ${ }^{1} \mathrm{H}$ NMR (400 $\left.\mathrm{MHz} \mathrm{CDCl}_{3}\right): \delta$ 7.53-7.43 (m, 6H), 7.43-7.37 (m, 2H), 7.36-7.31 (m, 1H), 7.24-7.15 (m, 2H), 7.08-6.99 (m, 2H), $6.78(\mathrm{~s}, 1 \mathrm{H}), 5.11(\mathrm{~s}$, $2 \mathrm{H}), 4.30-4.14(\mathrm{~m}, 4 \mathrm{H}), 2.78-2.68(\mathrm{~m}, 2 \mathrm{H}), 2.57-2.48(\mathrm{~m}$, $2 \mathrm{H}), 1.99(\mathrm{~s}, 3 \mathrm{H}), 1.26(\mathrm{t}, J=7.1 \mathrm{~Hz}, 6 \mathrm{H}) .{ }^{13} \mathrm{C}$ NMR $(101$ $\left.\mathrm{MHz}, \mathrm{CDCl}_{3}\right): \delta 169.2,168.2,158.4,139.2,137.1,133.9$, 129.0, 128.8, 128.1, 127.6, 126.8, 115.3, 70.2, 66.5, 62.7, 33.4, 29.0, 23.1, 14.1. HRMS-ESI $(m / z)$ : calcd for $\mathrm{C}_{30} \mathrm{H}_{34} \mathrm{NO}_{6}[\mathrm{M}+$ $\mathrm{H}]^{+}$504.2386, found: 504.2383.

Diethyl 2-Acetamido-2-[2-(4'-pentyl-[1,1'-biphenyl]-4-yl)ethyl]malonate (8). General procedure B was followed using 2 (90.0 mg, $0.225 \mathrm{mmol})$, 4-pentylphenylboronic acid $(51.9 \mathrm{mg}$, 0.270 mmol, 1.2 equiv $), \mathrm{Pd}_{2}(\mathrm{dba})_{3}(10.3 \mathrm{mg}, 0.0113 \mathrm{mmol}$, 0.05 equiv), SPhos ( $9.2 \mathrm{mg}, 0.023 \mathrm{mmol}, 0.1$ equiv), $\mathrm{K}_{2} \mathrm{CO}_{3}$ (93.3 $\mathrm{mg}, 0.675 \mathrm{mmol}, 3.0$ equiv), and toluene/water (4:1, 2 $\mathrm{mL})$. Compound 8 was obtained as a yellow-white solid (90 $\mathrm{mg}, 86 \%) .{ }^{1} \mathrm{H}$ NMR $\left(400 \mathrm{MHz}, \mathrm{CDCl}_{3}\right): \delta$ 7.53-7.44 (m, $4 \mathrm{H}), 7.28-7.17(\mathrm{~m}, 4 \mathrm{H}), 6.78(\mathrm{~s}, 1 \mathrm{H}), 4.28-4.14(\mathrm{~m}, 4 \mathrm{H})$, $2.78-2.69(\mathrm{~m}, 2 \mathrm{H}), 2.63(\mathrm{t}, J=7.6 \mathrm{~Hz}, 2 \mathrm{H}), 2.57-2.49(\mathrm{~m}$, $2 \mathrm{H}), 1.98(\mathrm{~s}, 3 \mathrm{H}), 1.71-1.59(\mathrm{~m}, 2 \mathrm{H}), 1.41-1.29(\mathrm{~m}, 4 \mathrm{H})$, $1.25(\mathrm{t}, J=7.1 \mathrm{~Hz}, 6 \mathrm{H}), 0.95-0.86(\mathrm{~m}, 3 \mathrm{H}) .{ }^{13} \mathrm{C} \mathrm{NMR}(101$ $\left.\mathrm{MHz}, \mathrm{CDCl}_{3}\right): \delta 169.2,168.2,142.1,139.5,138.4,128.98$, $128.95,127.1,126.9,66.5,62.7,35.7,33.4,31.7,31.3,29.9$, 23.1, 22.7, 14.2, 14.1. HRMS-ESI $(m / z)$ : calcd for $\mathrm{C}_{28} \mathrm{H}_{38} \mathrm{NO}_{5}$ $[\mathrm{M}+\mathrm{H}]^{+}$468.2750, found: 468.2750.

Diethyl (E)-2-Acetamido-2-[4-(3-phenylprop-1-en-1-yl)phenethyl]malonate (9). General procedure B was followed using $2(0.100 \mathrm{~g}, 0.250 \mathrm{mmol})$, trans-3-phenylpropen-1-ylboronic acid (48.6 mg, $0.300 \mathrm{mmol}, 1.2$ equiv), $\mathrm{Pd}_{2}(\mathrm{dba})_{3}$ (11.4 mg, $0.0125 \mathrm{mmol}, 0.05$ equiv), SPhos (10.3 mg, 0.0250 mmol, 0.1 equiv), $\mathrm{K}_{2} \mathrm{CO}_{3}$ ( $0.104 \mathrm{mg}, 0.750 \mathrm{mmol}, 3.0$ equiv), and toluene/water $(4: 1,2 \mathrm{~mL})$. Compound 9 was obtained as a yellow-white solid (71 mg, 65\%). ${ }^{1} \mathrm{H}$ NMR (400 MHz, $\left.\mathrm{CDCl}_{3}\right): \delta 7.35-7.17(\mathrm{~m}, 7 \mathrm{H}), 7.10-7.04(\mathrm{~m}, 2 \mathrm{H}), 6.76(\mathrm{~s}$, $1 \mathrm{H}), 6.41(\mathrm{~d}, J=15.8 \mathrm{~Hz}, 1 \mathrm{H}), 6.35-6.26(\mathrm{~m}, 1 \mathrm{H}), 4.28-4.14$ $(\mathrm{m}, 4 \mathrm{H}), 3.54(\mathrm{~d}, J=6.6 \mathrm{~Hz}, 2 \mathrm{H}), 2.72-2.63(\mathrm{~m}, 2 \mathrm{H}), 2.50-$ $2.41(\mathrm{~m}, 2 \mathrm{H}), 1.98(\mathrm{~s}, 3 \mathrm{H}), 1.25(\mathrm{t}, J=7.1 \mathrm{~Hz}, 6 \mathrm{H}) .{ }^{13} \mathrm{C} \mathrm{NMR}$ $\left(101 \mathrm{MHz}, \mathrm{CDCl}_{3}\right): \delta 169.1,168.1,140.1,139.5,135.5,130.8$, $128.7,128.6,128.5,126.2,126.1,66.4,62.6,39.4,33.3,29.9$, 23.0, 14.0. HRMS-ESI $(\mathrm{m} / z)$ : calcd for $\mathrm{C}_{26} \mathrm{H}_{32} \mathrm{NO}_{5}[\mathrm{M}+\mathrm{H}]^{+}$ 438.2280, found: 438.2282 . 
2-Amino-2-(4-hexylphenethyl)propane-1,3-diol (10). General procedure D was followed using $3(63.7 \mathrm{mg}, 0.157 \mathrm{mmol})$, $\mathrm{NaBH}_{4}$ (29.7 mg, $0.786 \mathrm{mmol}, 5.0$ equiv), $\mathrm{CaCl}_{2}$ (43.6 mg, $0.393 \mathrm{mmol}, 2.5$ equiv), and EtOH/water (4:1, $2 \mathrm{~mL}) ; \mathrm{N}$ acetylated diol intermediate (white solid, $64 \mathrm{mg}$ ), $\mathrm{MeOH}$ / THF $(2 \mathrm{~mL})$, and $2 \mathrm{M} \mathrm{LiOH}$ (aq., $2 \mathrm{~mL}$ ). Compound 10 was obtained as a white solid (24 mg, 55\%). ${ }^{1} \mathrm{H}$ NMR (400 MHz, $\left.\mathrm{CD}_{3} \mathrm{OD}\right): \delta 7.14-7.09(\mathrm{~m}, 2 \mathrm{H}), 7.08-7.03(\mathrm{~m}, 2 \mathrm{H}), 3.48(\mathrm{q}, J$ $=14.6,10.9 \mathrm{~Hz}, 4 \mathrm{H}), 2.64-2.58(\mathrm{~m}, 2 \mathrm{H}), 2.55(\mathrm{t}, J=7.5 \mathrm{~Hz}$, $2 \mathrm{H}), 1.70-1.62(\mathrm{~m}, 2 \mathrm{H}), 1.61-1.53(\mathrm{~m}, 2 \mathrm{H}), 1.37-1.26(\mathrm{~m}$, $6 \mathrm{H}), 0.93-0.85(\mathrm{~m}, 3 \mathrm{H}) .{ }^{13} \mathrm{C}$ NMR (101 MHz, $\left.\mathrm{CD}_{3} \mathrm{OD}\right): \delta$ $141.3,141.2$, 129.4, 129.2, 66.5, 56.8, 37.7, 36.5, 32.9, 32.8, 30.0, 23.7, 14.4. HRMS-ESI $(m / z)$ : calcd for $\mathrm{C}_{17} \mathrm{H}_{30} \mathrm{NO}_{2}[\mathrm{M}+$ $\mathrm{H}]^{+}$280.2277, found: 280.2277 .

2-Amino-2-(4-decylphenethyl)propane-1,3-diol (11). General procedure D was followed using $4(63.5 \mathrm{mg}, 0.138 \mathrm{mmol})$, $\mathrm{NaBH}_{4}$ (26.0 mg, $0.668 \mathrm{mmol}, 5.0$ equiv), $\mathrm{CaCl}_{2}$ (38.2 mg, $0.344 \mathrm{mmol}, 2.5$ equiv), and $\mathrm{EtOH} /$ water $(4: 1,1.0 \mathrm{~mL})$; $\mathrm{N}$ acetylated diol intermediate (white solid, $51 \mathrm{mg}$ ), $\mathrm{MeOH}$ / THF ( $1 \mathrm{~mL}$ ), and $2 \mathrm{M} \mathrm{LiOH}$ (aq., $2 \mathrm{~mL}$ ). Compound 11 was obtained as a white solid (30 mg, 65\%). ${ }^{1} \mathrm{H}$ NMR (400 MHz, $\mathrm{CD}_{3} \mathrm{OD}$ ): $\delta 7.14-7.09(\mathrm{~m}, 2 \mathrm{H}), 7.08-7.03(\mathrm{~m}, 2 \mathrm{H}), 3.49(\mathrm{q}, J$ $=14.4,10.9 \mathrm{~Hz}, 4 \mathrm{H}), 2.65-2.58(\mathrm{~m}, 2 \mathrm{H}), 2.55(\mathrm{t}, J=7.4 \mathrm{~Hz}$, $2 \mathrm{H}), 1.70-1.61(\mathrm{~m}, 2 \mathrm{H}), 1.64-1.53(\mathrm{~m}, 2 \mathrm{H}), 1.37-1.21(\mathrm{~m}$, $14 \mathrm{H}), 0.94-0.86(\mathrm{~m}, 3 \mathrm{H}) .{ }^{13} \mathrm{C} \mathrm{NMR}\left(101 \mathrm{MHz}, \mathrm{CD}_{3} \mathrm{OD}\right): \delta$ $141.3,141.2$, 129.4, 129.2, 66.4, 56.9, 37.7, 36.5, 33.1, 32.8, $30.73,30.71,30.6,30.4,30.3,30.0,23.7,14.4$. HRMS-ESI $(\mathrm{m} /$ $z$ ): calcd for $\mathrm{C}_{21} \mathrm{H}_{38} \mathrm{NO}_{2}[\mathrm{M}+\mathrm{H}]^{+}$336.2903, found: 336.2906 .

2-Amino-2-(4-benzylphenethyl)propane-1,3-diol (12). General procedure D was followed using $5(62.5 \mathrm{mg}, 0.152$ mmol), $\mathrm{NaBH}_{4}$ (28.7 mg, $0.760 \mathrm{mmol}$, 5.0 equiv), $\mathrm{CaCl}_{2}$ (41.9 $\mathrm{mg}, 0.380 \mathrm{mmol}, 2.5$ equiv), and $\mathrm{EtOH} /$ water $(4: 1,2.0 \mathrm{~mL})$; $\mathrm{N}$-acetylated diol intermediate (transparent oil, $53.8 \mathrm{mg}$ ), $\mathrm{MeOH} / \mathrm{THF}(1 \mathrm{~mL})$, and $2 \mathrm{M} \mathrm{LiOH}$ (aq., $2 \mathrm{~mL}$ ). Compound 12 was obtained as a white solid (21 mg, 49\%). ${ }^{1} \mathrm{H}$ NMR (400 $\left.\mathrm{MHz}, \mathrm{CD}_{3} \mathrm{OD}\right): \delta 7.28-7.20(\mathrm{~m}, 2 \mathrm{H}), 7.19-7.10(\mathrm{~m}, 5 \mathrm{H})$, 7.10-7.05 (m, 2H), $3.91(\mathrm{~s}, 2 \mathrm{H}), 3.49(\mathrm{q}, J=13.9,10.9 \mathrm{~Hz}$, $4 \mathrm{H}), 2.66-2.57(\mathrm{~m}, 2 \mathrm{H}), 1.70-1.61(\mathrm{~m}, 2 \mathrm{H}) .{ }^{13} \mathrm{C}$ NMR (101 $\left.\mathrm{MHz}, \mathrm{CD}_{3} \mathrm{OD}\right): \delta 143.0,141.7,140.1,129.90,129.85,129.41$, 129.38, 126.9, 66.4, 57.0, 42.4, 37.6, 30.0. HRMS-ESI $(\mathrm{m} / \mathrm{z})$ : calcd for $\mathrm{C}_{18} \mathrm{H}_{24} \mathrm{NO}_{2}[\mathrm{M}+\mathrm{H}]^{+} 286.1807$, found: $286.1808{ }^{41}$

2-Amino-2-[2-(3', 4' -dimethoxy-[1, 1' -biphenyl]-4-yl)ethyl]propane-1,3-diol (13). General procedure D was followed using 6 (96.0 $\mathrm{mg}, 0.210 \mathrm{mmol}), \mathrm{NaBH}_{4}(39.7 \mathrm{mg}$, $1.05 \mathrm{mmol}, 5.0$ equiv), $\mathrm{CaCl}_{2}$ (58.3 mg, $0.525 \mathrm{mmol}, 2.5$ equiv), and $\mathrm{EtOH} /$ water $(4: 1,2 \mathrm{~mL}) ; \mathrm{N}$-acetylated diol intermediate (white solid, $64 \mathrm{mg}$ ), $\mathrm{MeOH} / \mathrm{THF}$ (2:1, $2 \mathrm{~mL}$ ), and $2 \mathrm{M} \mathrm{LiOH} \mathrm{(aq.,} 2 \mathrm{~mL}$ ). Compound 13 was obtained as a white solid ( $38 \mathrm{mg}, 54 \%) .{ }^{1} \mathrm{H}$ NMR $\left(400 \mathrm{MHz}, \mathrm{CD}_{3} \mathrm{OD}\right): \delta$ 7.51-7.46 (m, 2H), 7.30-7.25 (m, 2H), 7.17-7.13 (m, 2H), 7.00 (d, $J=8.2 \mathrm{~Hz}, 1 \mathrm{H}), 3.89(\mathrm{~s}, 3 \mathrm{H}), 3.86(\mathrm{~s}, 3 \mathrm{H}), 3.51$ (q, $J$ $=13.9,10.9 \mathrm{~Hz}, 4 \mathrm{H}), 2.72-2.65(\mathrm{~m}, 2 \mathrm{H}), 1.74-1.67(\mathrm{~m}, 2 \mathrm{H})$. ${ }^{13} \mathrm{C}$ NMR (101 MHz, CD $\left.{ }_{3} \mathrm{OD}\right): \delta 150.7,150.0,142.8,139.8$, 135.7, 129.8, 127.7, 120.4, 113.4, 111.9, 66.5, 56.9, 56.7, 37.6, 30.0. HRMS-ESI $(m / z)$ : calcd for $\mathrm{C}_{19} \mathrm{H}_{26} \mathrm{NO}_{4}[\mathrm{M}+\mathrm{H}]^{+}$ 332.1862, found: 332.1862 .

2-Amino-2-[2-[4'-(benzyloxy)-[1,1'-biphenyl]-4-yl]ethyl]propane-1,3-diol (14). General procedure $\mathrm{D}$ was followed using 7 (50.0 mg, $0.0993 \mathrm{mmol}), \mathrm{NaBH}_{4}(18.8 \mathrm{mg}, 0.497$ mmol, 5.0 equiv), $\mathrm{CaCl}_{2}$ (27.5 mg, $0.248 \mathrm{mmol}, 2.5$ equiv), and $\mathrm{EtOH} /$ water $(4: 1,1 \mathrm{~mL}) ; \mathrm{N}$-acetylated diol intermediate (white solid, $37 \mathrm{mg}$ ), $\mathrm{MeOH} / \mathrm{THF}(1 \mathrm{~mL})$, and $2 \mathrm{M} \mathrm{LiOH}$ (aq., $2 \mathrm{~mL}$ ). Compound 14 was obtained as a white solid (23 $\mathrm{mg}, 60 \%) .{ }^{1} \mathrm{H}$ NMR $\left(400 \mathrm{MHz}, \mathrm{DMSO}-d_{6}\right): \delta 7.59-7.53(\mathrm{~m}$, $2 \mathrm{H}), 7.53-7.44(\mathrm{~m}, 4 \mathrm{H}), 7.44-7.37(\mathrm{~m}, 2 \mathrm{H}), 7.36-7.30(\mathrm{~m}$, $1 \mathrm{H}), 7.26-7.21(\mathrm{~m}, 2 \mathrm{H}), 7.11-7.04(\mathrm{~m}, 2 \mathrm{H}), 5.15(\mathrm{~s}, 2 \mathrm{H})$, $4.46(\mathrm{~s}, 1 \mathrm{H}), 3.33-3.18(\mathrm{~m}, 5 \mathrm{H}), 2.65-2.56(\mathrm{~m}, 2 \mathrm{H}), 1.56-$ 1.47 (m, 2H), $1.32(\mathrm{~s}, 1 \mathrm{H}) .{ }^{13} \mathrm{C}$ NMR (101 MHz, DMSO- $\left.d_{6}\right)$ : $\delta 157.7,142.0,137.1,137.0,132.8,128.7,128.5,127.8,127.7$, 127.5, 126.0, 115.2, 69.2, 65.4, 55.4, 36.8, 28.6. HRMS-ESI $(m / z)$ : calcd for $\mathrm{C}_{24} \mathrm{H}_{28} \mathrm{NO}_{3}[\mathrm{M}+\mathrm{H}]^{+} 378.2069$, found: 378.2070.

2-Amino-2-[2-(4'-pentyl-[1,1'-biphenyl]-4-yl)ethyl]propane-1,3-diol (15). General procedure $\mathrm{D}$ was followed using 8 ( $86.0 \mathrm{mg}, 0.184 \mathrm{mmol}), \mathrm{NaBH}_{4}(34.8 \mathrm{mg}, 0.920 \mathrm{mmol}$, 5.0 equiv), $\mathrm{CaCl}_{2}(51.1 \mathrm{mg}, 0.460 \mathrm{mmol}, 2.5$ equiv $)$, and $\mathrm{EtOH} /$ water $(4: 1,2 \mathrm{~mL}) ; \mathrm{N}$-acetylated diol intermediate (white solid, $69 \mathrm{mg}$ ), $\mathrm{MeOH} / \mathrm{THF}(2 \mathrm{~mL})$, and $2 \mathrm{M} \mathrm{LiOH}$ (aq., $2 \mathrm{~mL}$ ). Compound $\mathbf{1 5}$ was obtained as a white solid (36 $\mathrm{mg}, 57 \%) .{ }^{1} \mathrm{H}$ NMR (400 MHz, $\left.\mathrm{CD}_{3} \mathrm{OD}\right): \delta$ 7.52-7.46 (m, $4 \mathrm{H}), 7.31-7.25(\mathrm{~m}, 2 \mathrm{H}), 7.25-7.19(\mathrm{~m}, 2 \mathrm{H}), 3.50(\mathrm{q}, J=$ 14.4, $10.8 \mathrm{~Hz}, 4 \mathrm{H}), 2.73-2.66(\mathrm{~m}, 2 \mathrm{H}), 2.63(\mathrm{t}, J=7.3 \mathrm{~Hz}$, $2 \mathrm{H}), 1.75-1.67(\mathrm{~m}, 2 \mathrm{H}), 1.67-1.59(\mathrm{~m}, 2 \mathrm{H}), 1.43-1.28(\mathrm{~m}$, $4 \mathrm{H}), 0.96-0.88(\mathrm{~m}, 3 \mathrm{H}) .{ }^{13} \mathrm{C}$ NMR (101 MHz, $\left.\mathrm{CD}_{3} \mathrm{OD}\right): \delta$ $142.94,142.92,139.9,139.8,129.9,129.8,127.8,127.7,66.5$, 56.9, 37.6, 36.5, 32.6, 32.5, 30.1, 23.6, 14.4. HRMS-ESI $(\mathrm{m} / z)$ : calcd for $\mathrm{C}_{22} \mathrm{H}_{32} \mathrm{NO}_{2}[\mathrm{M}+\mathrm{H}]^{+} 342.2433$, found: $342.2434 .{ }^{42}$

(E)-2-Amino-2-[4-(3-phenylprop-1-en-1-yl)phenethyl]propane-1,3-diol (16). General procedure $\mathrm{D}$ was followed using 10 (70.0 mg, $0.160 \mathrm{mmol}), \mathrm{NaBH}_{4}(30.3 \mathrm{mg}, 0.800$ mmol, 5.0 equiv), $\mathrm{CaCl}_{2}$ (44.4 mg, $0.400 \mathrm{mmol}, 2.5$ equiv), and $\mathrm{EtOH} /$ water $(4: 1,2 \mathrm{~mL})$; N-acetylated diol intermediate (white solid, $62 \mathrm{mg}$ ), $\mathrm{MeOH} / \mathrm{THF}(1 \mathrm{~mL})$, and $2 \mathrm{M} \mathrm{LiOH}$ (aq., $2 \mathrm{~mL}$ ). Compound $\mathbf{1 6}$ was obtained as a white solid (34 mg, 67\%). ${ }^{1} \mathrm{H}$ NMR (400 MHz, $\left.\mathrm{CD}_{3} \mathrm{OD}\right): \delta 7.32-7.10(\mathrm{~m}$, $9 \mathrm{H}), 6.41(\mathrm{~d}, J=15.9 \mathrm{~Hz}, 1 \mathrm{H}), 6.35-6.26(\mathrm{~m}, 1 \mathrm{H}), 3.55-3.42$ $(\mathrm{m}, 6 \mathrm{H}), 2.66-2.57(\mathrm{~m}, 2 \mathrm{H}), 1.70-1.61(\mathrm{~m}, 2 \mathrm{H}) .{ }^{13} \mathrm{C} \mathrm{NMR}$ $\left(101 \mathrm{MHz}, \mathrm{CD}_{3} \mathrm{OD}\right): \delta 143.0,141.7,136.6,132.0,129.6$, $129.53,129.51,129.48,127.2,127.1,66.5,56.8,40.3,37.5$, 30.1. HRMS-ESI $(m / z)$ : calcd for $\mathrm{C}_{20} \mathrm{H}_{26} \mathrm{NO}_{2}[\mathrm{M}+\mathrm{H}]^{+}$ 312.1964, found: 312.1966 .

4-(Benzyloxy)phenethyl Methanesulfonate (18). To a cooled solution of 2-[4-(benzyloxy)phenyl]ethanol (17) $(1.50 \mathrm{~g}, 6.57 \mathrm{mmol})$ and triethylamine $\left(\mathrm{Et}_{3} \mathrm{~N} ; 1.37 \mathrm{~mL}, 9.86\right.$ mmol, 1.5 equiv) in anhydrous DCM $(25 \mathrm{~mL})$ was added methanesulfonyl chloride $(0.66 \mathrm{~mL}, 8.54 \mathrm{mmol}, 1.3$ equiv $)$, and the reaction mixture was stirred for $2 \mathrm{~h}$. The mixture was diluted with DCM and washed with brine. The organic layer was dried over anhydrous $\mathrm{Na}_{2} \mathrm{SO}_{4}$, filtered, and concentrated on a rotary evaporator. Column chromatography, with an increasing gradient of EtOAc in $n$-heptane, starting with $20 \%$ of EtOAc, gave compound 18 as a white solid (1.72 g, 86\%). ${ }^{1} \mathrm{H}$ NMR (400 MHz, $\mathrm{CDCl}_{3}$ ): $\delta 7.47-7.36(\mathrm{~m}, 4 \mathrm{H}), 7.36-$ $7.30(\mathrm{~m}, 1 \mathrm{H}), 7.18-7.12(\mathrm{~m}, 2 \mathrm{H}), 6.97-6.91(\mathrm{~m}, 2 \mathrm{H}), 5.06$ $(\mathrm{s}, 2 \mathrm{H}), 4.38(\mathrm{t}, J=6.9 \mathrm{~Hz}, 2 \mathrm{H}), 3.00(\mathrm{t}, J=6.9 \mathrm{~Hz}, 2 \mathrm{H}), 2.83$ $(\mathrm{s}, 3 \mathrm{H}) .{ }^{13} \mathrm{C}$ NMR $\left(101 \mathrm{MHz}, \mathrm{CDCl}_{3}\right): \delta 158.0,137.1,130.2$, $128.7,128.1,127.6,115.3,70.7,70.2,37.4,34.9$. HRMS-ESI $(m / z)$ : calcd for $\mathrm{C}_{16} \mathrm{H}_{18} \mathrm{O}_{4} \mathrm{~S}[\mathrm{M}+\mathrm{H}]^{+}$306.0926, found: 306.0925 .

Diethyl 2-Acetamido-2-[4-(benzyloxy)phenethyl]malonate (19). General procedure A was followed using 18 ( $1.70 \mathrm{~g}, 5.62 \mathrm{mmol}, 1.2$ equiv), DEAM (1.02 g, $4.68 \mathrm{mmol})$, $\mathrm{Cs}_{2} \mathrm{CO}_{3}$ (3.05 g, $9.36 \mathrm{mmol}, 2.0$ equiv), and anhydrous $\mathrm{MeCN}$ $(20 \mathrm{~mL})$. Compound 19 was obtained as a yellow-white solid (0.97 g, 49\%). ${ }^{1} \mathrm{H}$ NMR (400 MHz, $\left.\mathrm{CDCl}_{3}\right): \delta 7.44-7.34(\mathrm{~m}$, $4 \mathrm{H}), 7.34-7.28(\mathrm{~m}, 1 \mathrm{H}), 7.08-7.03(\mathrm{~m}, 2 \mathrm{H}), 6.91-6.85(\mathrm{~m}$, 
$2 \mathrm{H}), 6.76$ (bs, $1 \mathrm{H}), 5.04$ (s, 2H), 4.27-4.12 (m, 4H), 2.70$2.62(\mathrm{~m}, 2 \mathrm{H}), 2.47-2.39(\mathrm{~m}, 2 \mathrm{H}), 1.98(\mathrm{~s}, 3 \mathrm{H}), 1.24(\mathrm{t}, J=7.1$ $\mathrm{Hz}, 6 \mathrm{H}) .{ }^{13} \mathrm{C}$ NMR (101 MHz, $\mathrm{CDCl}_{3}$ ): $\delta 169.1,168.2,157.3$, 137.3, 133.0, 129.5, 128.7, 128.0, 127.6, 114.9, 70.1, 66.5, 62.7, 33.6, 29.4, 23.1, 14.1. HRMS-ESI $(m / z)$ : calcd for $\mathrm{C}_{24} \mathrm{H}_{30} \mathrm{NO}_{6}$ $[\mathrm{M}+\mathrm{H}]^{+}$428.2073, found: 428.2075 .

Diethyl 2-Acetamido-2-(4-hydroxyphenethyl)malonate (20). To a solution of $19(0.788 \mathrm{~g}, 1.84 \mathrm{mmol})$ in EtOH/ EtOAc $(1: 1,20 \mathrm{~mL})$ was added $10 \%$ palladium on carbon (0.196 g, $0.184 \mathrm{mmol}, 0.1$ equiv). The reaction mixture was stirred at room temperature under a hydrogen atmosphere for $5 \mathrm{~h}$, after which it was filtered through Celite and concentrated on a rotary evaporator. The resulting solid was washed with diisopropyl ether and dried in a vacuum to give $\mathbf{2 0}$ as a white solid (547 mg, 88\%). ${ }^{1} \mathrm{H}$ NMR (400 MHz, $\mathrm{CD}_{3} \mathrm{OD}$ ): $\delta 7.00-$ $6.94(\mathrm{~m}, 2 \mathrm{H}), 6.73-6.68(\mathrm{~m}, 2 \mathrm{H}), 4.27-4.13(\mathrm{~m}, 4 \mathrm{H}), 2.54-$ $2.48(\mathrm{~m}, 2 \mathrm{H}), 2.45-2.39(\mathrm{~m}, 2 \mathrm{H}), 2.01(\mathrm{~s}, 3 \mathrm{H}), 1.25(\mathrm{t}, J=7.1$ $\mathrm{Hz}, 6 \mathrm{H}) .{ }^{13} \mathrm{C}$ NMR (101 MHz, $\left.\mathrm{CD}_{3} \mathrm{OD}\right): \delta 172.5,169.2$, 156.7, 132.9, 130.3, 116.2, 67.9, 63.4, 35.7, 30.2, 22.3, 14.3. HRMS-ESI $(m / z)$ : calcd for $\mathrm{C}_{17} \mathrm{H}_{24} \mathrm{NO}_{6}[\mathrm{M}+\mathrm{H}]^{+} 338.1604$, found: 338.1603 .

Diethyl 2-Acetamido-2-[4-[[4-(trifluoromethyl)benzyl]oxy]phenethyl]malonate (21). General procedure $\mathrm{C}$ was followed using $20(80.0 \mathrm{mg}, 0.237 \mathrm{mmol}), \mathrm{K}_{2} \mathrm{CO}_{3}(65.5 \mathrm{mg}$, $0.474 \mathrm{mmol}, 2.0$ equiv), 1-(bromomethyl)-4-(trifluoromethyl)benzene $(68.0 \mathrm{mg}, 0.285 \mathrm{mmol}, 1.2$ equiv), and anhydrous DMF $(2 \mathrm{~mL})$. Compound 21 was obtained as a yellow solid (102 mg, 87\%). ${ }^{1} \mathrm{H}$ NMR (400 MHz, $\left.\mathrm{CDCl}_{3}\right): \delta 7.67-7.60$ (m, 2H), 7.57-7.50 (m, 2H), 7.10-7.02 (m, 2H), 6.90-6.82 $(\mathrm{m}, 2 \mathrm{H}), 6.76(\mathrm{bs}, 1 \mathrm{H}), 5.10(\mathrm{~s}, 2 \mathrm{H}), 4.27-4.13(\mathrm{~m}, 4 \mathrm{H})$, $2.70-2.61(\mathrm{~m}, 2 \mathrm{H}), 2.47-2.38(\mathrm{~m}, 2 \mathrm{H}), 1.99(\mathrm{~s}, 3 \mathrm{H}), 1.24(\mathrm{t}$, $J=7.1 \mathrm{~Hz}, 6 \mathrm{H}) .{ }^{13} \mathrm{C} \mathrm{NMR}\left(101 \mathrm{MHz}, \mathrm{CDCl}_{3}\right): \delta 169.1$, $168.20,168.18,156.9,141.4,133.5,130.1(\mathrm{q}, J=32.7 \mathrm{~Hz})$, 129.6, 127.5, $125.7(\mathrm{q}, J=4.0 \mathrm{~Hz}), 114.9,69.3,66.5,66.4$, 62.7, 33.6, 29.4, 23.2, 23.1, 14.1. ${ }^{19} \mathrm{~F}$ NMR (377 MHz, $\left.\mathrm{CDCl}_{3}\right): \delta-64.0$. HRMS-ESI $(\mathrm{m} / z)$ : calcd for $\mathrm{C}_{25} \mathrm{H}_{29} \mathrm{NO}_{6} \mathrm{~F}_{3}$ $[\mathrm{M}+\mathrm{H}]^{+}$496.1947, found: 496.1949 .

Diethyl 2-Acetamido-2-[4-[[6-(trifluoromethyl)pyridin-3yl]methoxy]phenethyl]malonate (22). General procedure C was followed using $20(90.0 \mathrm{mg}, 0.267 \mathrm{mmol}), \mathrm{K}_{2} \mathrm{CO}_{3}(73.8$ $\mathrm{mg}, \quad 0.534 \mathrm{mmol}, 2.0$ equiv), 5-(bromomethyl)-2(trifluoromethyl)pyridine $(76.8 \mathrm{mg}, 0.320 \mathrm{mmol}, 1.2$ equiv), and anhydrous DMF ( $2 \mathrm{~mL})$. Compound 22 was obtained as a white solid (116 mg, 88\%). ${ }^{1} \mathrm{H}$ NMR (400 MHz, $\left.\mathrm{CDCl}_{3}\right): \delta$ $8.77(\mathrm{~d}, J=1.8 \mathrm{~Hz}, 1 \mathrm{H}), 7.98-7.93(\mathrm{~m}, 1 \mathrm{H}), 7.71(\mathrm{~d}, J=7.7$ $\mathrm{Hz}, 1 \mathrm{H}), 7.11-7.05(\mathrm{~m}, 2 \mathrm{H}), 6.90-6.84(\mathrm{~m}, 2 \mathrm{H}), 6.77$ (bs, $1 \mathrm{H}), 5.13(\mathrm{~s}, 2 \mathrm{H}), 4.28-4.13(\mathrm{~m}, 4 \mathrm{H}), 2.70-2.61(\mathrm{~m}, 2 \mathrm{H})$, $2.47-2.38(\mathrm{~m}, 2 \mathrm{H}), 2.00(\mathrm{~s}, 3 \mathrm{H}), 1.25(\mathrm{t}, J=7.1 \mathrm{~Hz}, 6 \mathrm{H}) .{ }^{13} \mathrm{C}$ NMR $\left(101 \mathrm{MHz}, \mathrm{CDCl}_{3}\right): \delta 169.2,168.2,156.5,149.0,136.4$, 134.0, 129.7, 120.5 (d, $J=2.9 \mathrm{~Hz}), 114.9,67.0,66.5,62.7$, 33.7, 29.4, 23.1, 14.1. ${ }^{19} \mathrm{~F} \mathrm{NMR}\left(377 \mathrm{MHz}, \mathrm{CDCl}_{3}\right): \delta-67.9$. HRMS-ESI $(m / z)$ : calcd for $\mathrm{C}_{24} \mathrm{H}_{28} \mathrm{~N}_{2} \mathrm{O}_{6} \mathrm{~F}_{3}[\mathrm{M}+\mathrm{H}]^{+}$ 497.1899, found: 497.1896.

Diethyl 2-Acetamido-2-[4-[(7-chloroquinolin-2-yl)methoxy]phenethyl]malonate (23). General procedure $\mathrm{C}$ was followed using $20(80.0 \mathrm{mg}, 0.237 \mathrm{mmol}), \mathrm{K}_{2} \mathrm{CO}_{3}(65.5$ $\mathrm{mg}, 0.474 \mathrm{mmol}, 2.0$ equiv), 2-(bromomethyl)-7-chloroquinoline ( $72.9 \mathrm{mg}, 0.284 \mathrm{mmol}, 1.2$ equiv), and anhydrous DMF (2 $\mathrm{mL})$. Compound 23 was obtained as a white solid $(118 \mathrm{mg}$, 97\%). ${ }^{1} \mathrm{H}$ NMR (400 MHz, $\left.\mathrm{CDCl}_{3}\right): \delta 8.15(\mathrm{~d}, J=8.5 \mathrm{~Hz}$, $1 \mathrm{H}), 8.08(\mathrm{~d}, J=2.0 \mathrm{~Hz}, 1 \mathrm{H}), 7.75(\mathrm{~d}, J=8.7 \mathrm{~Hz}, 1 \mathrm{H}), 7.65$ $(\mathrm{d}, J=8.5 \mathrm{~Hz}, 1 \mathrm{H}), 7.50(\mathrm{dd}, J=8.7,2.1 \mathrm{~Hz}, 1 \mathrm{H}), 7.08-7.02$ (m, 2H), 6.94-6.88 (m, 2H), 6.75 (bs, 1H), 5.34 (s, 2H), $4.26-4.11(\mathrm{~m}, 4 \mathrm{H}), 2.68-2.59(\mathrm{~m}, 2 \mathrm{H}), 2.45-2.37(\mathrm{~m}, 2 \mathrm{H})$, $1.97(\mathrm{~s}, 3 \mathrm{H}), 1.23(\mathrm{t}, J=7.1 \mathrm{~Hz}, 6 \mathrm{H}) .{ }^{13} \mathrm{C} \mathrm{NMR}(101 \mathrm{MHz}$, $\left.\mathrm{CDCl}_{3}\right): \delta 169.1,168.2,159.4,156.8,137.0,135.8,133.5$, 129.7, 129.0, 128.1, 127.8, 126.1, 119.4, 114.9, 71.1, 66.5, 62.7, 33.6, 29.4, 23.1, 14.1. HRMS-ESI $(\mathrm{m} / z)$ : calcd for $\mathrm{C}_{27} \mathrm{H}_{30} \mathrm{~N}_{2} \mathrm{O}_{6} \mathrm{Cl}[\mathrm{M}+\mathrm{H}]^{+}$513.1792, found: 513.1794.

Diethyl 2-Acetamido-2-[4-[(4-butylbenzyl)oxy]phenethyl]malonate (24). General procedure $\mathrm{C}$ was followed using 20 (70.0 mg, $0.207 \mathrm{mmol}), \mathrm{K}_{2} \mathrm{CO}_{3}(57.2 \mathrm{mg}, 0.414$ mmol, 2.0 equiv), 4-butylbenzyl bromide (56.4 $\mathrm{mg}, 0.248$ mmol, 1.2 equiv), and anhydrous DMF ( $2 \mathrm{~mL})$. Compound 24 was obtained as a white solid (54 mg, 54\%). ${ }^{1} \mathrm{H}$ NMR (400 $\left.\mathrm{MHz}, \mathrm{CDCl}_{3}\right): \delta 7.35-7.30(\mathrm{~m}, 2 \mathrm{H}), 7.22-7.16(\mathrm{~m}, 2 \mathrm{H})$, $7.08-7.02(\mathrm{~m}, 2 \mathrm{H}), 6.91-6.85(\mathrm{~m}, 2 \mathrm{H}), 6.75$ (bs, $1 \mathrm{H}), 4.99$ (s, 2H), 4.26-4.11 (m, 4H), 2.70-2.57 (m, 4H), 2.47-2.38 $(\mathrm{m}, 2 \mathrm{H}), 1.98(\mathrm{~s}, 3 \mathrm{H}), 1.65-1.53(\mathrm{~m}, 2 \mathrm{H}), 1.41-1.30(\mathrm{~m}$, $2 \mathrm{H}), 1.24(\mathrm{t}, J=7.1 \mathrm{~Hz}, 6 \mathrm{H}), 0.92(\mathrm{t}, J=7.3 \mathrm{~Hz}, 3 \mathrm{H}) .{ }^{13} \mathrm{C}$ NMR (101 MHz, $\left.\mathrm{CDCl}_{3}\right): \delta 169.1,168.2,157.4,142.9,134.4$, $132.9,129.5,128.8,127.7,114.9,70.1,66.5,62.7,35.5,33.7$, 33.6, 29.4, 23.1, 22.5, 14.12, 14.07. HRMS-ESI $(\mathrm{m} / z)$ : calcd for $\mathrm{C}_{28} \mathrm{H}_{38} \mathrm{NO}_{6}[\mathrm{M}+\mathrm{H}]^{+}$: 484.2699, found: 484.2700 .

2-Amino-2-[4-(benzyloxy)phenethyl]propane-1,3-diol (25). Modified general procedure D was followed using 19 (45.0 mg, $0.105 \mathrm{mmol}), \mathrm{LiBH}_{4}(2 \mathrm{M}$ solution in THF, 0.16 $\mathrm{mL}, 0.315 \mathrm{mmol}, 3.0$ equiv), and THF $(1 \mathrm{~mL}) ; \mathrm{N}$-acetylated diol intermediate (transparent oil, $34 \mathrm{mg}$ ), MeOH/THF (1 $\mathrm{mL}$ ), and $2 \mathrm{M} \mathrm{LiOH}$ (aq., $1 \mathrm{~mL}$ ). Compound 25 was obtained as a white solid (12 mg, 38\%). ${ }^{1} \mathrm{H}$ NMR $\left(400 \mathrm{MHz}, \mathrm{CD}_{3} \mathrm{OD}\right)$ : $\delta 7.44-7.39(\mathrm{~m}, 2 \mathrm{H}), 7.38-7.32(\mathrm{~m}, 2 \mathrm{H}), 7.31-7.26(\mathrm{~m}, 1 \mathrm{H})$, 7.16-7.10 (m, 2H), 6.91-6.86 (m, 2H), $5.03(\mathrm{~s}, 2 \mathrm{H}), 3.48(\mathrm{q}$, $J=14.5,10.9 \mathrm{~Hz}, 4 \mathrm{H}), 2.63-2.54(\mathrm{~m}, 2 \mathrm{H}), 1.68-1.59(\mathrm{~m}$, $2 \mathrm{H}) .{ }^{13} \mathrm{C}$ NMR (101 MHz, CD $\left.\mathrm{OD}\right): \delta$ 158.4, 139.0, 136.4, 130.2 , 129.5, 128.8, 128.5, 115.9, 71.0, 66.5, 56.8, 37.8, 29.5. HRMS-ESI $(m / z)$ : calcd for $\mathrm{C}_{18} \mathrm{H}_{24} \mathrm{NO}_{3}[\mathrm{M}+\mathrm{H}]^{+} 302.1756$, found: 302.1754 .

2-Amino-2-[4-[[4-(trifluoromethyl)benzyl]oxy]phenethyl]propane-1,3-diol (26). General procedure D was followed using 21 (91.0 mg, $0.184 \mathrm{mmol}$ ), $\mathrm{NaBH}_{4}$ (34.7 mg, 0.919 mmol, 5.0 equiv), $\mathrm{CaCl}_{2}$ (50.9 mg, $0.459 \mathrm{mmol}, 2.5$ equiv), and $\mathrm{EtOH} /$ water $(4: 1,2 \mathrm{~mL})$; $\mathrm{N}$-acetylated diol intermediate (white solid, $77 \mathrm{mg}$ ), $\mathrm{MeOH} / \mathrm{THF}(1 \mathrm{~mL})$, and $2 \mathrm{M} \mathrm{LiOH}$ (aq., $2 \mathrm{~mL}$ ). Compound 26 was obtained as a white solid (50 $\mathrm{mg}, 73 \%$ ). ${ }^{1} \mathrm{H}$ NMR (400 MHz, $\left.\mathrm{CD}_{3} \mathrm{OD}\right): \delta 7.64$ (q, $J=10.7$, $8.3 \mathrm{~Hz}, 4 \mathrm{H}), 7.19-7.10(\mathrm{~m}, 2 \mathrm{H}), 6.95-6.86(\mathrm{~m}, 2 \mathrm{H}), 5.14(\mathrm{~s}$, $2 \mathrm{H}), 3.50(\mathrm{q}, J=12.3,10.9 \mathrm{~Hz}, 4 \mathrm{H}), 2.64-2.55(\mathrm{~m}, 2 \mathrm{H})$, $1.72-1.63(\mathrm{~m}, 2 \mathrm{H}) .{ }^{13} \mathrm{C}$ NMR (101 MHz, $\left.\mathrm{CD}_{3} \mathrm{OD}\right): \delta$ 158.1, $143.7,136.7,130.5$ (q, $J=32.7,32.0 \mathrm{~Hz}), 130.4,128.7,127.1$, $126.4(\mathrm{q}, J=3.7 \mathrm{~Hz}), 124.4,115.9,70.1,66.5,37.8,29.5 .{ }^{19} \mathrm{~F}$ NMR (377 MHz, $\left.\mathrm{CD}_{3} \mathrm{OD}\right): \delta-64.0$. HRMS-ESI $(\mathrm{m} / z)$ : calcd for $\mathrm{C}_{19} \mathrm{H}_{23} \mathrm{NO}_{3} \mathrm{~F}_{3}[\mathrm{M}+\mathrm{H}]^{+}$370.1630, found: 370.1631 .

2-Amino-2-[4-[[5-(trifluoromethyl)pyridin-2-yl]methoxy]phenethyl]propane-1,3-diol (27). Modified general procedure $\mathrm{D}$ was followed using $22(0.101 \mathrm{~g}, 0.203 \mathrm{mmol}), \mathrm{LiBH}_{4}(2 \mathrm{M}$ solution in THF, $0.30 \mathrm{~mL}, 0.609 \mathrm{mmol}, 3.0$ equiv), and THF $(1 \mathrm{~mL}$ ); $\mathrm{N}$-acetylated diol intermediate (white solid, $73 \mathrm{mg}$ ), $\mathrm{MeOH} / \mathrm{THF}(1.5 \mathrm{~mL}$ ), and $2 \mathrm{M} \mathrm{LiOH}$ (aq., $1.5 \mathrm{~mL}$ ). Compound 27 was obtained as a white solid $(26 \mathrm{mg}, 34 \%) .{ }^{1} \mathrm{H}$ NMR (400 MHz, CD 3 OD): $\delta 8.78(\mathrm{~d}, J=2.1 \mathrm{~Hz}, 1 \mathrm{H}), 8.14-$ $8.08(\mathrm{~m}, 1 \mathrm{H}), 7.83(\mathrm{~d}, J=8.1 \mathrm{~Hz}, 1 \mathrm{H}), 7.20-7.13(\mathrm{~m}, 2 \mathrm{H})$, 6.97-6.90 (m, 2H), $5.22(\mathrm{~s}, 2 \mathrm{H}), 3.48(\mathrm{q}, J=14.0,11.0 \mathrm{~Hz}$, $4 \mathrm{H}), 2.65-2.56(\mathrm{~m}, 2 \mathrm{H}), 1.69-1.60(\mathrm{~m}, 2 \mathrm{H}) .{ }^{13} \mathrm{C}$ NMR $(101$ $\left.\mathrm{MHz}, \mathrm{CD}_{3} \mathrm{OD}\right): \delta 157.8,150.0,148.7,148.3,148.0,138.8$, 138.2 , 137.1, 130.5, 124.4, 121.69, 121.66, 121.63, 121.60, 
115.9, 67.8, 66.4, 56.9, 37.7, 29.5. ${ }^{19} \mathrm{~F}$ NMR (377 MHz, $\left.\mathrm{CD}_{3} \mathrm{OD}\right): \delta$-69.3. HRMS-ESI $(\mathrm{m} / z)$ : calcd for $\mathrm{C}_{18} \mathrm{H}_{22} \mathrm{~N}_{2} \mathrm{O}_{3} \mathrm{~F}_{3}[\mathrm{M}+\mathrm{H}]^{+}$371.1583, found: 371.1582 .

2-Amino-2-[4-[(7-chloroquinolin-2-yl)methoxy]phenethyl]propane-1,3-diol (28). General procedure D was followed using $23(99.0 \mathrm{mg}, 0.193 \mathrm{mmol}), \mathrm{NaBH}_{4}(36.5 \mathrm{mg}$, $0.965 \mathrm{mmol}, 5.0$ equiv), $\mathrm{CaCl}_{2}(53.6 \mathrm{mg}, 0.483 \mathrm{mmol}, 2.5$ equiv), and $\mathrm{EtOH} /$ water (4:1, $2 \mathrm{~mL}) ; \mathrm{N}$-acetylated diol intermediate (white solid, $80 \mathrm{mg}$ ), $\mathrm{MeOH} / \mathrm{THF}(1: 3,2 \mathrm{~mL}$ ), and $2 \mathrm{M} \mathrm{LiOH} \mathrm{(aq.,} 2 \mathrm{~mL}$ ). Compound 28 was obtained as a white solid (49 mg, 66\%). ${ }^{1} \mathrm{H}$ NMR (400 MHz, DMSO- $\left.d_{6}\right): \delta$ $8.46(\mathrm{~d}, J=8.6 \mathrm{~Hz}, 1 \mathrm{H}), 8.09-8.03(\mathrm{~m}, 2 \mathrm{H}), 7.69(\mathrm{~d}, J=8.5$ $\mathrm{Hz}, 1 \mathrm{H}), 7.66(\mathrm{dd}, J=8.7,2.2 \mathrm{~Hz}, 1 \mathrm{H}), 7.13-7.07(\mathrm{~m}, 2 \mathrm{H})$, 6.98-6.92 (m, 2H), 5.33 (s, 2H), 4.41 (bs, $2 \mathrm{H}), 3.28-3.15$ (m, $4 \mathrm{H}), 1.50-1.41(\mathrm{~m}, 2 \mathrm{H}), 1.26(\mathrm{bs}, 1 \mathrm{H})$ (one peak covered by DMSO). ${ }^{13} \mathrm{C}$ NMR (101 MHz, DMSO-d $): \delta 159.4,156.0$, $147.3,137.1,136.0,134.4,130.0,129.2,127.2,125.8,119.9$, 114.6, 70.6, 65.4, 55.4, 37.0, 28.0. HRMS-ESI $(\mathrm{m} / z)$ : calcd for $\mathrm{C}_{21} \mathrm{H}_{24} \mathrm{~N}_{2} \mathrm{O}_{3} \mathrm{Cl}[\mathrm{M}+\mathrm{H}]^{+}$387.1475, found: 387.1474 .

2-Amino-2-[4-[(4-butylbenzyl)oxy]phenethyl]propane1,3-diol (29). General procedure $\mathrm{D}$ was followed using 24 (53.0 mg, $0.110 \mathrm{mmol}), \mathrm{NaBH}_{4}(20.8 \mathrm{mg}, 0.550 \mathrm{mmol}, 5.0$ equiv), $\mathrm{CaCl}_{2}$ (30.5 mg, $0.275 \mathrm{mmol}, 2.5$ equiv), and $\mathrm{EtOH} /$ water $(4: 1,1.5 \mathrm{~mL})$; $\mathrm{N}$-acetylated diol intermediate (white solid, $47 \mathrm{mg}$ ), $\mathrm{MeOH} / \mathrm{THF}(2 \mathrm{~mL}$ ), and $2 \mathrm{M} \mathrm{LiOH}$ (aq., 2 $\mathrm{mL})$. Compound 29 was obtained as a white solid $(26 \mathrm{mg}$, 66\%). ${ }^{1} \mathrm{H}$ NMR (400 MHz, $\left.\mathrm{CD}_{3} \mathrm{OD}\right): \delta 7.35-7.28(\mathrm{~m}, 2 \mathrm{H})$, 7.21-7.15 (m, 2H), 7.15-7.09 (m, 2H), 6.91-6.84 (m, 2H), $4.99(\mathrm{~s}, 2 \mathrm{H}), 3.48(\mathrm{q}, J=14.5,10.7 \mathrm{~Hz}, 4 \mathrm{H}), 2.65-2.54(\mathrm{~m}$, $4 \mathrm{H}), 1.68-1.54(\mathrm{~m}, 4 \mathrm{H}), 1.41-1.30(\mathrm{~m}, 2 \mathrm{H}), 0.94(\mathrm{t}, J=7.4$ $\mathrm{Hz}, 3 \mathrm{H}) .{ }^{13} \mathrm{C}$ NMR $\left(101 \mathrm{MHz}, \mathrm{CD}_{3} \mathrm{OD}\right): \delta 158.5,143.7$, 136.3, 136.1, 130.2, 129.5, 128.7, 115.9, 71.0, 66.5, 56.8, 37.8, 36.3, 35.0, 29.5, 23.3, 14.5. HRMS-ESI $(\mathrm{m} / z)$ : calcd for $\mathrm{C}_{22} \mathrm{H}_{32} \mathrm{NO}_{3}[\mathrm{M}+\mathrm{H}]^{+}$358.2382, found: 358.2383 .

2-(Quinolin-2-yl)ethyl Methanesulfonate (31). To a cooled solution of 2-(quinolin-2-yl)ethan-1-ol (30) (0.150 g, 0.866 $\mathrm{mmol})$ and $\mathrm{Et}_{3} \mathrm{~N}(0.247 \mathrm{~mL}, 1.77 \mathrm{mmol}, 2.0$ equiv $)$ in anhydrous DCM (4 mL) was added methanesulfonyl chloride $(0.122 \mathrm{~mL}, 1.06 \mathrm{mmol}, 1.2$ equiv), and the reaction mixture was stirred for $3 \mathrm{~h}$. The mixture was diluted with DCM and washed with water and brine. The organic layer was dried over anhydrous $\mathrm{Na}_{2} \mathrm{SO}_{4}$, filtered, and concentrated on a rotary evaporator. Column chromatography, with an increasing gradient of EtOAc in $n$-heptane, starting with $20 \%$ of EtOAc, gave 31 as a white solid $(78 \mathrm{mg}, 37 \%) .{ }^{1} \mathrm{H} \mathrm{NMR} \mathrm{(400} \mathrm{MHz,}$ $\left.\mathrm{CDCl}_{3}\right): \delta 8.12(\mathrm{~d}, J=8.4 \mathrm{~Hz}, 1 \mathrm{H}), 8.01(\mathrm{~d}, J=8.5 \mathrm{~Hz}, 1 \mathrm{H})$, $7.81(\mathrm{~d}, J=8.1 \mathrm{~Hz}, 1 \mathrm{H}), 7.74-7.68(\mathrm{~m}, 1 \mathrm{H}), 7.57-7.48(\mathrm{~m}$, $1 \mathrm{H}), 7.34(\mathrm{~d}, J=8.4 \mathrm{~Hz}, 1 \mathrm{H}), 4.81(\mathrm{t}, J=6.4 \mathrm{~Hz}, 2 \mathrm{H}), 3.42(\mathrm{t}$, $J=6.4 \mathrm{~Hz}, 2 \mathrm{H}), 2.93(\mathrm{~s}, 3 \mathrm{H}) .{ }^{13} \mathrm{C} \mathrm{NMR}\left(101 \mathrm{MHz} \mathrm{CDCl}_{3}\right): \delta$ 157.2 , 148.0, 136.8, 129.9, 128.9, 127.8, 127.2, 126.5, 122.0, 69.0, 38.1, 37.4.

Diethyl 2-Acetamido-2-[2-(quinolin-2-yl)ethyl]malonate (32). General procedure A was followed using $31(76.6 \mathrm{mg}$, $0.305 \mathrm{mmol}, 1.2$ equiv), DEAM (55.0 mg, $0.254 \mathrm{mmol})$, $\mathrm{Cs}_{2} \mathrm{CO}_{3}$ (166 mg, $0.508 \mathrm{mmol}, 2.0$ equiv), and anhydrous $\mathrm{MeCN}(2 \mathrm{~mL})$. Compound 32 was obtained as a yellow oil (50 mg, 53\%). ${ }^{1} \mathrm{H}$ NMR (400 MHz, $\left.\mathrm{CDCl}_{3}\right): \delta 8.06$ (d, $J=8.6$ $\mathrm{Hz}, 1 \mathrm{H}), 8.00(\mathrm{~d}, J=8.4 \mathrm{~Hz}, 1 \mathrm{H}), 7.76(\mathrm{~d}, J=8.2 \mathrm{~Hz}, 1 \mathrm{H})$, $7.70-7.64(\mathrm{~m}, 1 \mathrm{H}), 7.51-7.45(\mathrm{~m}, 1 \mathrm{H}), 7.28(\mathrm{~d}, J=8.5 \mathrm{~Hz}$, $1 \mathrm{H}), 6.98(\mathrm{~s}, 1 \mathrm{H}), 4.29-4.10(\mathrm{~m}, 4 \mathrm{H}), 2.89(\mathrm{~s}, 4 \mathrm{H}), 1.97(\mathrm{~s}$, $3 \mathrm{H}), 1.24(\mathrm{t}, J=7.1 \mathrm{~Hz}, 6 \mathrm{H}) .{ }^{13} \mathrm{C} \mathrm{NMR}\left(101 \mathrm{MHz}, \mathrm{CDCl}_{3}\right): \delta$ $169.3,168.2$, 161.1, 147.9, 136.5, 129.6, 128.9, 127.6, 126.9, 126.1, 121.3, 66.4, 62.7, 33.6, 32.0, 23.1, 14.1. HRMS-ESI (m/ $z)$ : calcd for $\mathrm{C}_{20} \mathrm{H}_{25} \mathrm{~N}_{2} \mathrm{O}_{5}[\mathrm{M}+\mathrm{H}]^{+}$373.1763, found: 373.1763.

2-Amino-2-[2-(quinolin-2-yl)ethyl]propane-1,3-diol (33). General procedure D was followed using $32(48.0 \mathrm{mg}, 0.129$ $\mathrm{mmol}$ ), $\mathrm{NaBH}_{4}$ (24.0 mg, $0.645 \mathrm{mmol}, 5.0$ equiv), $\mathrm{CaCl}_{2}$ (36.0 $\mathrm{mg}, 0.322 \mathrm{mmol}, 2.5$ equiv), and $\mathrm{EtOH} /$ water (4:1, $1 \mathrm{~mL})$; Nacetylated diol intermediate (yellow oil, $33 \mathrm{mg}$ ), $\mathrm{MeOH} / \mathrm{THF}$ $(1 \mathrm{~mL}$ ), and $2 \mathrm{M} \mathrm{LiOH}$ (aq., $2 \mathrm{~mL}$ ). Compound 33 was obtained as a white solid $(0.010 \mathrm{~g}, 31 \%) .{ }^{1} \mathrm{H}$ NMR $(400 \mathrm{MHz}$, $\mathrm{CDCl}_{3}$ ): $\delta 8.07(\mathrm{~d}, J=8.5 \mathrm{~Hz}, 1 \mathrm{H}), 7.99(\mathrm{~d}, J=8.5 \mathrm{~Hz}, 1 \mathrm{H})$, $7.77(\mathrm{~d}, J=8.1 \mathrm{~Hz}, 1 \mathrm{H}), 7.72-7.64(\mathrm{~m}, 1 \mathrm{H}), 7.53-7.46(\mathrm{~m}$, $1 \mathrm{H}), 7.29$ (d, $J=8.5 \mathrm{~Hz}, 1 \mathrm{H}), 3.55(\mathrm{q}, J=11.2 \mathrm{~Hz}, 4 \mathrm{H}), 3.19$ (bs, $4 \mathrm{H}), 3.10(\mathrm{t}, J=6.9 \mathrm{~Hz}, 2 \mathrm{H}), 2.05(\mathrm{t}, J=6.9 \mathrm{~Hz}, 2 \mathrm{H}) .{ }^{13} \mathrm{C}$ NMR $\left(101 \mathrm{MHz}, \mathrm{CDCl}_{3}\right): \delta 162.6,147.3,137.0,130.0$, $128.16,127.7,126.9,126.3,122.0,66.8,56.7,32.5,31.8$. HRMS-ESI $(m / z)$ : calcd for $\mathrm{C}_{14} \mathrm{H}_{19} \mathrm{~N}_{2} \mathrm{O}_{2}[\mathrm{M}+\mathrm{H}]^{+}$247.1447, found: 247.1445 .

Diethyl 2-Acetamido-2-(3-bromophenethyl)malonate (36). General procedure A was followed using 1-bromo-3-(2bromoethyl)benzene (34) ( $0.500 \mathrm{~g}, 1.89 \mathrm{mmol}, 1.4$ equiv), DEAM (0.294 g, $1.35 \mathrm{mmol}), \mathrm{Cs}_{2} \mathrm{CO}_{3}(0.661 \mathrm{~g}, 2.03 \mathrm{mmol}$, 1.5 equiv), and anhydrous $\mathrm{MeCN}(10 \mathrm{~mL})$. Compound 36 was obtained as a yellow solid (283 mg, 52\%). ${ }^{1} \mathrm{H}$ NMR (400 $\left.\mathrm{MHz}, \mathrm{CDCl}_{3}\right): \delta 7.34-7.28(\mathrm{~m}, 2 \mathrm{H}), 7.16-7.10(\mathrm{~m}, 1 \mathrm{H})$, 7.09-7.05 (m, 1H), 6.76 (bs, 1H), 4.29-4.14 (m, 4H), 2.72$2.63(\mathrm{~m}, 2 \mathrm{H}), 2.50-2.41(\mathrm{~m}, 2 \mathrm{H}), 2.01(\mathrm{~s}, 3 \mathrm{H}), 1.25(\mathrm{t}, J=7.1$ $\mathrm{Hz}, 6 \mathrm{H}) .{ }^{13} \mathrm{C} \mathrm{NMR}\left(101 \mathrm{MHz}, \mathrm{CDCl}_{3}\right): \delta 169.3,168.1,143.1$, 131.6, 130.1, 129.4, 127.3, 122.5, 66.4, 62.82, 33.3, 30.0, 23.1, 14.1. HRMS-ESI $(m / z)$ : calcd for $\mathrm{C}_{17} \mathrm{H}_{23} \mathrm{NO}_{5} \mathrm{Br}[\mathrm{M}+\mathrm{H}]^{+}$ 400.0760, found: 400.0763 .

Diethyl 2-Acetamido-2-(4-bromobenzyl)malonate (37). General procedure A was followed using 1-bromo-4(bromomethyl)benzene (35) (1.50 g, $6.00 \mathrm{mmol}, 1.4$ equiv), DEAM (0.931 g, $4.29 \mathrm{mmol}), \mathrm{Cs}_{2} \mathrm{CO}_{3}(2.10 \mathrm{~g}$, $6.43 \mathrm{mmol}, 1.5$ equiv), and anhydrous $\mathrm{MeCN}(15 \mathrm{~mL})$. Compound 37 was obtained as a white solid (1.49 g, 90\%). ${ }^{1} \mathrm{H}$ NMR (400 MHz, $\left.\mathrm{CDCl}_{3}\right): \delta 7.41-7.35(\mathrm{~m}, 2 \mathrm{H}), 6.91-6.85(\mathrm{~m}, 2 \mathrm{H}), 6.52(\mathrm{bs}$, $1 \mathrm{H}), 4.34-4.18(\mathrm{~m}, 4 \mathrm{H}), 3.61(\mathrm{~s}, 2 \mathrm{H}), 2.03(\mathrm{~s}, 3 \mathrm{H}), 1.29(\mathrm{t}, J$ $=7.1 \mathrm{~Hz}, 6 \mathrm{H}) \cdot{ }^{13} \mathrm{C} \mathrm{NMR}\left(101 \mathrm{MHz}, \mathrm{CDCl}_{3}\right): \delta 169.3,167.5$, 134.5, 131.7, 131.6, 121.5, 67.1, 62.9, 37.4, 23.2, 14.2. HRMSESI $(m / z)$ : calcd for $\mathrm{C}_{16} \mathrm{H}_{21} \mathrm{NO}_{5} \mathrm{Br}[\mathrm{M}+\mathrm{H}]^{+}$386.0603, found: 386.0606 .

Diethyl (E)-2-Acetamido-2-[4-(oct-1-en-1-yl)phenethyl]malonate (38). General procedure B was followed using 2 $(0.100 \mathrm{~g}, 0.250 \mathrm{mmol})$, trans-1-octen-1-yl-boronic acid (46.9 $\mathrm{mg}, 0.300 \mathrm{mmol}, 1.2$ equiv), $\mathrm{Pd}_{2}(\mathrm{dba})_{3}(11.4 \mathrm{mg}, 0.0125$ mmol, 0.05 equiv), SPhos ( $10.3 \mathrm{mg}, 0.0250 \mathrm{mmol}, 0.1$ equiv), $\mathrm{K}_{2} \mathrm{CO}_{3}$ (0.104 g, $0.750 \mathrm{mmol}, 3.0$ equiv), and toluene/water $(4: 1,2 \mathrm{~mL})$. Compound 38 was obtained as a yellow solid (84 $\mathrm{mg}, 78 \%) .{ }^{1} \mathrm{H}$ NMR $\left(400 \mathrm{MHz}, \mathrm{CDCl}_{3}\right): \delta 7.26-7.21(\mathrm{~m}$, $2 \mathrm{H}), 7.08-7.04(\mathrm{~m}, 2 \mathrm{H}), 6.76(\mathrm{~s}, 1 \mathrm{H}), 6.32(\mathrm{~d}, J=15.6 \mathrm{~Hz}$, $1 \mathrm{H}), 6.21-6.12(\mathrm{~m}, 1 \mathrm{H}), 4.27-4.13(\mathrm{~m}, 4 \mathrm{H}), 2.71-2.63(\mathrm{~m}$, $2 \mathrm{H}), 2.50-2.41(\mathrm{~m}, 2 \mathrm{H}), 2.22-2.13(\mathrm{~m}, 2 \mathrm{H}), 1.98(\mathrm{~s}, 3 \mathrm{H})$, $1.51-1.40(\mathrm{~m}, 2 \mathrm{H}), 1.37-1.20(\mathrm{~m}, 12 \mathrm{H}), 0.92-0.83(\mathrm{~m}, 3 \mathrm{H})$. ${ }^{13} \mathrm{C}$ NMR $\left(101 \mathrm{MHz} \mathrm{CDCl}_{3}\right): \delta 169.2,168.2,139.2,136.1$, $130.8,129.4,128.7,126.0,66.5,62.7,33.4,33.2,31.9,29.9$, $29.5,29.0,23.1,22.8,14.2,14.1$. HRMS-ESI $(\mathrm{m} / z)$ : calcd for $\mathrm{C}_{25} \mathrm{H}_{38} \mathrm{NO}_{5}[\mathrm{M}+\mathrm{H}]^{+}$432.2750, found: 432.2747 .

Diethyl 2-Acetamido-2-(3-octylphenethyl)malonate (39). General procedure B was followed using $36(0.100 \mathrm{~g}, 0.250$ $\mathrm{mmol}$ ), $n$-octylboronic acid (47.4 $\mathrm{mg}, 0.300 \mathrm{mmol}, 1.2$ equiv), $\mathrm{Pd}_{2}(\mathrm{dba})_{3}$ (11.4 mg, $0.0125 \mathrm{mmol}, 0.05$ equiv), SPhos (10.3 $\mathrm{mg}, 0.0250 \mathrm{mmol}, 0.1$ equiv), $\mathrm{K}_{2} \mathrm{CO}_{3}(0.104 \mathrm{~g}, 0.750 \mathrm{mmol}$, 
3.0 equiv), and toluene/water (4:1, $2 \mathrm{~mL})$. Compound 39 was obtained as a white solid (81 mg, 75\%). ${ }^{1} \mathrm{H}$ NMR (400 MHz, $\left.\mathrm{CDCl}_{3}\right): \delta 7.20-7.13(\mathrm{~m}, 1 \mathrm{H}), 7.02-6.97(\mathrm{~m}, 1 \mathrm{H}), 6.97-6.92$ $(\mathrm{m}, 2 \mathrm{H}), 6.76(\mathrm{~s}, 1 \mathrm{H}), 4.30-4.13(\mathrm{~m}, 4 \mathrm{H}), 2.72-2.64(\mathrm{~m}$, $2 \mathrm{H}), 2.55(\mathrm{t}, J=7.7 \mathrm{~Hz}, 2 \mathrm{H}), 2.49-2.41(\mathrm{~m}, 2 \mathrm{H}), 1.98(\mathrm{~s}$, $3 \mathrm{H}), 1.64-1.52(\mathrm{~m}, 2 \mathrm{H}), 1.36-1.21(\mathrm{~m}, 16 \mathrm{H}), 0.92-0.84(\mathrm{~m}$, $3 \mathrm{H}) .{ }^{13} \mathrm{C} \mathrm{NMR}\left(101 \mathrm{MHz}, \mathrm{CDCl}_{3}\right): \delta 169.2,168.2,143.3$, 140.6, 128.7, 128.4, 126.3, 125.8, 66.6, 62.7, 36.1, 33.5, 32.0, $31.8,30.2,29.6,29.6,29.4,23.1,22.8,14.2,14.1$. HRMS-ESI $(m / z)$ : calcd for $\mathrm{C}_{25} \mathrm{H}_{40} \mathrm{NO}_{5}[\mathrm{M}+\mathrm{H}]^{+} 434.2906$, found: 434.2909.

Diethyl 2-Acetamido-2-(4-octylbenzyl)malonate (40). General procedure B was followed using $37(0.100 \mathrm{~g}, 0.259$ $\mathrm{mmol}), n$-octylboronic acid ( $49.1 \mathrm{mg}, 0.311 \mathrm{mmol}, 1.2$ equiv), $\mathrm{Pd}_{2}(\mathrm{dba})_{3}$ (11.8 mg, $0.0129 \mathrm{mmol}, 0.05$ equiv), SPhos (10.6 $\mathrm{mg}, 0.0259 \mathrm{mmol}, 0.1$ equiv), $\mathrm{K}_{2} \mathrm{CO}_{3}(0.107 \mathrm{~g}, 0.777 \mathrm{mmol}$, 3.0 equiv), and toluene/water $(4: 1,2 \mathrm{~mL})$. Compound $\mathbf{4 0}$ was obtained as a white solid (73 mg, 68\%). ${ }^{1} \mathrm{H}$ NMR (400 MHz, $\left.\mathrm{CDCl}_{3}\right): \delta 7.10-7.02(\mathrm{~m}, 2 \mathrm{H}), 6.94-6.86(\mathrm{~m}, 2 \mathrm{H}), 6.52(\mathrm{~s}$, $1 \mathrm{H}), 4.33-4.20(\mathrm{~m}, 4 \mathrm{H}), 3.60(\mathrm{~s}, 2 \mathrm{H}), 2.55(\mathrm{t}, J=7.7 \mathrm{~Hz}$, $2 \mathrm{H}), 2.03(\mathrm{~s}, 3 \mathrm{H}), 1.63-1.52(\mathrm{~m}, 2 \mathrm{H}), 1.37-1.20(\mathrm{~m}, 16 \mathrm{H})$, 0.92-0.84 (m, 3H). $\left.{ }^{13} \mathrm{C} \mathrm{NMR} \mathrm{(101} \mathrm{MHz}, \mathrm{CDCl}_{3}\right): \delta 169.1$, $167.8,142.0,132.4,129.9,128.5,67.4,62.7,37.0,35.7,32.0$, $31.5,29.6,29.5,29.4,23.2,22.8,14.3,14.2$. HRMS-ESI $(\mathrm{m} / z)$ : calcd for $\mathrm{C}_{24} \mathrm{H}_{38} \mathrm{NO}_{5}[\mathrm{M}+\mathrm{H}]^{+} 420.2750$, found: 420.2754 .

Diethyl 2-Acetamido-2-(4-decylbenzyl)malonate (41). General procedure B was followed using $37(0.200 \mathrm{~g}, 0.518$ $\mathrm{mmol}), n$-decylboronic acid ( $0.116 \mathrm{~g}, 0.621 \mathrm{mmol}, 1.2$ equiv), $\mathrm{Pd}_{2}(\mathrm{dba})_{3}$ (23.6 mg, $0.0258 \mathrm{mmol}, 0.05$ equiv), SPhos (21.2 $\mathrm{mg}, 0.0518 \mathrm{mmol}, 0.1$ equiv), $\mathrm{K}_{2} \mathrm{CO}_{3}(0.215 \mathrm{~g}$, $1.55 \mathrm{mmol}, 3.0$ equiv), and toluene/water $(4: 1,4 \mathrm{~mL})$. Compound 41 was obtained as a white solid (136 mg, 59\%). ${ }^{1} \mathrm{H}$ NMR (400 MHz, $\left.\mathrm{CDCl}_{3}\right): \delta 7.09-7.03(\mathrm{~m}, 2 \mathrm{H}), 6.93-6.87(\mathrm{~m}, 2 \mathrm{H}), 6.52(\mathrm{~s}$, $1 \mathrm{H}), 4.32-4.21(\mathrm{~m}, 4 \mathrm{H}), 3.60(\mathrm{~s}, 2 \mathrm{H}), 2.54(\mathrm{t}, J=7.9 \mathrm{~Hz}$, $2 \mathrm{H}), 2.03(\mathrm{~s}, 3 \mathrm{H}), 1.57(\mathrm{p}, J=7.3,6.7 \mathrm{~Hz}, 2 \mathrm{H}), 1.35-1.21(\mathrm{~m}$, $20 \mathrm{H}), 0.88(\mathrm{t}, J=6.8 \mathrm{~Hz}, 3 \mathrm{H}) .{ }^{13} \mathrm{C} \mathrm{NMR}\left(101 \mathrm{MHz}, \mathrm{CDCl}_{3}\right)$ : $\delta 169.1,167.8,142.0,132.4,129.9,128.5,67.4,62.7,37.6$, $35.7,32.1,31.5,29.8,29.7,29.6,29.54,29.48,23.2,22.8,14.36$, 14.12. HRMS-ESI $(m / z)$ : calcd for $\mathrm{C}_{26} \mathrm{H}_{42} \mathrm{NO}_{5}[\mathrm{M}+\mathrm{H}]^{+}$ 448.3063, found: 448.3065 .

(E)-2-Amino-2-[4-(oct-1-en-1-yl)phenethyl]propane-1,3diol (42). General procedure D was followed using 38 (83.0 $\mathrm{mg}, 0.192 \mathrm{mmol}$ ), $\mathrm{NaBH}_{4}$ (36.3 mg, $0.960 \mathrm{mmol}, 5.0$ equiv), $\mathrm{CaCl}_{2}$ (53.3 mg, $0.480 \mathrm{mmol}, 2.5$ equiv), and $\mathrm{EtOH} /$ water (4:1, $2 \mathrm{~mL}) ; \mathrm{N}$-acetylated diol intermediate (white solid, 69 $\mathrm{mg}$ ), $\mathrm{MeOH} / \mathrm{THF}$ 1:1 (1 mL), and $2 \mathrm{M} \mathrm{LiOH} \mathrm{(aq.)}(2 \mathrm{~mL})$. Compound 42 was obtained as a white solid $(42 \mathrm{mg}, 72 \%) .{ }^{1} \mathrm{H}$ NMR (400 MHz, $\left.\mathrm{CD}_{3} \mathrm{OD}\right): \delta 7.27-7.20(\mathrm{~m}, 2 \mathrm{H}), 7.16-7.11$ $(\mathrm{m}, 2 \mathrm{H}), 6.33(\mathrm{~d}, J=15.9 \mathrm{~Hz}, 1 \mathrm{H}), 6.24-6.12(\mathrm{~m}, 1 \mathrm{H}), 3.48$ (q) $J=14.3,10.9 \mathrm{~Hz}, 4 \mathrm{H}), 2.67-2.57(\mathrm{~m}, 2 \mathrm{H}), 2.24-2.14(\mathrm{~m}$, $2 \mathrm{H}), 1.70-1.61(\mathrm{~m}, 2 \mathrm{H}), 1.46(\mathrm{td}, J=7.7,4.5 \mathrm{~Hz}, 2 \mathrm{H}), 1.41-$ $1.24(\mathrm{~m}, 6 \mathrm{H}), 0.95-0.88(\mathrm{~m}, 3 \mathrm{H}) .{ }^{13} \mathrm{C}$ NMR (101 MHz, $\left.\mathrm{CD}_{3} \mathrm{OD}\right): \delta 142.7,136.9,131.0,130.9,129.5,127.0,66.4,56.9$, 37.5, 34.1, 32.9, 30.6, 30.09, 30.06, 23.7, 14.4. HRMS-ESI $(\mathrm{m} /$ $z$ ): calcd for $\mathrm{C}_{19} \mathrm{H}_{32} \mathrm{NO}_{2}[\mathrm{M}+\mathrm{H}]^{+}$306.2433, found: 306.2437 .

2-Amino-2-(3-octylphenethyl)propane-1,3-diol (43). General procedure $\mathrm{D}$ was followed using $39(78.2 \mathrm{mg}, 0.180$ mmol), $\mathrm{NaBH}_{4}$ (34.1 mg, $0.902 \mathrm{mmol}$, 5.0 equiv), $\mathrm{CaCl}_{2}$ (50.1 $\mathrm{mg}, 0.451 \mathrm{mmol}, 2.5$ equiv), and $\mathrm{EtOH} /$ water (4:1, $2 \mathrm{~mL}) ; \mathrm{N}$ acetylated diol intermediate (transparent oil, $60 \mathrm{mg}$ ), $\mathrm{MeOH}$ / THF ( $1 \mathrm{~mL}$ ), and $2 \mathrm{M} \mathrm{LiOH} \mathrm{(aq.,} 2 \mathrm{~mL}$ ). Compound 43 was obtained as a white solid (40 mg, 71\%). ${ }^{1} \mathrm{H}$ NMR (400 MHz, $\left.\mathrm{CD}_{3} \mathrm{OD}\right): \delta 7.14(\mathrm{t}, J=7.5 \mathrm{~Hz}, 1 \mathrm{H}), 7.06-6.99(\mathrm{~m}, 2 \mathrm{H}), 6.96$ (d, $J=7.5 \mathrm{~Hz}, 1 \mathrm{H}), 3.49$ (q, $J=14.5,10.8 \mathrm{~Hz}, 4 \mathrm{H}), 2.66-2.59$ $(\mathrm{m}, 2 \mathrm{H}), 2.56(\mathrm{t}, J=7.5 \mathrm{~Hz}, 2 \mathrm{H}), 1.70-1.63(\mathrm{~m}, 2 \mathrm{H}), 1.63-$ $1.55(\mathrm{~m}, 2 \mathrm{H}), 1.38-1.22(\mathrm{~m}, 10 \mathrm{H}), 0.94-0.85(\mathrm{~m}, 3 \mathrm{H}) .{ }^{13} \mathrm{C}$ NMR (101 MHz, $\left.\mathrm{CD}_{3} \mathrm{OD}\right): \delta 144.1,144.0,129.5,129.3$, $126.8,126.7,66.5,56.8,37.7,36.9,33.0,32.8,30.6,30.41$, $30.38,23.7,14.4$. HRMS-ESI $(m / z)$ : calcd for $\mathrm{C}_{19} \mathrm{H}_{34} \mathrm{NO}_{2}[\mathrm{M}$ $+\mathrm{H}]^{+}$308.2590, found: 308.2588 . $^{43}$

2-Amino-2-(4-octylbenzyl)propane-1,3-diol (44). General procedure D was followed using $40(67.9 \mathrm{mg}, 0.162 \mathrm{mmol})$, $\mathrm{NaBH}_{4}$ (30.6 mg, 0.809 mmol, 5.0 equiv), $\mathrm{CaCl}_{2}$ (44.9 mg, $0.405 \mathrm{mmol}, 2.5$ equiv), and $\mathrm{EtOH} /$ water (4:1, $1 \mathrm{~mL}$ ); Nacetylated diol intermediate (white solid, $54 \mathrm{mg}$ ), $\mathrm{MeOH}$ / THF ( $1 \mathrm{~mL}$ ), and $2 \mathrm{M} \mathrm{LiOH}$ (aq., $2 \mathrm{~mL}$ ). Compound 44 was obtained as a white solid $(28 \mathrm{mg}, 60 \%) .{ }^{1} \mathrm{H}$ NMR $(400 \mathrm{MHz}$, $\left.\mathrm{CD}_{3} \mathrm{OD}\right): \delta 7.18-7.14(\mathrm{~m}, 2 \mathrm{H}), 7.13-7.08(\mathrm{~m}, 2 \mathrm{H}), 3.38(\mathrm{q}, J$ $=10.8,1.9 \mathrm{~Hz}, 4 \mathrm{H}), 2.68(\mathrm{~s}, 2 \mathrm{H}), 2.57(\mathrm{t}, J=8.6,6.8 \mathrm{~Hz}, 2 \mathrm{H})$, $1.59(\mathrm{p}, J=7.2 \mathrm{~Hz}, 2 \mathrm{H}), 1.38-1.22(\mathrm{~m}, 10 \mathrm{H}), 0.93-0.85(\mathrm{~m}$, $3 \mathrm{H}) .{ }^{13} \mathrm{C} \mathrm{NMR}\left(101 \mathrm{MHz}, \mathrm{CD}_{3} \mathrm{OD}\right): \delta 142.2,135.2,131.6$, 129.3, 66.0, 57.3, 40.1, 36.5, 33.0, 32.8, 30.6, 30.40, 30.37, 23.7, 14.4. HRMS-ESI $(m / z)$ : calcd for $\mathrm{C}_{18} \mathrm{H}_{32} \mathrm{NO}_{2}[\mathrm{M}+\mathrm{H}]^{+}$ 294.2433, found: 294.2435.

2-Amino-2-(4-decylbenzyl)propane-1,3-diol (45). General procedure D was followed using $41(125 \mathrm{mg}, 0.279 \mathrm{mmol})$, $\mathrm{NaBH}_{4}\left(52.8 \mathrm{mg}, 1.40 \mathrm{mmol}\right.$, 5.0 equiv), $\mathrm{CaCl}_{2}(77.5 \mathrm{mg}$, $0.698 \mathrm{mmol}, 2.5$ equiv), and $\mathrm{EtOH} /$ water $(4: 1,2 \mathrm{~mL}) ; \mathrm{N}$ acetylated diol intermediate (white solid, $91 \mathrm{mg}$ ), $\mathrm{MeOH}$ / THF $(2 \mathrm{~mL}$ ), and $2 \mathrm{M} \mathrm{LiOH} \mathrm{(aq.,} 3 \mathrm{~mL}$ ). Compound 45 was obtained as a white solid (53 mg, 59\%). ${ }^{1} \mathrm{H}$ NMR $(400 \mathrm{MHz}$, $\left.\mathrm{CD}_{3} \mathrm{OD}\right): \delta 7.18-7.13(\mathrm{~m}, 2 \mathrm{H}), 7.13-7.08(\mathrm{~m}, 2 \mathrm{H}), 3.38(\mathrm{q}, J$ $=10.7,1.9 \mathrm{~Hz}, 4 \mathrm{H}), 2.68(\mathrm{~s}, 2 \mathrm{H}), 2.57(\mathrm{t}, J=7.7 \mathrm{~Hz}, 2 \mathrm{H}), 1.59$ $(\mathrm{p}, J=7.1 \mathrm{~Hz}, 2 \mathrm{H}), 1.30(\mathrm{~d}, J=15.7 \mathrm{~Hz}, 14 \mathrm{H}), 0.95-0.84(\mathrm{~m}$, $3 \mathrm{H}) .{ }^{13} \mathrm{C}$ NMR (101 MHz, CD $\left.\mathrm{OD}\right): \delta 142.2,135.2,131.6$, 129.3, 66.0, 57.2, 40.1, 36.5, 33.1, 32.8, 30.7, 30.6, 30.5, 30.4, 23.7, 14.4. HRMS-ESI $(m / z)$ : calcd for $\mathrm{C}_{20} \mathrm{H}_{36} \mathrm{NO}_{2}[\mathrm{M}+\mathrm{H}]^{+}$ 322.2746, found: 322.2748 .

Diethyl 2-Acetamido-2-[4-(octyloxy)phenethyl]malonate (46). General procedure $\mathrm{C}$ was followed using 20 (0.100 g, $0.296 \mathrm{mmol}$ ), $\mathrm{K}_{2} \mathrm{CO}_{3}$ (81.9 mg, $0.593 \mathrm{mmol}, 2.0$ equiv), 1bromooctane ( $0.115 \mathrm{~g}, 0.593 \mathrm{mmol}, 2.0$ equiv), and anhydrous DMF $(2 \mathrm{~mL})$. Compound 46 was obtained as a white solid $(0.101 \mathrm{~g}, 76 \%) .{ }^{1} \mathrm{H}$ NMR $\left(400 \mathrm{MHz}, \mathrm{CDCl}_{3}\right): \delta 7.07-7.00$ $(\mathrm{m}, 2 \mathrm{H}), 6.82-6.77(\mathrm{~m}, 2 \mathrm{H}), 6.76(\mathrm{bs}, 1 \mathrm{H}), 4.27-4.14(\mathrm{~m}$, $4 \mathrm{H}), 3.91(\mathrm{t}, J=6.6 \mathrm{~Hz}, 2 \mathrm{H}), 2.70-2.61(\mathrm{~m}, 2 \mathrm{H}), 2.46-2.37$ $(\mathrm{m}, 2 \mathrm{H}), 1.99(\mathrm{~s}, 3 \mathrm{H}), 1.81-1.70(\mathrm{~m}, 2 \mathrm{H}), 1.49-1.38(\mathrm{~m}$, $2 \mathrm{H}), 1.37-1.21(\mathrm{~m}, 14 \mathrm{H}), 0.92-0.84(\mathrm{~m}, 3 \mathrm{H}) .{ }^{13} \mathrm{C}$ NMR $\left(101 \mathrm{MHz}, \mathrm{CDCl}_{3}\right): \delta 169.1,168.2,157.7,132.5,129.4,114.6$, 68.2, 66.5, 62.3, 33.7, 31.9, 29.5, 29.43, 29.37, 26.2, 23.2, 22.8, 14.2, 14.1. HRMS-ESI $(\mathrm{m} / z)$ : calcd for $\mathrm{C}_{25} \mathrm{H}_{40} \mathrm{NO}_{6}[\mathrm{M}+\mathrm{H}]^{+}$ 450.2856, found: 450.2856 .

Diethyl 2-Acetamido-2-[4-(decyloxy)phenethyl]malonate (47). General procedure $\mathrm{C}$ was followed using 20 (0.100 g, $0.296 \mathrm{mmol}$ ), $\mathrm{K}_{2} \mathrm{CO}_{3}$ (81.9 mg, $0.593 \mathrm{mmol}, 2.0$ equiv), 1 bromodecane $(0.131 \mathrm{~g}, 0.593 \mathrm{mmol}, 2.0$ equiv), and anhydrous DMF $(2 \mathrm{~mL})$. Compound 47 was obtained as a white solid $(0.110 \mathrm{~g}, 78 \%) .{ }^{1} \mathrm{H} \mathrm{NMR}\left(400 \mathrm{MHz}, \mathrm{CDCl}_{3}\right): \delta 7.06-7.01$ $(\mathrm{m}, 2 \mathrm{H}), 6.82-6.77(\mathrm{~m}, 2 \mathrm{H}), 6.76(\mathrm{bs}, 1 \mathrm{H}), 4.28-4.13(\mathrm{~m}$, $4 \mathrm{H}), 3.91(\mathrm{t}, J=6.6 \mathrm{~Hz}, 2 \mathrm{H}), 2.70-2.61(\mathrm{~m}, 2 \mathrm{H}), 2.46-2.37$ $(\mathrm{m}, 2 \mathrm{H}), 1.99(\mathrm{~s}, 3 \mathrm{H}), 1.81-1.69(\mathrm{~m}, 2 \mathrm{H}), 1.49-1.37(\mathrm{~m}$, $2 \mathrm{H}), 1.36-1.21(\mathrm{~m}, 18 \mathrm{H}), 0.92-0.84(\mathrm{~m}, 3 \mathrm{H}) .{ }^{13} \mathrm{C} \mathrm{NMR}$ $\left(101 \mathrm{MHz}, \mathrm{CDCl}_{3}\right): \delta 169.1,168.2,157.7,132.5,129.4,114.6$, $68.2,66.5,62.7,33.7,32.0,29.72,29.70,29.54,29.46,29.44$, 29.36, 26.2, 23.2, 22.8, 14.3, 14.1. HRMS-ESI $(\mathrm{m} / z)$ : calcd for $\mathrm{C}_{27} \mathrm{H}_{44} \mathrm{NO}_{6}[\mathrm{M}+\mathrm{H}]^{+}$478.3169, found: 478.3170 . 
2-Amino-2-[4-(octyloxy)phenethyl]propane-1,3-diol (48). General procedure D was followed using $46(95.1 \mathrm{mg}, 0.212$ mmol), $\mathrm{NaBH}_{4}$ (40.0 mg, $1.06 \mathrm{mmol}, 5.0$ equiv), $\mathrm{CaCl}_{2}$ (58.7 $\mathrm{mg}, 0.529 \mathrm{mmol}, 2.5$ equiv), and $\mathrm{EtOH} /$ water $(4: 1,2 \mathrm{~mL}) ; \mathrm{N}$ acetylated diol intermediate (white solid, $76 \mathrm{mg}$ ), $\mathrm{MeOH}$ / THF ( $1 \mathrm{~mL}$ ), and $2 \mathrm{M} \mathrm{LiOH}$ (aq., $2 \mathrm{~mL}$ ). Compound 48 was obtained as a white solid (50 mg, 73\%). ${ }^{1} \mathrm{H}$ NMR (400 MHz, $\left.\mathrm{CD}_{3} \mathrm{OD}\right): \delta 7.14-7.08(\mathrm{~m}, 2 \mathrm{H}), 6.83-6.77(\mathrm{~m}, 2 \mathrm{H}), 3.92(\mathrm{t}, J$ $=6.5 \mathrm{~Hz}, 2 \mathrm{H}), 3.48(\mathrm{q}, J=14.8,10.7 \mathrm{~Hz}, 4 \mathrm{H}), 2.62-2.54(\mathrm{~m}$, $2 \mathrm{H}), 1.80-1.68(\mathrm{~m}, 2 \mathrm{H}), 1.68-1.59(\mathrm{~m}, 2 \mathrm{H}), 1.51-1.42(\mathrm{~m}$, $2 \mathrm{H}), 1.41-1.24(\mathrm{~m}, 8 \mathrm{H}), 0.95-0.87(\mathrm{~m}, 3 \mathrm{H}) .{ }^{13} \mathrm{C}$ NMR (101 $\left.\mathrm{MHz}, \mathrm{CD}_{3} \mathrm{OD}\right): \delta 158.7,135.9,130.2,115.5,69.0,66.5,56.8$, 37.8, 33.0, 30.51, 30.48, 30.4, 29.5, 27.2, 23.7, 14.4. HRMS-ESI $(m / z)$ : calcd for $\mathrm{C}_{19} \mathrm{H}_{34} \mathrm{NO}_{3}[\mathrm{M}+\mathrm{H}]^{+} 324.2539$, found: 324.2542 . $^{44}$

2-Amino-2-[4-(decyloxy)phenethyl]propane-1,3-diol (49). General procedure D was followed using $47(0.104 \mathrm{~g}, 0.218$ mmol), $\mathrm{NaBH}_{4}$ (41.2 mg, 1.09 mmol, 5.0 equiv), $\mathrm{CaCl}_{2}$ (60.4 $\mathrm{mg}, 0.544 \mathrm{mmol}, 2.5$ equiv), and $\mathrm{EtOH} /$ water (4:1, $2 \mathrm{~mL})$; Nacetylated diol intermediate (white solid, $87 \mathrm{mg}$ ), $\mathrm{MeOH} /$ THF ( $1 \mathrm{~mL}$ ), and $2 \mathrm{M} \mathrm{LiOH}$ (aq., $2 \mathrm{~mL}$ ). Compound 49 was obtained as a white solid (54 mg, 71\%). ${ }^{1} \mathrm{H}$ NMR (400 MHz, $\left.\mathrm{CD}_{3} \mathrm{OD}\right): \delta 7.14-7.08(\mathrm{~m}, 2 \mathrm{H}), 6.83-6.76(\mathrm{~m}, 2 \mathrm{H}), 3.92(\mathrm{t}, J$ $=6.5 \mathrm{~Hz}, 2 \mathrm{H}), 3.48(\mathrm{q}, J=14.6,10.9 \mathrm{~Hz}, 4 \mathrm{H}), 2.62-2.54(\mathrm{~m}$, $2 \mathrm{H}), 1.80-1.68(\mathrm{~m}, 2 \mathrm{H}), 1.68-1.59(\mathrm{~m}, 2 \mathrm{H}), 1.46(\mathrm{p}, J=7.2$ $\mathrm{Hz}, 2 \mathrm{H}), 1.40-1.24(\mathrm{~m}, 12 \mathrm{H}), 0.94-0.86(\mathrm{~m}, 3 \mathrm{H}) .{ }^{13} \mathrm{C} \mathrm{NMR}$ (101 $\left.\mathrm{MHz} \mathrm{CD}_{3} \mathrm{OD}\right): \delta 158.7,135.9,130.2,115.5,69.0,66.5$, $56.8,37.8,33.1,30.73,30.68,30.53,30.48,30.45,29.5,27.2$, 23.7, 14.4. HRMS-ESI $(m / z)$ : calcd for $\mathrm{C}_{21} \mathrm{H}_{38} \mathrm{NO}_{3}[\mathrm{M}+\mathrm{H}]^{+}$ 352.2852, found: 352.2852 .

Diethyl 2-Acetamido-2-[2-(4-bromophenyl)-2-oxoethyl]malonate (51). General procedure A was followed using 2bromo-1-(4-bromophenyl)ethan-1-one (50) (1.00 g, 3.60 mmol, 1.4 equiv), DEAM (0.558 g, $2.57 \mathrm{mmol}), \mathrm{Cs}_{2} \mathrm{CO}_{3}$ (1.76 g, $5.40 \mathrm{mmol}, 1.5$ equiv), and anhydrous $\mathrm{MeCN}$ (15 $\mathrm{mL})$. Compound $\mathbf{5 1}$ was obtained as an orange solid $(429 \mathrm{mg}$, 40\%). ${ }^{1} \mathrm{H}$ NMR (400 MHz, $\left.\mathrm{CDCl}_{3}\right): \delta 7.85-7.79(\mathrm{~m}, 2 \mathrm{H})$, 7.64-7.58 (m, 2H), 7.09 (s, 1H), 4.31-4.24 (m, 4H), 4.23 (s, $2 \mathrm{H}), 1.97(\mathrm{~s}, 3 \mathrm{H}), 1.24(\mathrm{t}, J=7.1 \mathrm{~Hz}, 6 \mathrm{H}) .{ }^{13} \mathrm{C}$ NMR $(101$ $\left.\mathrm{MHz}, \mathrm{CDCl}_{3}\right): \delta 196.1,169.7,167.3,134.9,132.2,129.9$, 129.2, 64.1, 63.1, 42.3, 23.1, 14.1. HRMS-ESI $(\mathrm{m} / z)$ : calcd for $\mathrm{C}_{17} \mathrm{H}_{21} \mathrm{NO}_{6} \mathrm{Br}[\mathrm{M}+\mathrm{H}]^{+}$414.0552, found: 414.0553 .

Diethyl 2-Acetamido-2-[2-(4-octylphenyl)-2-oxoethyl]malonate (52). General procedure B was followed using 51 $(0.150 \mathrm{~g}, 0.362 \mathrm{mmol}), n$-octylboronic acid $(68.7 \mathrm{mg}, 0.435$ mmol, 1.2 equiv), $\mathrm{Pd}_{2}(\mathrm{dba})_{3}(16.6 \mathrm{mg}, 0.0181 \mathrm{mmol}, 0.05$ equiv), SPhos (14.9 mg, $0.0362 \mathrm{mmol}, 0.1$ equiv), $\mathrm{K}_{2} \mathrm{CO}_{3}$ (0.150 g, $1.09 \mathrm{mmol}, 3.0$ equiv), and toluene/water (4:1, 2 $\mathrm{mL})$. Compound $\mathbf{5 2}$ was obtained as a yellow oil $(147 \mathrm{mg}$, 91\%). ${ }^{1} \mathrm{H}$ NMR (400 MHz, $\left.\mathrm{CDCl}_{3}\right): \delta 7.91-7.84(\mathrm{~m}, 2 \mathrm{H})$, 7.30-7.22 (m, 2H), 7.11 (bs, $1 \mathrm{H}), 4.33-4.21(\mathrm{~m}, 6 \mathrm{H}), 2.65$ $(\mathrm{t}, J=7.5 \mathrm{~Hz}, 2 \mathrm{H}), 1.97(\mathrm{~s}, 3 \mathrm{H}), 1.67-1.55(\mathrm{~m}, 2 \mathrm{H}), 1.35-$ $1.20(\mathrm{~m}, 16 \mathrm{H}), 0.92-0.84(\mathrm{~m}, 3 \mathrm{H}) .{ }^{13} \mathrm{C}$ NMR $(101 \mathrm{MHz}$, $\left.\mathrm{CDCl}_{3}\right): \delta 196.7,169.6,167.5,149.8,134.0,128.9,128.5,64.2$, 63.0, 42.3, 36.2, 32.0, 31.2, 29.5, 29.4, 29.3, 23.1, 22.8, 14.2, 14.0. HRMS-ESI $(m / z)$ : calcd for $\mathrm{C}_{25} \mathrm{H}_{38} \mathrm{NO}_{6}[\mathrm{M}+\mathrm{H}]^{+}$ 448.2699, found: 448.2700 .

Diethyl 2-Acetamido-2-[2-(4-decylphenyl)-2-oxoethyl]malonate (53). General procedure B was followed using 51 $(0.150 \mathrm{~g}, 0.362 \mathrm{mmol}), n$-decylboronic acid $(80.9 \mathrm{mg}, 0.435$ mmol, 1.2 equiv), $\mathrm{Pd}_{2}(\mathrm{dba})_{3}(16.6 \mathrm{mg}, 0.0181 \mathrm{mmol}, 0.05$ equiv), SPhos (14.9 mg, $0.0362 \mathrm{mmol}, 0.1$ equiv), $\mathrm{K}_{2} \mathrm{CO}_{3}$ (0.150 g, $1.09 \mathrm{mmol}, 3.0$ equiv), and toluene/water (4:1, 2
$\mathrm{mL})$. Compound $\mathbf{5 3}$ was obtained as a yellow oil $(124 \mathrm{mg}$, 72\%). ${ }^{1} \mathrm{H}$ NMR (400 MHz, $\left.\mathrm{CDCl}_{3}\right): \delta 7.91-7.84(\mathrm{~m}, 2 \mathrm{H})$, $7.30-7.23(\mathrm{~m}, 2 \mathrm{H}), 7.10(\mathrm{~s}, 1 \mathrm{H}), 4.33-4.21(\mathrm{~m}, 6 \mathrm{H}), 2.65(\mathrm{t}$, $J=7.9 \mathrm{~Hz}, 2 \mathrm{H}), 1.97(\mathrm{~s}, 3 \mathrm{H}), 1.67-1.55(\mathrm{~m}, 2 \mathrm{H}), 1.35-1.20$ $(\mathrm{m}, 20 \mathrm{H}), 0.92-0.84(\mathrm{~m}, 3 \mathrm{H}) .{ }^{13} \mathrm{C} \mathrm{NMR}\left(101 \mathrm{MHz}, \mathrm{CDCl}_{3}\right)$ : $\delta$ 196.7, 169.5, 167.5, 149.8, 134.0, 128.9, 128.5, 64.2, 63.0, 42.3, 36.2, 32.0, 31.2, 29.73, 29.68, 29.58, 29.44, 29.38, 23.1, $22.8,14.2,14.0$. HRMS-ESI $(m / z)$ : calcd for $\mathrm{C}_{27} \mathrm{H}_{42} \mathrm{NO}_{6}[\mathrm{M}+$ $\mathrm{H}]^{+}$476.3012, found: 476.3013 .

3-Amino-3-(hydroxymethyl)-1-(4-octylphenyl)butane-1,4diol (54). General procedure D was followed using 52 (131 $\mathrm{mg}, 0.293 \mathrm{mmol}$ ), $\mathrm{NaBH}_{4}$ (55.4 mg, $1.46 \mathrm{mmol}, 5.0$ equiv), $\mathrm{CaCl}_{2}$ (81.2 mg, $0.732 \mathrm{mmol}, 2.5$ equiv), and $\mathrm{EtOH} /$ water (4:1, $2 \mathrm{~mL})$; $\mathrm{N}$-acetylated diol intermediate (light yellow oil, $104 \mathrm{mg}$ ), $\mathrm{MeOH} / \mathrm{THF}(2 \mathrm{~mL})$, and $2 \mathrm{M} \mathrm{LiOH} \mathrm{(aq.,} 3 \mathrm{~mL}$ ). Compound 54 was obtained as a white solid $(67 \mathrm{mg}, 71 \%) .{ }^{1} \mathrm{H}$ NMR (400 MHz, $\left.\mathrm{CD}_{3} \mathrm{OD}\right): \delta 7.31-7.25(\mathrm{~m}, 2 \mathrm{H}), 7.16-7.10$ $(\mathrm{m}, 2 \mathrm{H}), 4.93(\mathrm{dd}, J=10.5,2.7 \mathrm{~Hz}, 1 \mathrm{H}), 3.57(\mathrm{q}, J=10.8,6.8$ $\mathrm{Hz}, 2 \mathrm{H}), 3.50(\mathrm{~s}, 2 \mathrm{H}), 2.58(\mathrm{t}, J=7.6 \mathrm{~Hz}, 2 \mathrm{H}), 1.78(\mathrm{dd}, J=$ $14.8,10.5 \mathrm{~Hz}, 1 \mathrm{H}), 1.69$ (dd, $J=14.7,2.7 \mathrm{~Hz}, 1 \mathrm{H}), 1.65-1.53$ $(\mathrm{m}, 2 \mathrm{H}), 1.38-1.22(\mathrm{~m}, 10 \mathrm{H}), 0.93-0.85(\mathrm{~m}, 3 \mathrm{H}) .{ }^{13} \mathrm{C} \mathrm{NMR}$ (101 MHz, $\left.\mathrm{CD}_{3} \mathrm{OD}\right): \delta 144.4,143.0,129.3,126.8,71.6,67.7$, 66.4, 57.3, 44.5, 36.6, 33.0, 32.8, 30.6, 30.4, 30.3, 23.7, 14.4 . HRMS-ESI $(m / z)$ : calcd for $\mathrm{C}_{19} \mathrm{H}_{34} \mathrm{NO}_{3}[\mathrm{M}+\mathrm{H}]^{+}$324.2539, found: $324.2540 .^{45}$

3-Amino-3-(hydroxymethyl)-1-(4-decylphenyl)butane1,4-diol (55). General procedure D was followed using 53 (112 $\mathrm{mg}, 0.234 \mathrm{mmol}$ ), $\mathrm{NaBH}_{4}$ (44.3 mg, $1.17 \mathrm{mmol}, 5.0$ equiv), $\mathrm{CaCl}_{2}$ (65.0 mg, $0.586 \mathrm{mmol}, 2.5$ equiv), and $\mathrm{EtOH} /$ water $(4: 1,2 \mathrm{~mL}) ; \mathrm{N}$-acetylated diol intermediate (white solid, 93 $\mathrm{mg}$ ), $\mathrm{MeOH} / \mathrm{THF} 1: 1(2 \mathrm{~mL})$, and $2 \mathrm{M} \mathrm{LiOH}$ (aq.) (3 mL). Compound 55 was obtained as a white solid $(60 \mathrm{mg}, 73 \%) .{ }^{1} \mathrm{H}$ NMR (400 MHz, $\left.\mathrm{CD}_{3} \mathrm{OD}\right): \delta 7.31-7.25(\mathrm{~m}, 2 \mathrm{H}), 7.16-7.10$ $(\mathrm{m}, 2 \mathrm{H}), 4.93(\mathrm{dd} J=10.5,2.7 \mathrm{~Hz}, 1 \mathrm{H}), 3.58(\mathrm{q}, J=10.9,6.9$ $\mathrm{Hz}, 2 \mathrm{H}), 3.50(\mathrm{~s}, 2 \mathrm{H}), 2.58(\mathrm{t}, J=7.6 \mathrm{~Hz}, 2 \mathrm{H}), 1.78(\mathrm{dd}, J=$ 14.7, $10.5 \mathrm{~Hz}, 1 \mathrm{H}), 1.69$ (dd, $J=14.7,2.7 \mathrm{~Hz}, 1 \mathrm{H}), 1.65-1.53$ (m, 2H), $1.37-1.22(\mathrm{~m}, 14 \mathrm{H}), 0.94-0.86(\mathrm{~m}, 3 \mathrm{H}) .{ }^{13} \mathrm{C}$ NMR (101 MHz, $\left.\mathrm{CD}_{3} \mathrm{OD}\right): \delta 144.4,143.0,129.3,126.8,71.6,67.7$, $66.4,57.3,44.5,36.6,33.1,32.8,30.74,30.72,30.6,30.4,30.2$, 23.7, 14.4. HRMS-ESI $(\mathrm{m} / z)$ : calcd for $\mathrm{C}_{21} \mathrm{H}_{38} \mathrm{NO}_{3}[\mathrm{M}+\mathrm{H}]^{+}$ 352.2852, found: 352.2856 .

2-(5-Bromopyridin-2-yl)ethyl Methanesulfonate (57). To a cooled solution of 2-(5-bromopyridin-2-yl)ethan-1-ol (56) $(0.500 \mathrm{~g}, 2.48 \mathrm{mmol})$ and $\mathrm{Et}_{3} \mathrm{~N}(0.518 \mathrm{~mL}, 3.71 \mathrm{mmol}, 1.5$ equiv) in anhydrous DCM $(12 \mathrm{~mL})$ was added methanesulfonyl chloride $(0.249 \mathrm{~mL}, 3.22 \mathrm{mmol}, 1.3$ equiv), and the reaction mixture was stirred for $3 \mathrm{~h}$. The mixture was diluted with DCM and washed repeatedly with water and brine. The organic layer was dried over anhydrous $\mathrm{Na}_{2} \mathrm{SO}_{4}$ and concentrated on a rotary evaporator to give $\mathbf{5 7}$ as a yellow oil (662 mg, 96\%). ${ }^{1} \mathrm{H}$ NMR (400 MHz, $\left.\mathrm{CDCl}_{3}\right): \delta 8.61$ (d, J $=2.4 \mathrm{~Hz}, 1 \mathrm{H}), 7.76(\mathrm{dd}, J=8.3,2.4 \mathrm{~Hz}, 1 \mathrm{H}), 7.13(\mathrm{~d}, J=8.3$ $\mathrm{Hz}, 1 \mathrm{H}), 4.63(\mathrm{t}, J=6.4 \mathrm{~Hz}, 2 \mathrm{H}), 3.18(\mathrm{t}, J=6.4 \mathrm{~Hz}, 2 \mathrm{H}), 2.93$ $(\mathrm{s}, 3 \mathrm{H}) \cdot{ }^{13} \mathrm{C}$ NMR $\left(101 \mathrm{MHz}, \mathrm{CDCl}_{3}\right): \delta 155.2,150.8,139.3$, 125.3, 119.3, 68.6, 37.4, 37.0. HRMS-ESI $(\mathrm{m} / z)$ : calcd for $\mathrm{C}_{8} \mathrm{H}_{11} \mathrm{NO}_{3} \mathrm{SBr}[\mathrm{M}+\mathrm{H}]^{+}$279.9643, found: 279.9643 .

Diethyl 2-Acetamido-2-[2-(5-bromopyridin-2-yl)ethyl]malonate (58). General procedure A was followed using 57 (0.661 g, $2.36 \mathrm{mmol}, 1.2$ equiv), DEAM (0.427 g, $1.97 \mathrm{mmol})$, $\mathrm{Cs}_{2} \mathrm{CO}_{3}$ (1.28 g, $3.93 \mathrm{mmol}, 2.0$ equiv), and anhydrous $\mathrm{MeCN}$ $(15 \mathrm{~mL})$. Compound $\mathbf{5 8}$ was obtained as a yellow solid (342 $\mathrm{mg}, 43 \%) .{ }^{1} \mathrm{H}$ NMR $\left(400 \mathrm{MHz}, \mathrm{CDCl}_{3}\right): \delta 8.55(\mathrm{~d}, J=2.2 \mathrm{~Hz}$, $1 \mathrm{H}), 7.70(\mathrm{dd}, J=8.3,2.4 \mathrm{~Hz}, 1 \mathrm{H}), 7.05(\mathrm{~d}, J=8.2 \mathrm{~Hz}, 1 \mathrm{H})$, 
$6.83(\mathrm{~s}, 1 \mathrm{H}), 4.31-4.14(\mathrm{~m}, 4 \mathrm{H}), 2.79-2.71(\mathrm{~m}, 2 \mathrm{H}), 2.69-$ $2.61(\mathrm{~m}, 2 \mathrm{H}), 2.00(\mathrm{~s}, 3 \mathrm{H}), 1.25(\mathrm{t}, J=7.1 \mathrm{~Hz}, 6 \mathrm{H}) .{ }^{13} \mathrm{C} \mathrm{NMR}$ $\left(101 \mathrm{MHz}, \mathrm{CDCl}_{3}\right): \delta 169.3,168.1,159.3,150.3,139.0,124.2$, $118.4,66.3,62.8,32.2,32.1,23.2$, 14.1. HRMS-ESI $(\mathrm{m} / z)$ : calcd for $\mathrm{C}_{16} \mathrm{H}_{22} \mathrm{~N}_{2} \mathrm{O}_{5} \mathrm{Br}[\mathrm{M}+\mathrm{H}]^{+}$401.0712, found: 401.0711 .

Diethyl 2-Acetamido-2-[2-(5-octylpyridin-2-yl)ethyl]malonate (59). General procedure B was followed using 58 (0.100 g, $0.249 \mathrm{mmol})$, n-octylboronic acid $(47.3 \mathrm{mg}, 0.299$ mmol, 1.2 equiv), $\mathrm{Pd}_{2}(\mathrm{dba})_{3}(11.4 \mathrm{mg}, 0.0125 \mathrm{mmol}, 0.05$ equiv), SPhos (10.2 mg, $0.0250 \mathrm{mmol}, 0.1$ equiv), $\mathrm{K}_{2} \mathrm{CO}_{3}$ (0.103 g, $0.748 \mathrm{mmol}, 3.0$ equiv), and toluene/water (4:1, 2 $\mathrm{mL})$. Compound $\mathbf{5 9}$ was obtained as a yellow oil $(51 \mathrm{mg}$, 47\%). ${ }^{1} \mathrm{H}$ NMR (400 MHz, $\left.\mathrm{CDCl}_{3}\right): \delta 8.30(\mathrm{~d}, J=2.0 \mathrm{~Hz}$, $1 \mathrm{H}), 7.39$ (dd, $J=7.9,2.4 \mathrm{~Hz}, 1 \mathrm{H}), 7.05(\mathrm{~d}, J=7.9 \mathrm{~Hz}, 1 \mathrm{H})$, 6.94 (bs, $1 \mathrm{H}), 4.29-4.12(\mathrm{~m}, 4 \mathrm{H}), 2.80-2.70(\mathrm{~m}, 2 \mathrm{H}), 2.71-$ $2.62(\mathrm{~m}, 2 \mathrm{H}), 2.55(\mathrm{t}, J=7.5 \mathrm{~Hz}, 2 \mathrm{H}), 1.99(\mathrm{~s}, 3 \mathrm{H}), 1.56(\mathrm{p}, J$ $=7.3 \mathrm{~Hz}, 2 \mathrm{H}), 1.34-1.20(\mathrm{~m}, 16 \mathrm{H}), 0.91-0.83(\mathrm{~m}, 3 \mathrm{H}) .{ }^{13} \mathrm{C}$ NMR $\left(101 \mathrm{MHz}, \mathrm{CDCl}_{3}\right): \delta 169.2,168.2,157.8,149.3,136.5$, 135.6, 122.3, 66.4, 62.7, 32.7, 32.4, 32.3, 32.0, 31.4, 29.5, 29.4, $29.3,23.2,22.8,14.2,14.1$. HRMS-ESI $(\mathrm{m} / z)$ : calcd for $\mathrm{C}_{24} \mathrm{H}_{39} \mathrm{~N}_{2} \mathrm{O}_{5}[\mathrm{M}+\mathrm{H}]^{+}$435.2859, found: 435.2851.

Diethyl 2-Acetamido-2-[2-(5-decylpyridin-2-yl)ethyl]malonate (60). General procedure B was followed using 58 $(0.100 \mathrm{~g}, 0.249 \mathrm{mmol}), n$-decylboronic acid $(55.6 \mathrm{mg}, 0.299$ mmol, 1.2 equiv), $\mathrm{Pd}_{2}(\mathrm{dba})_{3}(11.4 \mathrm{mg}, 0.0125 \mathrm{mmol}, 0.05$ equiv), SPhos (10.2 mg, $0.0250 \mathrm{mmol}, 0.1$ equiv), $\mathrm{K}_{2} \mathrm{CO}_{3}$ (0.103 g, $0.748 \mathrm{mmol}, 3.0$ equiv), and toluene/water (4:1, 2 $\mathrm{mL})$. Compound 60 was obtained as a yellow oil $(69 \mathrm{mg}$, 60\%). ${ }^{1} \mathrm{H}$ NMR (400 MHz, $\left.\mathrm{CDCl}_{3}\right): \delta 8.30(\mathrm{~d}, J=2.3 \mathrm{~Hz}$, $1 \mathrm{H}), 7.39(\mathrm{dd}, J=7.9,2.3 \mathrm{~Hz}, 1 \mathrm{H}), 7.05(\mathrm{~d}, J=8.0 \mathrm{~Hz}, 1 \mathrm{H})$, 6.95 (bs, $1 \mathrm{H}), 4.30-4.12(\mathrm{~m}, 4 \mathrm{H}), 2.80-2.70(\mathrm{~m}, 2 \mathrm{H}), 2.71-$ $2.60(\mathrm{~m}, 2 \mathrm{H}), 2.54(\mathrm{t}, J=7.5 \mathrm{~Hz}, 2 \mathrm{H}), 1.99(\mathrm{~s}, 3 \mathrm{H}), 1.56(\mathrm{p}, J$ $=7.4 \mathrm{~Hz}, 2 \mathrm{H}), 1.33-1.20(\mathrm{~m}, 20 \mathrm{H}), 0.91-0.83(\mathrm{~m}, 3 \mathrm{H}) .{ }^{13} \mathrm{C}$ NMR $\left(101 \mathrm{MHz}, \mathrm{CDCl}_{3}\right): \delta 169.2,168.2,157.8,149.3,136.5$, 135.6, 122.3, 66.4, 62.7, 32.7, 32.4, 32.3, 32.0, 31.4, 29.73, 29.70, 29.6, 29.4, 29.3, 23.2, 22.8, 14.2, 14.1. HRMS-ESI $(\mathrm{m} /$ $z$ ): calcd for $\mathrm{C}_{26} \mathrm{H}_{43} \mathrm{~N}_{2} \mathrm{O}_{5}[\mathrm{M}+\mathrm{H}]^{+}$463.3172, found: 463.3173 .

2-Amino-2-[2-(5-octylpyridin-2-yl)ethyl]propane-1,3-diol (61). General procedure D was followed using $59(47.5 \mathrm{mg}$, $0.109 \mathrm{mmol}$ ), $\mathrm{NaBH}_{4}(20.7 \mathrm{mg}, 0.547 \mathrm{mmol}, 5.0$ equiv $), \mathrm{CaCl}_{2}$ (30.3 mg, $0.273 \mathrm{mmol}, 2.5$ equiv), and $\mathrm{EtOH} /$ water (4:1, 1 $\mathrm{mL}$ ); $\mathrm{N}$-acetylated diol intermediate (yellow oil, $33 \mathrm{mg}$ ), $\mathrm{MeOH} / \mathrm{THF}(1 \mathrm{~mL}$ ), and $2 \mathrm{M} \mathrm{LiOH}$ (aq., $2 \mathrm{~mL}$ ). Compound 61 was obtained as a white solid (18 mg, 52\%). ${ }^{1} \mathrm{H}$ NMR (400 $\left.\mathrm{MHz}, \mathrm{CD}_{3} \mathrm{OD}\right): \delta 8.25(\mathrm{~d}, J=1.8 \mathrm{~Hz}, 1 \mathrm{H}), 7.59$ (dd, $J=8.0$, $2.3 \mathrm{~Hz}, 1 \mathrm{H}), 7.25$ (d, $J=8.0 \mathrm{~Hz}, 1 \mathrm{H}), 3.49$ (q, $J=13.3,11.0$ $\mathrm{Hz}, 4 \mathrm{H}), 2.83-2.75(\mathrm{~m}, 2 \mathrm{H}), 2.61(\mathrm{t}, J=7.5 \mathrm{~Hz}, 2 \mathrm{H}), 1.77-$ $1.68(\mathrm{~m}, 2 \mathrm{H}), 1.61(\mathrm{p}, J=7.3,6.7 \mathrm{~Hz}, 2 \mathrm{H}), 1.40-1.22(\mathrm{~m}$, $10 \mathrm{H}), 0.93-0.85(\mathrm{~m}, 3 \mathrm{H}) .{ }^{13} \mathrm{C}$ NMR (101 MHz, $\left.\mathrm{CD}_{3} \mathrm{OD}\right): \delta$ 160.7, 149.3, 138.8, 137.4, 124.2, 66.3, 57.0, 35.8, 33.4, 33.0, $32.3,31.9,30.5,30.4,30.2,23.7,14.4$. HRMS-ESI $(\mathrm{m} / z)$ : calcd for $\mathrm{C}_{18} \mathrm{H}_{33} \mathrm{~N}_{2} \mathrm{O}_{2}[\mathrm{M}+\mathrm{H}]^{+} 309.2542$, found: 309.2542 .

2-Amino-2-[2-(5-decylpyridin-2-yl)ethyl]propane-1,3-diol (62). General procedure D was followed using $60(64.7 \mathrm{mg}$, $0.140 \mathrm{mmol}$ ), $\mathrm{NaBH}_{4}$ (26.5 mg, $0.700 \mathrm{mmol}, 5.0$ equiv), $\mathrm{CaCl}_{2}$ (38.8 mg, $0.350 \mathrm{mmol}, 2.5$ equiv), and $\mathrm{EtOH} /$ water (4:1, 1 $\mathrm{mL})$; N-acetylated diol intermediate (transparent oil, $51 \mathrm{mg}$ ), $\mathrm{MeOH} / \mathrm{THF}(1 \mathrm{~mL})$, and $2 \mathrm{M} \mathrm{LiOH}$ (aq., $2 \mathrm{~mL}$ ). Compound 62 was obtained as a white solid $(15 \mathrm{mg}, 31 \%) .{ }^{1} \mathrm{H}$ NMR (400 $\left.\mathrm{MHz}, \mathrm{CD}_{3} \mathrm{OD}\right): \delta 8.25(\mathrm{~d}, J=1.8 \mathrm{~Hz}, 1 \mathrm{H}), 7.59$ (dd, $J=8.0$, $2.3 \mathrm{~Hz}, 1 \mathrm{H}$ ), 7.25 (d, $J=7.9 \mathrm{~Hz}, 1 \mathrm{H}), 3.49$ (q, $J=13.3,11.1$ $\mathrm{Hz}, 4 \mathrm{H}), 2.83-2.75(\mathrm{~m}, 2 \mathrm{H}), 2.61(\mathrm{t}, J=7.6 \mathrm{~Hz}, 2 \mathrm{H}), 1.77-$ $1.68(\mathrm{~m}, 2 \mathrm{H}), 1.61(\mathrm{p}, J=7.2 \mathrm{~Hz}, 2 \mathrm{H}), 1.39-1.21(\mathrm{~m}, 14 \mathrm{H})$, $0.94-0.86(\mathrm{~m}, 3 \mathrm{H}) .{ }^{13} \mathrm{C}$ NMR $\left(101 \mathrm{MHz}, \mathrm{CD}_{3} \mathrm{OD}\right): \delta 160.7$, $149.3,138.8,137.4,124.2,66.3,57.0,35.8,33.4,33.1,32.3$, 32.0, 30.7, 30.5, 30.4, 30.2, 23.7, 14.4. HRMS-ESI $(\mathrm{m} / z)$ : calcd for $\mathrm{C}_{20} \mathrm{H}_{37} \mathrm{~N}_{2} \mathrm{O}_{2}[\mathrm{M}+\mathrm{H}]^{+}$337.2855, found: 337.2858 .

Ethyl 2-(6-Bromoquinolin-2-yl)acetate (65). A mixture of diisopropylamine (1.89 mL, $13.5 \mathrm{mmol}, 3.0$ equiv) and anhydrous THF $(2.0 \mathrm{~mL})$ was cooled to $-78{ }^{\circ} \mathrm{C}$ under an argon atmosphere. $\mathrm{N}$-Butyllithium (a $2.5 \mathrm{M}$ solution in hexane, $5.04 \mathrm{~mL}, 12.6 \mathrm{mmol}, 2.8$ equiv) was slowly added and the mixture was stirred for $30 \mathrm{~min}$. Then, a solution of 6bromoquinaldine $(64,1.00 \mathrm{~g}, 4.50 \mathrm{mmol})$ in dry THF $(4.0$ $\mathrm{mL}$ ) was slowly added. After $30 \mathrm{~min}$, diethyl carbonate (1.91 $\mathrm{mL}, 15.8 \mathrm{mmol}, 3.5$ equiv) was slowly added and the mixture was stirred for $2 \mathrm{~h}$. The reaction was quenched with water and extracted with EtOAc. The combined organic layers were washed with brine, dried over anhydrous $\mathrm{Na}_{2} \mathrm{SO}_{4}$, filtered, and concentrated on a rotary evaporator, to give compound 65 as an orange solid $(1.28 \mathrm{~g}, 97 \%) .{ }^{1} \mathrm{H} \mathrm{NMR}\left(400 \mathrm{MHz}, \mathrm{CDCl}_{3}\right): \delta$ $8.04(\mathrm{~d}, J=8.5 \mathrm{~Hz}, 1 \mathrm{H}), 7.96(\mathrm{~d}, J=2.2 \mathrm{~Hz}, 1 \mathrm{H}), 7.93$ (d, $J=$ $8.9 \mathrm{~Hz}, 1 \mathrm{H}), 7.76(\mathrm{dd}, J=9.0,2.2 \mathrm{~Hz}, 1 \mathrm{H}), 7.46(\mathrm{~d}, J=8.5 \mathrm{~Hz}$, $1 \mathrm{H}), 4.20(\mathrm{q}, J=7.1 \mathrm{~Hz}, 2 \mathrm{H}), 4.02(\mathrm{~s}, 2 \mathrm{H}), 1.27(\mathrm{t}, J=7.1 \mathrm{~Hz}$ $3 \mathrm{H}) .{ }^{13} \mathrm{C} \mathrm{NMR}\left(101 \mathrm{MHz}, \mathrm{CDCl}_{3}\right): \delta 170.4,155.5,146.6$, 135.7, 133.2, 131.0, 129.7, 128.3, 122.8, 120.4, 61.4, 44.9, 14.3. HRMS-ESI $(m / z)$ : calcd for $\mathrm{C}_{13} \mathrm{H}_{13} \mathrm{NO}_{2} \mathrm{Br}[\mathrm{M}+\mathrm{H}]^{+}$ 294.0130, found: 294.0129.

2-(6-Bromoquinolin-2-yl)ethan-1-ol (66). To a solution of 65 (1.25 g, $4.24 \mathrm{mmol})$ in anhydrous THF $(10 \mathrm{~mL})$ was added a $1 \mathrm{M}$ solution of DIBAL-H in THF $(12.7 \mathrm{~mL}, 12.7 \mathrm{mmol}, 3.0$ equiv) dropwise over $30 \mathrm{~min}$ at $-78{ }^{\circ} \mathrm{C}$ and under an argon atmosphere. After the completion of the addition, the mixture was warmed to $-10{ }^{\circ} \mathrm{C}$ and stirred for $3 \mathrm{~h}$. The reaction was quenched with methanol. Then, $10 \%$ Rochelle's salt and EtOAc were added and the mixture was stirred vigorously for $30 \mathrm{~min}$. The layers were separated and the water layer was further extracted with EtOAc. The combined organic layers were washed with brine, dried over anhydrous $\mathrm{Na}_{2} \mathrm{SO}_{4}$, filtered, and concentrated on a rotary evaporator. Column chromatography, with an increasing gradient of EtOAc (starting with $30 \%$ ) in $n$-heptane, gave compound 66 as yellow solid (0.848 g, 79\%). ${ }^{1} \mathrm{H}$ NMR $\left(400 \mathrm{MHz} \mathrm{CDCl}_{3}\right): \delta$ $8.00(\mathrm{~d}, J=8.3 \mathrm{~Hz}, 1 \mathrm{H}), 7.94(\mathrm{~d}, J=2.2 \mathrm{~Hz}, 1 \mathrm{H}), 7.88(\mathrm{~d}, J=$ $8.9 \mathrm{~Hz}, 1 \mathrm{H}), 7.75(\mathrm{dd}, J=9.0,2.2 \mathrm{~Hz}, 1 \mathrm{H}), 7.29(\mathrm{~d}, J=8.5 \mathrm{~Hz}$, $1 \mathrm{H}), 4.46(\mathrm{bs}, 1 \mathrm{H}), 4.14(\mathrm{t}, J=5.5 \mathrm{~Hz}, 2 \mathrm{H}), 3.19(\mathrm{t}, J=5.5$ $\mathrm{Hz}, 2 \mathrm{H}) .{ }^{13} \mathrm{C} \mathrm{NMR}\left(101 \mathrm{MHz}, \mathrm{CDCl}_{3}\right): \delta 162.1,146.1,135.7$, 133.2, 130.7, 129.8, 128.1, 122.9, 112.0, 61.3, 39.5. HRMS-ESI $(\mathrm{m} / z)$ : calcd for $\mathrm{C}_{11} \mathrm{H}_{11} \mathrm{NOBr}[\mathrm{M}+\mathrm{H}]^{+}$225.0024, found: 225.0025 .

2-(6-Bromoquinolin-2-yl)ethyl Methanesulfonate (67). To a cooled solution of $66(0.750 \mathrm{~g}, 2.96 \mathrm{mmol})$ and $\mathrm{Et}_{3} \mathrm{~N}(0.62$ $\mathrm{mL}, 4.45 \mathrm{mmol}, 1.5$ equiv) in anhydrous DCM $(20 \mathrm{~mL})$ was added methanesulfonyl chloride $(0.298 \mathrm{~mL}, 3.85 \mathrm{mmol}, 1.3$ equiv), and the reaction mixture was stirred for $3 \mathrm{~h}$. The mixture was diluted with DCM and washed with water and brine. The organic layer was dried over anhydrous $\mathrm{Na}_{2} \mathrm{SO}_{4}$, filtered, and concentrated on a rotary evaporator. Greyish solid (0.901 g, 92\%). ${ }^{1} \mathrm{H}$ NMR (400 MHz, $\left.\mathrm{CDCl}_{3}\right): \delta 8.03$ (d, $J=$ $8.3 \mathrm{~Hz}, 1 \mathrm{H}), 7.97(\mathrm{~d}, J=2.2 \mathrm{~Hz}, 1 \mathrm{H}), 7.88(\mathrm{~d}, J=8.9 \mathrm{~Hz}, 1 \mathrm{H})$, $7.77(\mathrm{dd}, J=9.0,2.2 \mathrm{~Hz}, 1 \mathrm{H}), 7.35(\mathrm{~d}, J=8.4 \mathrm{~Hz}, 1 \mathrm{H}), 4.80(\mathrm{t}$, $J=6.5 \mathrm{~Hz}, 2 \mathrm{H}), 3.40(\mathrm{t}, J=6.5 \mathrm{~Hz}, 2 \mathrm{H}), 2.94(\mathrm{~s}, 3 \mathrm{H}) \cdot{ }^{13} \mathrm{C}$ $\operatorname{NMR}\left(101 \mathrm{MHz}, \mathrm{CDCl}_{3}\right): \delta 157.7,146.6,135.8,133.3,130.7$, $129.8,128.3,122.9,120.3,68.7,38.0,37.4$. HRMS-ESI $(\mathrm{m} / z)$ : 
calcd for $\mathrm{C}_{12} \mathrm{H}_{13} \mathrm{NO}_{3} \mathrm{SBr}[\mathrm{M}+\mathrm{H}]^{+}$329.9800, found: 329.9799 .

6-Bromo-2-(bromomethyl)quinolone (69). To a solution of 6-bromoquinaldine $(64,1.00 \mathrm{~g}, 4.50 \mathrm{mmol})$ in $\mathrm{MeCN}(20$ $\mathrm{mL}$ ) was added tert-butyl hydroperoxide $(4.64 \mathrm{~mL}, 36.0 \mathrm{mmol}$, 8.0 equiv) and copper bromide $(0.904 \mathrm{~g}, 6.30 \mathrm{mmol}, 1.4$ equiv), and the mixture was stirred at $70{ }^{\circ} \mathrm{C}$ for $8 \mathrm{~h}$. Then, it was cooled to room temperature and portioned between water and DCM. The layers were separated and the aqueous layer was extracted with DCM. Residual bromide in the organic phase was quenched with a saturated solution of sodium thiosulphate in $\mathrm{H}_{2} \mathrm{O}$. The layers were separated and the organic layer was washed with a saturated solution of $\mathrm{NH}_{4} \mathrm{Cl}$ in $\mathrm{H}_{2} \mathrm{O}$ and brine, dried over $\mathrm{Na}_{2} \mathrm{SO}_{4}$, filtered, and concentrated on a rotary evaporator. Column chromatography, with an increasing gradient of EtOAc (starting with $0 \%$ ) in $n$-heptane, gave compound 69 as a white solid (358 mg, 26\%). ${ }^{1} \mathrm{H}$ NMR $\left(400 \mathrm{MHz}, \mathrm{CDCl}_{3}\right): \delta 8.09(\mathrm{~d}, J=8.6 \mathrm{~Hz}, 1 \mathrm{H}), 7.98(\mathrm{~d}, J=2.2$ $\mathrm{Hz}, 1 \mathrm{H}), 7.93(\mathrm{~d}, J=9.0 \mathrm{~Hz}, 1 \mathrm{H}), 7.79(\mathrm{dd}, J=9.0,2.2 \mathrm{~Hz}$, $1 \mathrm{H}), 7.59$ (d, $J=8.5 \mathrm{~Hz}, 1 \mathrm{H}), 4.69(\mathrm{~s}, 2 \mathrm{H}) .{ }^{13} \mathrm{C}$ NMR $(101$ $\left.\mathrm{MHz}, \mathrm{CDCl}_{3}\right): \delta 157.5,146.3,136.4,133.6,131.1,129.7$, 128.6, 122.2, 121.2, 34.2. HRMS-ESI $(\mathrm{m} / z)$ : calcd for $\mathrm{C}_{10} \mathrm{H}_{8} \mathrm{NBr}[\mathrm{M}+\mathrm{H}]^{+}$299.9024, found: 299.9023 .

Diethyl 2-Acetamido-2-[(6-bromonaphthalen-2-yl)methyl]malonate (70). General procedure A was followed using 2-bromo-6-(bromomethyl)naphthalene $(63,0.250 \mathrm{~g}$, $0.833 \mathrm{mmol}, 1.4$ equiv), DEAM (0.129 g, $0.595 \mathrm{mmol})$, $\mathrm{Cs}_{2} \mathrm{CO}_{3}$ (0.291 g, $0.893 \mathrm{mmol}, 1.5$ equiv), and anhydrous $\mathrm{MeCN} / \mathrm{DMF}$ (1:1, $4 \mathrm{~mL})$. Compound 70 was obtained as a yellow solid (214 mg, 83\%). ${ }^{1} \mathrm{H}$ NMR $\left(400 \mathrm{MHz} \mathrm{CDCl}_{3}\right): \delta$ $7.96(\mathrm{~d}, J=2.0 \mathrm{~Hz}, 1 \mathrm{H}), 7.64(\mathrm{~d}, J=8.5 \mathrm{~Hz}, 1 \mathrm{H}), 7.60(\mathrm{~d}, J=$ $8.9 \mathrm{~Hz}, 1 \mathrm{H}), 7.52(\mathrm{dd}, J=8.7,2.0 \mathrm{~Hz}, 1 \mathrm{H}), 7.45(\mathrm{~s}, 1 \mathrm{H}), 7.14$ (dd, $J=8.4,1.7 \mathrm{~Hz}, 1 \mathrm{H}), 6.52(\mathrm{~s}, 1 \mathrm{H}), 4.35-4.23(\mathrm{~m}, 4 \mathrm{H})$, $3.81(\mathrm{~s}, 2 \mathrm{H}), 2.04(\mathrm{~s}, 3 \mathrm{H}), 1.31(\mathrm{t}, J=7.1 \mathrm{~Hz}, 6 \mathrm{H}) .{ }^{13} \mathrm{C} \mathrm{NMR}$ $\left(101 \mathrm{MHz}, \mathrm{CDCl}_{3}\right): \delta 169.3,167.6,133.7,133.6,131.8,129.8$, 129.7, 129.3, 129.0, 128.3, 127.1, 119.9, 67.3, 62.9, 38.0, 23.2, 14.2. HRMS-ESI $(m / z)$ : calcd for $\mathrm{C}_{20} \mathrm{H}_{23} \mathrm{NO}_{5} \mathrm{Br}[\mathrm{M}+\mathrm{H}]^{+}$ 436.0760, found: 436.0761 .

Diethyl 2-Acetamido-2-[2-(6-bromoquinolin-2-yl)ethyl]malonate (71). General procedure A was followed using 67 $(0.500 \mathrm{~g}, 1.51 \mathrm{mmol}, 1.2$ equiv), DEAM $(0.274 \mathrm{~g}, 1.26 \mathrm{mmol})$, $\mathrm{Cs}_{2} \mathrm{CO}_{3}$ (0.617 g, $1.89 \mathrm{mmol}, 1.5$ equiv), and anhydrous DMF $(10 \mathrm{~mL})$. Compound 71 was obtained as an orange solid (0.215 g, 38\%). ${ }^{1} \mathrm{H}$ NMR (400 MHz, $\left.\mathrm{CDCl}_{3}\right): \delta 7.97$ (d, $J=$ $8.4 \mathrm{~Hz}, 1 \mathrm{H}), 7.93(\mathrm{~d}, J=2.2 \mathrm{~Hz}, 1 \mathrm{H}), 7.87(\mathrm{~d}, J=9.0 \mathrm{~Hz}, 1 \mathrm{H})$, $7.74(\mathrm{dd}, J=9.0,2.2 \mathrm{~Hz}, 1 \mathrm{H}), 7.30(\mathrm{~d}, J=8.5 \mathrm{~Hz}, 1 \mathrm{H}), 6.90$ (s, 1H), 4.29-4.12 (m, 4H), 2.93-2.83 (m, 4H), $1.97(\mathrm{~s}, 3 \mathrm{H})$, $1.24(\mathrm{t}, J=7.1 \mathrm{~Hz}, 6 \mathrm{H}) .{ }^{13} \mathrm{C}$ NMR $\left(101 \mathrm{MHz}, \mathrm{CDCl}_{3}\right): \delta$ $169.3,168.1,161.6,146.5,135.4,133.0,130.8,129.7,128.0$, $122.2,119.8,66.4,62.8,33.6,31.8,23.2,14.1$. HRMS-ESI $(\mathrm{m} /$ $z$ ): calcd for $\mathrm{C}_{20} \mathrm{H}_{24} \mathrm{~N}_{2} \mathrm{O}_{5} \mathrm{Br}[\mathrm{M}+\mathrm{H}]^{+}$451.0869, found: 457.0870 .

Diethyl 2-Acetamido-2-[(7-chloroquinolin-2-yl)methyl]malonate (72). General procedure A was followed using 2(bromomethyl)-7-chloroquinoline $(68,90.0 \mathrm{mg}, 0.531 \mathrm{mmol}$, 1.4 equiv), DEAM ( $54.5 \mathrm{mg}, 0.251 \mathrm{mmol}), \mathrm{Cs}_{2} \mathrm{CO}_{3}(0.164 \mathrm{~g}$, $0.502 \mathrm{mmol}, 2.0$ equiv), and anhydrous $\mathrm{MeCN}(3 \mathrm{~mL})$. Compound 72 was obtained as a pink solid $(69 \mathrm{mg}, 70 \%) .{ }^{1} \mathrm{H}$ NMR $\left(400 \mathrm{MHz}, \mathrm{CDCl}_{3}\right): \delta 8.01(\mathrm{~d}, J=8.4 \mathrm{~Hz}, 1 \mathrm{H}), 7.89(\mathrm{~d}$, $J=2.0 \mathrm{~Hz}, 1 \mathrm{H}), 7.71(\mathrm{~d}, J=8.7 \mathrm{~Hz}, 1 \mathrm{H}), 7.44(\mathrm{dd}, J=8.7,2.1$ $\mathrm{Hz}, 1 \mathrm{H}), 7.20$ (d, $J=8.4 \mathrm{~Hz}, 1 \mathrm{H}), 6.87$ (s, 1H), 4.32 (q, $J=7.1$ $\mathrm{Hz}, 4 \mathrm{H}), 4.06$ (s, 2H), $1.92(\mathrm{~s}, 3 \mathrm{H}), 1.29$ (t, $J=7.1 \mathrm{~Hz}, 6 \mathrm{H})$. ${ }^{13} \mathrm{C}$ NMR $\left(101 \mathrm{MHz}, \mathrm{CDCl}_{3}\right): \delta 169.4,167.9,158.4,148.0$,
136.1, 135.4, 128.9, 128.0, 127.3, 125.3, 122.8, 66.2, 62.8, 40.5, 23.1, 14.1. HRMS-ESI $(m / z)$ : calcd for $\mathrm{C}_{19} \mathrm{H}_{22} \mathrm{~N}_{2} \mathrm{O}_{5} \mathrm{Cl}[\mathrm{M}+$ $\mathrm{H}]^{+}$393.1217, found: 393.1220.

Diethyl 2-Acetamido-2-[(6-bromoquinolin-2-yl)methyl]malonate (73). General procedure A was followed using 69 (0.350 g, $1.16 \mathrm{mmol}, 1.2$ equiv), DEAM (0.230 g, $1.06 \mathrm{mmol})$, $\mathrm{Cs}_{2} \mathrm{CO}_{3}(0.517 \mathrm{~g}, 1.59 \mathrm{mmol}, 1.5$ equiv), and anhydrous DMF $(10 \mathrm{~mL})$. Compound 73 was obtained as a brown solid (295 $\mathrm{mg}, 64 \%) .{ }^{1} \mathrm{H}$ NMR (400 MHz, $\left.\mathrm{CDCl}_{3}\right): \delta 7.98-7.92(\mathrm{~m}$, $2 \mathrm{H}), 7.78(\mathrm{~d}, J=9.0 \mathrm{~Hz}, 1 \mathrm{H}), 7.72(\mathrm{dd}, J=8.9,2.1 \mathrm{~Hz}, 1 \mathrm{H})$, $7.23(\mathrm{~d}, J=8.4 \mathrm{~Hz}, 1 \mathrm{H}), 6.87(\mathrm{~s}, 1 \mathrm{H}), 4.31(\mathrm{q}, J=7.1 \mathrm{~Hz}, 4 \mathrm{H})$, 4.05 (s, 2H), $1.92(\mathrm{~s}, 3 \mathrm{H}), 1.29(\mathrm{t}, J=7.1 \mathrm{~Hz}, 6 \mathrm{H}) .{ }^{13} \mathrm{C} \mathrm{NMR}$ $\left(101 \mathrm{MHz}, \mathrm{CDCl}_{3}\right): \delta 169.4,167.9,157.7,146.2,135.3,133.0$, 130.7, 129.8, 128.1, 123.4, 120.1, 66.2, 62.8, 40.5, 23.1, 14.1 . HRMS-ESI $(m / z)$ : calcd for $\mathrm{C}_{19} \mathrm{H}_{22} \mathrm{~N}_{2} \mathrm{O}_{5} \mathrm{Br}[\mathrm{M}+\mathrm{H}]^{+}$ 437.0712, found: 437.0711 .

Diethyl 2-Acetamido-2-[(6-octylnaphthalen-2-yl)methyl]malonate (74). General procedure B was followed using 70 $(0.100 \mathrm{~g}, 0.229 \mathrm{mmol})$, n-octylboronic acid $(43.5 \mathrm{mg}, 0.275$ mmol, 1.2 equiv), $\mathrm{Pd}_{2}(\mathrm{dba})_{3}(10.5 \mathrm{mg}, 0.0115 \mathrm{mmol}, 0.05$ equiv), SPhos (9.4 mg, $0.023 \mathrm{mmol}, 0.1$ equiv), $\mathrm{K}_{2} \mathrm{CO}_{3}$ (95.0 $\mathrm{mg}, 0.688 \mathrm{mmol}, 3.0$ equiv), and toluene/water $(4: 1,2 \mathrm{~mL})$. Compound 74 was obtained as a white solid $(85 \mathrm{mg}, 79 \%) .{ }^{1} \mathrm{H}$ NMR $\left(400 \mathrm{MHz}, \mathrm{CDCl}_{3}\right): \delta 7.65(\mathrm{dd}, J=8.4,5.2 \mathrm{~Hz}, 2 \mathrm{H})$, 7.56 (s, $1 \mathrm{H}), 7.43(\mathrm{~s}, 1 \mathrm{H}), 7.31(\mathrm{dd}, J=8.4,1.7 \mathrm{~Hz}, 1 \mathrm{H}), 7.08$ (dd, $J=8.4,1.8 \mathrm{~Hz}, 1 \mathrm{H}), 6.51(\mathrm{~s}, 1 \mathrm{H}), 4.29(\mathrm{q}, J=7.1 \mathrm{~Hz}$, $4 \mathrm{H}), 3.80(\mathrm{~s}, 2 \mathrm{H}), 2.74(\mathrm{t}, J=7.4 \mathrm{~Hz}, 2 \mathrm{H}), 2.03(\mathrm{~s}, 3 \mathrm{H}), 1.74-$ $1.62(\mathrm{~m}, 2 \mathrm{H}), 1.36-1.23(\mathrm{~m}, 16 \mathrm{H}), 0.93-0.84(\mathrm{~m}, 3 \mathrm{H}) .{ }^{13} \mathrm{C}$ NMR (101 MHz, $\left.\mathrm{CDCl}_{3}\right): \delta 169.3,167.7,140.7,132.9,132.0$, 131.9 , 128.7, 127.9, 127.6, 127.5, 126.2, 67.5, 62.8, 38.0, 36.2, 32.0, 31.6, 29.6, 29.5, 29.4, 23.2, 22.8, 14.24, 14.21. HRMS-ESI $(m / z)$ : calcd for $\mathrm{C}_{28} \mathrm{H}_{40} \mathrm{NO}_{5}[\mathrm{M}+\mathrm{H}]^{+}$470.2906, found: 470.2908 .

Diethyl 2-Acetamido-2-[2-(6-octylquinolin-2-yl)ethyl]malonate (75). General procedure B was followed using 71 (0.100 g, $0.222 \mathrm{mmol})$, n-octylboronic acid $(42.0 \mathrm{mg}, 0.266$ mmol, 1.2 equiv $), \mathrm{Pd}_{2}(\mathrm{dba})_{3}(10.1 \mathrm{mg}, 0.0111 \mathrm{mmol}, 0.05$ equiv), SPhos ( $9.1 \mathrm{mg}, 0.022 \mathrm{mmol}, 0.1$ equiv), $\mathrm{K}_{2} \mathrm{CO}_{3}$ (91.9 $\mathrm{mg}, 0.665 \mathrm{mmol}, 3.0$ equiv), and toluene/water $(4: 1,2 \mathrm{~mL})$. Compound 75 was obtained as a white solid $(91 \mathrm{mg}, 84 \%) .{ }^{1} \mathrm{H}$ NMR (400 MHz, $\left.\mathrm{CDCl}_{3}\right): \delta 7.99(\mathrm{~d}, J=8.4 \mathrm{~Hz}, 1 \mathrm{H}), 7.91(\mathrm{~d}$ $J=9.1 \mathrm{~Hz}, 1 \mathrm{H}), 7.56-7.49(\mathrm{~m}, 2 \mathrm{H}), 7.24(\mathrm{~d}, J=8.4 \mathrm{~Hz}, 1 \mathrm{H})$, $6.99(\mathrm{~s}, 1 \mathrm{H}), 4.29-4.11(\mathrm{~m}, 4 \mathrm{H}), 2.88(\mathrm{~s}, 4 \mathrm{H}), 2.76(\mathrm{t}, J=7.5$ $\mathrm{Hz}, 2 \mathrm{H}), 1.97(\mathrm{~s}, 3 \mathrm{H}), 1.69$ (p, J = 7.5 Hz, 2H), 1.40-1.20 (m, $16 \mathrm{H}), 0.91-0.83(\mathrm{~m}, 3 \mathrm{H}) .{ }^{13} \mathrm{C} \mathrm{NMR}\left(101 \mathrm{MHz}, \mathrm{CDCl}_{3}\right): \delta$ $169.3,168.2,160.1,146.7,140.9,136.0,131.2,128.7,126.9$, 125.9, 121.2, 66.5, 62.7, 36.0, 33.6, 32.1, 32.0, 31.4, 29.6, 29.44, $29.39,23.2,22.8,14.2,14.1$. HRMS-ESI $(\mathrm{m} / z)$ : calcd for $\mathrm{C}_{28} \mathrm{H}_{41} \mathrm{~N}_{2} \mathrm{O}_{5}[\mathrm{M}+\mathrm{H}]^{+} 485.3015$, found: 485.3016 .

Diethyl 2-Acetamido-2-[2-(6-decylquinolin-2-yl)ethyl]malonate (76). General procedure B was followed using 71 $(0.100 \mathrm{~g}, 0.222 \mathrm{mmol}), n$-decylboronic acid $(49.0 \mathrm{mg}, 0.266$ mmol, 1.2 equiv), $\mathrm{Pd}_{2}(\mathrm{dba})_{3}(10.1 \mathrm{mg}, 0.0111 \mathrm{mmol}, 0.05$ equiv), SPhos ( $9.1 \mathrm{mg}, 0.0222 \mathrm{mmol}, 0.1$ equiv), $\mathrm{K}_{2} \mathrm{CO}_{3}$ (91.9 $\mathrm{mg}, 0.665 \mathrm{mmol}, 3.0$ equiv), and toluene/water $(4: 1,2 \mathrm{~mL})$. Compound 76 was obtained as an orange solid ( $72 \mathrm{mg}, 64 \%)$. ${ }^{1} \mathrm{H}$ NMR $\left(400 \mathrm{MHz}, \mathrm{CDCl}_{3}\right): \delta 8.00(\mathrm{~d}, J=8.5 \mathrm{~Hz}, 1 \mathrm{H}), 7.92$ $(\mathrm{d}, J=9.0 \mathrm{~Hz}, 1 \mathrm{H}), 7.56-7.50(\mathrm{~m}, 2 \mathrm{H}), 7.24(\mathrm{~s}, 0 \mathrm{H}), 7.00(\mathrm{~s}$, $1 \mathrm{H}), 4.29-4.11(\mathrm{~m}, 4 \mathrm{H}), 2.88(\mathrm{~s}, 4 \mathrm{H}), 2.76(\mathrm{t}, J=7.5 \mathrm{~Hz}$, $2 \mathrm{H}), 1.97$ (s, 3H), 1.69 (p, J = 7.5 Hz, 2H), 1.38-1.20 (m, $20 \mathrm{H}), 0.91-0.83(\mathrm{~m}, 3 \mathrm{H}) .{ }^{13} \mathrm{C}$ NMR $\left(101 \mathrm{MHz}, \mathrm{CDCl}_{3}\right): \delta$ $169.3,168.2,160.1,146.7,140.9,136.1,131.2,128.7,126.9$, $125.9,121.2,66.5,62.7,36.0,33.6,32.1,32.0,31.4,29.75$, 
29.73, 29.65, 29.5, 29.4, 23.2, 22.8, 14.3, 14.1. HRMS-ESI $(\mathrm{m} /$ $z$ ): calcd for $\mathrm{C}_{30} \mathrm{H}_{45} \mathrm{~N}_{2} \mathrm{O}_{5}[\mathrm{M}+\mathrm{H}]^{+}$513.3328, found: 513.3327.

Diethyl 2-Acetamido-2-[(7-octylquinolin-2-yl)methyl]malonate (77). General procedure B was followed using 72 (68.0 mg, $0.173 \mathrm{mmol})$, $n$-octylboronic acid $(32.9 \mathrm{mg}, 0.208$ mmol, 1.2 equiv), $\mathrm{Pd}_{2}(\mathrm{dba})_{3}(7.9 \mathrm{mg}, 0.0087 \mathrm{mmol}, 0.05$ equiv), SPhos (7.1 mg, $0.017 \mathrm{mmol}, 0.1$ equiv), $\mathrm{K}_{2} \mathrm{CO}_{3}$ (71.7 $\mathrm{mg}, 0.519 \mathrm{mmol}, 3.0$ equiv), and toluene/water $(4: 1,2 \mathrm{~mL})$. Compound 77 was obtained as a yellow solid (75 mg, 93\%). ${ }^{1} \mathrm{H}$ NMR (400 MHz, $\left.\mathrm{CDCl}_{3}\right): \delta 7.99(\mathrm{~d}, J=8.3 \mathrm{~Hz}, 1 \mathrm{H})$, $7.71-7.64(\mathrm{~m}, 2 \mathrm{H}), 7.34(\mathrm{dd}, J=8.2,1.8 \mathrm{~Hz}, 1 \mathrm{H}), 7.13(\mathrm{~d}, J=$ $8.3 \mathrm{~Hz}, 1 \mathrm{H}), 6.96(\mathrm{~s}, 1 \mathrm{H}), 4.32(\mathrm{q}, J=7.1 \mathrm{~Hz}, 4 \mathrm{H}), 4.03(\mathrm{~s}$, $2 \mathrm{H}), 2.79(\mathrm{t}, J=7.6 \mathrm{~Hz}, 2 \mathrm{H}), 1.93(\mathrm{~s}, 3 \mathrm{H}), 1.75-1.65(\mathrm{~m}$, $2 \mathrm{H}), 1.42-1.22(\mathrm{~m}, 16 \mathrm{H}), 0.91-0.84(\mathrm{~m}, 3 \mathrm{H}) .{ }^{13} \mathrm{C}$ NMR $\left(101 \mathrm{MHz}, \mathrm{CDCl}_{3}\right): \delta 169.4,168.0,156.9,147.9,144.9,136.0$, $127.8,127.4,125.3,121.7,66.4,62.7,40.6,36.3,32.0,31.4$, 29.6, 29.5, 29.4, 23.2, 22.8, 14.2, 14.1. HRMS-ESI $(\mathrm{m} / z)$ : calcd for $\mathrm{C}_{27} \mathrm{H}_{39} \mathrm{~N}_{2} \mathrm{O}_{5}[\mathrm{M}+\mathrm{H}]^{+}$471.2859, found: 471.2859.

Diethyl 2-Acetamido-2-[(6-decylquinolin-2-yl)methyl]malonate (78). General procedure B was followed using 73 $(0.150 \mathrm{~g}, 0.229 \mathrm{mmol})$, $n$-decylboronic acid $(51.1 \mathrm{mg}, 0.274$ mmol, 1.2 equiv), $\mathrm{Pd}_{2}(\mathrm{dba})_{3}(10.4 \mathrm{mg}, 0.0114 \mathrm{mmol}, 0.05$ equiv), SPhos (9.4 mg, $0.023 \mathrm{mmol}, 0.1$ equiv), $\mathrm{K}_{2} \mathrm{CO}_{3}$ (94.8 $\mathrm{mg}, 0.686 \mathrm{mmol}, 3.0$ equiv), and toluene/water $(4: 1,2 \mathrm{~mL})$. Compound 78 was obtained as an orange solid (107 $\mathrm{mg}, 63 \%)$. ${ }^{1} \mathrm{H}$ NMR (400 MHz, $\left.\mathrm{CDCl}_{3}\right): \delta 7.96(\mathrm{~d}, J=8.3 \mathrm{~Hz}, 1 \mathrm{H}), 7.81$ $(\mathrm{d}, J=8.3 \mathrm{~Hz}, 1 \mathrm{H}), 7.55-7.47(\mathrm{~m}, 2 \mathrm{H}), 7.16(\mathrm{~d}, J=8.4 \mathrm{~Hz}$, $1 \mathrm{H}), 6.94(\mathrm{~s}, 1 \mathrm{H}), 4.38-4.26(\mathrm{~m}, 4 \mathrm{H}), 4.02(\mathrm{~s}, 2 \mathrm{H}), 2.76(\mathrm{t}, J$ $=7.6 \mathrm{~Hz}, 2 \mathrm{H}), 1.93(\mathrm{~s}, 3 \mathrm{H}), 1.69(\mathrm{p}, J=7.5 \mathrm{~Hz}, 2 \mathrm{H}), 1.46-$ $1.19(\mathrm{~m}, 20 \mathrm{H}), 0.93-0.83(\mathrm{~m}, 3 \mathrm{H}) .{ }^{13} \mathrm{C}$ NMR $(101 \mathrm{MHz}$, $\left.\mathrm{CDCl}_{3}\right): \delta 169.4,168.0,156.1,146.4,141.1,135.8,131.1$, $128.7,127.0,126.0,122.5,66.4,62.7,40.5,36.0,32.0,31.5$, 29.75, 29.73, 29.65, 29.5, 29.4, 23.2, 22.8, 14.3, 14.1. HRMSESI $(m / z)$ : calcd for $\mathrm{C}_{29} \mathrm{H}_{43} \mathrm{~N}_{2} \mathrm{O}_{5}[\mathrm{M}+\mathrm{H}]^{+}$499.3172, found: 499.3173 .

2-Amino-2-[(6-octylnaphthalen-2-yl)methyl]propane-1,3diol (79). General procedure D was followed using 74 (82.9 $\mathrm{mg}, 0.177 \mathrm{mmol}$ ), $\mathrm{NaBH}_{4}$ (33.4 mg, $0.883 \mathrm{mmol}, 5.0$ equiv), $\mathrm{CaCl}_{2}$ (49.0 mg, $0.441 \mathrm{mmol}, 2.5$ equiv), and EtOH/water (4:1, $2 \mathrm{~mL}) ; \mathrm{N}$-acetylated diol intermediate (white solid, 71 $\mathrm{mg}$ ), $\mathrm{MeOH} / \mathrm{THF}(1 \mathrm{~mL})$, and $2 \mathrm{M} \mathrm{LiOH}$ (aq., $2 \mathrm{~mL}$ ). Compound 79 was obtained as a white solid $(37 \mathrm{mg}, 60 \%) .{ }^{1} \mathrm{H}$ NMR (400 MHz, $\left.\mathrm{CD}_{3} \mathrm{OD}\right): \delta 7.72(\mathrm{dd}, J=8.4,3.9 \mathrm{~Hz}, 2 \mathrm{H})$, $7.68(\mathrm{~s}, 1 \mathrm{H}), 7.58(\mathrm{~s}, 1 \mathrm{H}), 7.39(\mathrm{dd}, J=8.4,1.8 \mathrm{~Hz}, 1 \mathrm{H}), 7.32$ $(\mathrm{dd}, J=8.4,1.7 \mathrm{~Hz}, 1 \mathrm{H}), 3.43(\mathrm{q}, J=10.8,1.0 \mathrm{~Hz}, 4 \mathrm{H}), 2.87$ (s, $2 \mathrm{H}), 2.76(\mathrm{t}, J=7.5 \mathrm{~Hz}, 2 \mathrm{H}), 1.69(\mathrm{p}, J=7.2 \mathrm{~Hz}, 2 \mathrm{H})$, $1.42-1.20(\mathrm{~m}, 10 \mathrm{H}), 0.92-0.84(\mathrm{~m}, 3 \mathrm{H}) .{ }^{13} \mathrm{C}$ NMR $(101$ $\left.\mathrm{MHz}, \mathrm{CD}_{3} \mathrm{OD}\right): \delta 141.2,134.8,134.0,133.4,130.1,129.9$, $128.5,128.5,128.2,127.0,66.0,57.6,40.6,37.0,33.0,32.6$, 30.6, 30.41, 30.36, 23.7, 14.4. HRMS-ESI $(\mathrm{m} / z)$ : calcd for $\mathrm{C}_{22} \mathrm{H}_{34} \mathrm{NO}_{2}[\mathrm{M}+\mathrm{H}]^{+}$344.2590, found: 344.2592.

2-Amino-2-[2-(6-octylquinolin-2-yl)ethyl]propane-1,3diol (80). To a cooled solution of $75(85.0 \mathrm{mg}, 0.183 \mathrm{mmol})$ in anhydrous THF $(2.0 \mathrm{~mL})$ was added a $1 \mathrm{M}$ solution of $\mathrm{LiAlH}_{4}$ in THF ( $0.37 \mathrm{~mL}, 0.37 \mathrm{mmol}, 2.0$ equiv) dropwise over 10 min, and the mixture was stirred for $1 \mathrm{~h}$ on an ice bath. Then, it was warmed up to room temperature and stirred for an additional $1 \mathrm{~h}$. The reaction was slowly quenched with water. Then, 10\% Rochelle's salt and EtOAc were added and the mixture was stirred vigorously overnight. The layers were separated and the water layer was further extracted with EtOAc. The combined organic layers were washed with brine, dried over anhydrous $\mathrm{Na}_{2} \mathrm{SO}_{4}$, filtered, and concentrated on a rotary evaporator to give an $\mathrm{N}$-acetylated diol intermediate as a yellow oil $(72 \mathrm{mg})$. The intermediate was dissolved in THF/ $\mathrm{MeOH}(2 \mathrm{~mL}), 2 \mathrm{M} \mathrm{LiOH}$ (aq., $2 \mathrm{~mL}$ ) was added, and the reaction mixture was refluxed for $4 \mathrm{~h}$. The reaction mixture was cooled to room temperature and portioned between water and EtOAc. The layers were separated and the aqueous layer was extracted with EtOAc. The combined organic layers were washed with brine, dried over anhydrous $\mathrm{Na}_{2} \mathrm{SO}_{4}$, filtered, and concentrated on a rotary evaporator. Column chromatography, using a Biotage SNAP KP-NH column and an increasing gradient of $\mathrm{MeOH}$ in $\mathrm{DCM}$, starting with $2 \%$ of $\mathrm{MeOH}$, gave compound 80 as a pale yellow solid (19 mg, 29\%). ${ }^{1} \mathrm{H}$ NMR (400 MHz, $\left.\mathrm{CD}_{3} \mathrm{OD}\right): \delta 8.19(\mathrm{~d}, J=8.4 \mathrm{~Hz}, 1 \mathrm{H}), 7.87(\mathrm{~d}, J=$ $8.6 \mathrm{~Hz}, 1 \mathrm{H}), 7.66(\mathrm{~d}, J=1.9 \mathrm{~Hz}, 1 \mathrm{H}), 7.60(\mathrm{dd}, J=8.7,2.0 \mathrm{~Hz}$, $1 \mathrm{H}), 7.44(\mathrm{~d}, J=8.5 \mathrm{~Hz}, 1 \mathrm{H}), 3.54(\mathrm{q}, J=10.9 \mathrm{~Hz}, 4 \mathrm{H}), 3.04-$ $2.96(\mathrm{~m}, 2 \mathrm{H}), 2.80(\mathrm{t}, J=7.5 \mathrm{~Hz}, 2 \mathrm{H}), 1.89-1.80(\mathrm{~m}, 2 \mathrm{H})$, $1.72(\mathrm{p}, J=7.5 \mathrm{~Hz}, 2 \mathrm{H}), 1.43-1.22(\mathrm{~m}, 10 \mathrm{H}), 0.92-0.84(\mathrm{~m}$, $3 \mathrm{H}) .{ }^{13} \mathrm{C}$ NMR (101 MHz, $\left.\mathrm{CD}_{3} \mathrm{OD}\right): \delta 163.6,147.2,142.3$, $138.3,132.5,128.4,128.2,127.3,122.8,66.3,57.1,36.7,35.5$, 33.2, 33.0, 32.5, 30.6, 30.38, 30.35, 23.7, 14.4. HRMS-ESI $(\mathrm{m} /$ $z)$ : calcd for $\mathrm{C}_{22} \mathrm{H}_{35} \mathrm{~N}_{2} \mathrm{O}_{2}[\mathrm{M}+\mathrm{H}]^{+}$359.2699, found: 359.2698 .

2-Amino-2-[2-(6-decylquinolin-2-yl)ethyl]propane-1,3diol (81). Synthesis was performed as described for compound 80 using 76 (65.0 mg, $0.127 \mathrm{mmol})$, a $1 \mathrm{M}$ solution of $\mathrm{LiAlH}_{4}$ in THF ( $0.25 \mathrm{~mL}, 0.25 \mathrm{mmol}, 2.0$ equiv), and anhydrous THF $(2.0 \mathrm{~mL}) ; \mathrm{N}$-acetylated diol intermediate (yellow oil, $56 \mathrm{mg}$ ), $\mathrm{THF} / \mathrm{MeOH}(1.5 \mathrm{~mL})$, and $2 \mathrm{M} \mathrm{LiOH} \mathrm{(aq.} 2 \mathrm{~mL}$ ). Compound 81 was obtained as a pale yellow solid $(19 \mathrm{mg}$, 40\%). ${ }^{1} \mathrm{H}$ NMR (400 MHz, CD 3 OD): $\delta 8.19$ (d, $J=8.3 \mathrm{~Hz}$, $1 \mathrm{H}), 7.87(\mathrm{~d}, J=8.6 \mathrm{~Hz}, 1 \mathrm{H}), 7.66(\mathrm{~d}, J=1.9 \mathrm{~Hz}, 1 \mathrm{H}), 7.60$ $(\mathrm{dd}, J=8.7,2.0 \mathrm{~Hz}, 1 \mathrm{H}), 7.44(\mathrm{~d}, J=8.4 \mathrm{~Hz}, 1 \mathrm{H}), 3.53(\mathrm{q}, J=$ $12.1,11.0 \mathrm{~Hz}, 4 \mathrm{H}), 3.04-2.96(\mathrm{~m}, 2 \mathrm{H}), 2.80(\mathrm{t}, J=7.6 \mathrm{~Hz}$, $2 \mathrm{H}), 1.89-1.80(\mathrm{~m}, 2 \mathrm{H}), 1.71(\mathrm{p}, J=7.4 \mathrm{~Hz}, 2 \mathrm{H}), 1.42-1.23$ (m, 14H), 0.92-0.84 (m, 3H). ${ }^{13} \mathrm{C}$ NMR (101 MHz, $\left.\mathrm{CD}_{3} \mathrm{OD}\right): \delta 163.6,147.2,142.3,138.3,132.5,128.4,128.2$, $127.3,122.8,66.3,57.2,36.7,35.5,33.2,33.1,32.4,30.7,30.6$, $30.4,30.3,23.7,14.4$. HRMS-ESI $(\mathrm{m} / z)$ : calcd for $\mathrm{C}_{24} \mathrm{H}_{39} \mathrm{~N}_{2} \mathrm{O}_{2}[\mathrm{M}+\mathrm{H}]^{+}$387.3012, found: 387.3013.

2-Amino-2-[(7-octylquinolin-2-yl)methyl]propane-1,3diol (82). General procedure D was followed using 77 (74.0 $\mathrm{mg}, 0.157 \mathrm{mmol}), \mathrm{NaBH}_{4}(29.7 \mathrm{mg}, 0.785 \mathrm{mmol}, 5.0$ equiv), $\mathrm{CaCl}_{2}$ (43.6 mg, $0.393 \mathrm{mmol}, 2.5$ equiv), and $\mathrm{EtOH} /$ water (4:1, $2 \mathrm{~mL}) ; \mathrm{N}$-acetylated diol intermediate (yellow oil, 59 $\mathrm{mg}$ ), $\mathrm{MeOH} / \mathrm{THF}(2 \mathrm{~mL})$, and $2 \mathrm{M} \mathrm{LiOH}$ (aq., $2 \mathrm{~mL}$ ). Compound 82 was obtained as a white solid $(28 \mathrm{mg}, 51 \%) .{ }^{1} \mathrm{H}$ NMR (400 MHz, $\left.\mathrm{CD}_{3} \mathrm{OD}\right): \delta 8.20(\mathrm{~d}, J=8.4 \mathrm{~Hz}, 1 \mathrm{H}), 7.81$ $(\mathrm{d}, J=8.3 \mathrm{~Hz}, 1 \mathrm{H}), 7.75(\mathrm{~s}, 1 \mathrm{H}), 7.45-7.40(\mathrm{~m}, 2 \mathrm{H}), 3.47(\mathrm{~s}$, $4 \mathrm{H}), 3.09$ (s, 2H), $2.82(\mathrm{t}, J=7.6 \mathrm{~Hz}, 2 \mathrm{H}), 1.73(\mathrm{p}, J=7.4 \mathrm{~Hz}$, $2 \mathrm{H}), 1.44-1.21(\mathrm{~m}, 10 \mathrm{H}), 0.92-0.84(\mathrm{~m}, 3 \mathrm{H}) .{ }^{13} \mathrm{C}$ NMR $\left(101 \mathrm{MHz}, \mathrm{CD}_{3} \mathrm{OD}\right): \delta 160.3,148.7,146.5,137.9,129.0$, $128.7,127.4,126.7,124.0,66.8,58.5,43.6,37.1,33.0,32.3$, 30.6, 30.4, 30.3, 23.7, 14.4. HRMS-ESI $(\mathrm{m} / z)$ : calcd for $\mathrm{C}_{21} \mathrm{H}_{33} \mathrm{~N}_{2} \mathrm{O}_{2}[\mathrm{M}+\mathrm{H}]^{+}$345.2542, found: 345.2544.

2-Amino-2-[(6-decylquinolin-2-yl)methyl]propane-1,3diol (83). General procedure D was followed using 78 (0.100 g, $0.201 \mathrm{mmol}$ ), $\mathrm{NaBH}_{4}$ (37.9 mg, $1.00 \mathrm{mmol}, 5.0$ equiv), $\mathrm{CaCl}_{2}$ (55.6 mg, $0.501 \mathrm{mmol}, 2.5$ equiv), and $\mathrm{EtOH} /$ water $(4: 1,2$ $\mathrm{mL}) ; \mathrm{N}$-acetylated diol intermediate (yellow solid, $83 \mathrm{mg}$ ), $\mathrm{MeOH} / \mathrm{THF}(2 \mathrm{~mL})$, and $2 \mathrm{M} \mathrm{LiOH}$ (aq., $2 \mathrm{~mL}$ ). Compound 83 was obtained as a light yellow solid $(13 \mathrm{mg}, 17 \%) .{ }^{1} \mathrm{H}$ NMR $\left(400 \mathrm{MHz}, \mathrm{CD}_{3} \mathrm{OD}\right): \delta 8.19$ (d, $\left.J=8.4 \mathrm{~Hz}, 1 \mathrm{H}\right), 7.89$ (d, $J=$ 
$8.6 \mathrm{~Hz}, 1 \mathrm{H}), 7.67(\mathrm{~d}, J=1.9 \mathrm{~Hz}, 1 \mathrm{H}), 7.61(\mathrm{dd}, J=8.7,2.0 \mathrm{~Hz}$, $1 \mathrm{H}), 7.46(\mathrm{~d}, J=8.4 \mathrm{~Hz}, 1 \mathrm{H}), 3.47(\mathrm{~s}, 4 \mathrm{H}), 3.10(\mathrm{~s}, 2 \mathrm{H}), 2.81$ $(\mathrm{t}, J=7.6 \mathrm{~Hz}, 2 \mathrm{H}), 1.72(\mathrm{p}, J=7.3 \mathrm{~Hz}, 2 \mathrm{H}), 1.39-1.23(\mathrm{~m}$, $14 \mathrm{H}), 0.93-0.85(\mathrm{~m}, 3 \mathrm{H}) .{ }^{13} \mathrm{C} \mathrm{NMR}\left(101 \mathrm{MHz}, \mathrm{CD}_{3} \mathrm{OD}\right): \delta$ $159.4,147.2,142.5,137.7,132.5,128.8,128.4,127.2,124.7$, 66.5, 58.8, 43.2, 36.7, 33.1, 32.44 30.7, 30.6, 30.4, 30.3, 23.7, 14.4. HRMS-ESI $(m / z)$ : calcd for $\mathrm{C}_{23} \mathrm{H}_{37} \mathrm{~N}_{2} \mathrm{O}_{2}[\mathrm{M}+\mathrm{H}]^{+}$ 373.2855 , found: 373.2858 .

\section{BIOLOGY}

Bacterial Strains and Culture Conditions. S. aureus ATCC 25923 was provided by the Faculty of Pharmacy of the University of Helsinki (Helsinki, Finland). S. aureus ATCC 12598 was kindly provided by Dr. Per Saris from the Antimicrobials, probiotics and fermented food laboratory, Faculty of Agriculture and Forestry, University of Helsinki (Helsinki, Finland). S. aureus P2 was isolated from a hip prosthetic implant at the Hospital Fundación Jiménez Diaz (Madrid, Spain) and was kindly given by Dr. Ramón PérezTanoira. A. baumannii NCTC 13423 and C. violaceum NCTC 13278 (Tn5-mutant CV026) were bought from the National Collection of Type Culture (NCTC) (Salisbury, United Kingdom). P. aeruginosa ATCC 9027 and C. violaceum ATCC 31532 were bought from the American Type Culture Collection (ATCC) (Wesel, Germany). At the start of all experiments, every strain (except for $P$. aeruginosa and $C$. violaceum) was first grown on tryptic soy agar (TSA) (Lab M Ltd., Heywood, U.K.) overnight at $37{ }^{\circ} \mathrm{C}$ under aerobic conditions. Then, the colonies were suspended in $5 \mathrm{~mL}$ of tryptic soy broth (TSB) (Lab M Ltd., Heywood, U.K.) in a 50 $\mathrm{mL}$ Falcon tube (Greiner Bio-One, Kremsmünster, Austria) and grown to exponential phase under aerobic conditions at 37 ${ }^{\circ} \mathrm{C}$ with shaking (220 rpm), until the culture reached a concentration of approximately $1 \times 10^{8}$ colony-forming unit (CFU) $\mathrm{mL}^{-1}$. The culture was diluted to $1 \times 10^{6} \mathrm{CFU} \mathrm{mL}^{-1}$ before starting the experiment. The same was done with $P$. aeruginosa using Lennox broth (LB) and LB-agar (LBA) (Lab M Ltd., Heywood, U.K.). For the $Q S$ inhibition analysis, $C$. violaceum was grown on LBA overnight at $27^{\circ} \mathrm{C}$, and the colonies were used to start the experiment directly.

Compounds. Fingolimod, with purity $\geq 98 \%$, was purchased from Carbosynth (Compton, U.K.). Fingolimod was dissolved into dimethyl sulfoxide (DMSO) and sonicated for 5 min using a Branson 3800 ultrasonic bath (Cleanosonic, Richmond, VA) at $40 \mathrm{~Hz}$.

Antibacterial Activity Evaluation. The antimicrobial activity was assessed in a similar way for the initial screening and the dose-response evaluation against different bacterial strains. With the exception of the post-exposure experiment, the compounds were added to the wells along with the bacteria to test the ability of compounds to prevent bacterial growth and biofilm formation (pre-exposure). The compounds were diluted in DMSO and plated directly in 96-well plates before adding the bacterial culture, and plates were incubated for $18 \mathrm{~h}$ under aerobic conditions at $37^{\circ} \mathrm{C}$ with shaking $(220 \mathrm{rpm})$. The antibacterial activity of the compounds was assessed on planktonic cells and biofilms separately using two different measurements for each: optical density (turbidity) and resazurin reduction (viability) on planktonic cells and resazurin followed by a crystal violet staining assay (total biomass) on biofilms, as described in the following sections.

For the post-exposure experiment, bacteria were grown with no compounds in the same conditions for $18 \mathrm{~h}$, after which the media was changed, and compounds were added on the preformed biofilms. The plates were then incubated in the same conditions for an additional $24 \mathrm{~h}$ before proceeding to the staining assays.

Resazurin Staining. The resazurin staining was performed according to the protocol previously optimized with a few modifications. ${ }^{46}$ Briefly, the planktonic solution was first transferred into a new 96-well plate and the OD of the planktonic solution was measured using a Varioskan LUX Multimode microplate reader (Thermo Scientific, Vantaa, Finland). Then, $10 \mu \mathrm{L}$ of a $400 \mu \mathrm{M}$ resazurin (R7017, SigmaAldrich, St. Louis, MO) diluted in phosphate-buffered saline (PBS) (Thermo Fisher Scientific, MA) was added to the wells (for a final resazurin concentration of $20 \mu \mathrm{M}$ ). The plate was incubated in the dark with shaking $(220 \mathrm{rpm})$ for about 3-10 min at room temperature with $S$. aureus and $A$. baumannii (until the bacteria controls turned pink) or for $20 \mathrm{~min}$ at $37^{\circ} \mathrm{C}$ with $P$. aeruginosa. Fluorescence was measured at $\lambda_{\mathrm{ex}}=560 \mathrm{~nm}$ and $\lambda_{\mathrm{em}}=590 \mathrm{~nm}$ using the top optics of the Varioskan LUX Multimode microplate reader. The planktonic plate was then discarded. The original challenge plate containing the biofilms was washed once with PBS, and $200 \mu \mathrm{L}$ of a $20 \mu \mathrm{M}$ resazurin solution was added to the wells. The plate was incubated in the dark at $37{ }^{\circ} \mathrm{C}$ with shaking $(220 \mathrm{rpm})$ for $30 \mathrm{~min}$ with $S$. aureus, $60 \mathrm{~min}$ with $A$. baumannii, and $90 \mathrm{~min}$ with $P$. aeruginosa. Fluorescence was measured as described for the planktonic solution. The biofilms were next treated with crystal violet staining.

Crystal Violet Staining. After removing the resazurin solution from the plate, biofilms were fixed with ethanol $100 \%$ for $15 \mathrm{~min}$ at room temperature. Ethanol was then removed, and the biofilms were left to air-dry completely at RT. Crystal violet, diluted to $1: 100$ in deionized water from the $2.3 \%$ commercial solution (HT90132, Sigma-Aldrich, St. Louis, MO), was added to the wells and, after a 5 min incubation with the dye, the biofilms were washed twice with deionized water and left to air-dry for about $10 \mathrm{~min}$. The dye was solubilized in ethanol $100 \%$ for $1 \mathrm{~h}$, and absorbance was measured at $595 \mathrm{~nm}$ using a Multiskan Sky microplate spectrophotometer (Thermo Scientific, Vantaa, Finland).

Quorum Sensing Inhibition Assay. The QS inhibitory activity of the compounds was assessed as described previously. ${ }^{31,47}$ Briefly, two QS reporter strains, C. violaceum ATCC 31532 and the violacein-negative, mini-Tn5 mutant of C. violaceum CV026 (NCTC 13278), were grown on LBA (for CV026, the agar was supplemented with kanamycin at $100 \mu \mathrm{g}$ $\mathrm{mL}^{-1}$ ) overnight at $27^{\circ} \mathrm{C}$. Colonies were suspended in PDYT ( $0.5 \%$ peptone, $0.3 \%$ D-glucose, $0.25 \%$ yeast extract, $0.05 \% \mathrm{~L}$ tryptophan, w/v) to reach an OD600 of 0.02 . The CV026 culture was supplemented with C6-HSL ( $N$-hexanoyl-Lhomoserine lactone) (10007896, Cayman Chemical, MI) at $0.5 \mu \mathrm{M}$ to induce the QS-moderated synthesis of violacein. For each strain, $200 \mu \mathrm{L}$ of bacterial culture was added per well in two identical 96-well plates containing the compounds $(2 \mu \mathrm{L}$ per well for a final DMSO concentration of $1 \%)$. In each 96well plate, untreated cells were used as negative controls and quercetin (Q4951, Sigma-Aldrich) and azithromycin (PZ0007, Sigma-Aldrich) were included as positive controls for QS inhibition and cell viability (bactericidal activity), respectively. The plates were incubated at $27{ }^{\circ} \mathrm{C}$ under aerobic conditions (200 rpm) for $22 \mathrm{~h}$.

The synthesized and nonsoluble violacein was collected from the first 96-well plate by centrifugation ( $4000 \mathrm{rpm}$, for 15 
min, $20{ }^{\circ} \mathrm{C}$ ), and the supernatants were removed. Violacein was dissolved in $100 \mu \mathrm{L}$ per well of $96 \%$ (v/v) ethanol and was separated from cells by centrifugation as described above. The supernatant containing violacein was then transferred to a new 96-well plate, and the absorbance was measured at $595 \mathrm{~nm}$ using a Multiskan Sky Microplate spectrophotometer. To detect any bactericidal effects, the viability of the cells was measured in the second replica plate by adding $10 \mu \mathrm{L}$ of 400 $\mu \mathrm{M}$ resazurin in each well and incubating the plate for $30 \mathrm{~min}$ in the dark at $27{ }^{\circ} \mathrm{C}(220 \mathrm{rpm})$. After centrifugation of the plate to separate the cells from the solution, $100 \mu \mathrm{L}$ of each well were transferred into a new 96-well plate and the fluorescence was recorded as described above using the Varioskan LUX multimode plate reader.

Culture of Human Cells. The human lung adenocarcinoma epithelial cells A549, the cervical adenocarcinoma HeLaderived human epithelial type 2 (Hep-2) cells, and the HL-60 cells were all purchased from the American Type Culture Collection (ATCC, Wesel, Germany). The A549 cells were grown in Dulbecco's modified Eagle's medium (DMEM) (BE12-707F, Lonza, Basel, Switzerland) supplemented with $10 \%$ heat-inactivated fetal bovine serum (FBS) (Sigma-Aldrich, St. Louis, MO), $2 \mathrm{mM}$ glutamine (Sigma-Aldrich, St. Louis, $\mathrm{MO}$ ), and $20 \mu \mathrm{g} \mathrm{mL}^{-1}$ gentamycin (Sigma-Aldrich, St. Louis, MO). The HEp-2 cells were grown in DMEM (41966-029, Sigma-Aldrich, St. Louis, MO), supplemented with $10 \%$ (v/v) heat-inactivated FBS and $20 \mu \mathrm{g} \mathrm{mL}^{-1}$ gentamycin. Both cell lines were maintained at $37{ }^{\circ} \mathrm{C}$ in $5 \% \mathrm{CO}_{2}$ in a humidified incubator. HL-60 cells were grown and maintained in Roswell Park Memorial Institute (RPMI) 1640 Medium (R8758, Sigma-Aldrich, St. Louis, MO), supplemented with $10 \%$ (v/v) heat-inactivated FBS and $1 \%(\mathrm{v} / \mathrm{v})$ penicillin/streptomycin (Sigma-Aldrich, St. Louis, MO). The cells were maintained at $37{ }^{\circ} \mathrm{C}$ in $5 \% \mathrm{CO}_{2}$ in a humidified incubator. Before each experiment, the HL-60 cells were differentiated into neutrophile-like cells by culturing the cells for 6 days in the maintenance medium supplemented with $100 \mathrm{mM}$ of $N, N-$ dimethylformamide (DMF) (Sigma-Aldrich, St. Louis, MO). ${ }^{48}$

Cytotoxicity Assessment. The cytotoxicity of the compounds was assessed on the three different human cell lines, A549, HEp-2, and HL-60, using the redox-based resazurin staining assay. The cells were seeded in clear 96well plates at a density of $1 \times 10^{4}$ cells per well in a volume of $200 \mu \mathrm{L}$ per well. The adherent cells were let to attach for $24 \mathrm{~h}$ before changing the media and adding the compounds (final concentration of $0.25 \%$ DMSO). HL-60 were counted and added to the plates at a density of $1 \times 10^{4}$ cells per well in a volume of $200 \mu \mathrm{L}$ directly with the compounds. Untreated cells were used as negative controls, and cells treated with $1 \%$ TritonX-100 (Sigma-Aldrich, St. Louis, MO) were used as positive controls for cytotoxicity. The cells were incubated with the compounds for $24 \mathrm{~h}$.

For the resazurin assay, the media was first removed, and the adherent cells were washed once with PBS. Then, $200 \mu \mathrm{L}$ of 20 $\mu \mathrm{M}$ resazurin was added per well and cells were incubated for two more hours before the measurement of fluorescence, as mentioned earlier. For HL-60, $10 \mu \mathrm{L}$ of $400 \mu \mathrm{M}$ resazurin was added directly to the wells and the cells were incubated for an additional $4 \mathrm{~h}$ before the measurement of fluorescence.

Effect of Fingolimod on S. aureus in Coculture with Differentiated HL-60 Cells. The coculture system was as previously described. ${ }^{40}$ Briefly, the bacteria were prepared as described above and the concentration was adjusted to $2 \times 10^{7}$
CFU mL $\mathrm{mL}^{-1}$ in RPMI 1640. The media of the differentiated HL60 cells was refreshed with RPMI $164024 \mathrm{~h}$ before the experiments to remove possible traces of antibiotics. On the day of the experiment, the cells were counted and adjusted to a concentration of $2 \times 10^{5}$ cells $\mathrm{mL}^{-1}$ in RPMI 1640. Each suspension (bacterial and differentiated HL-60 cells, $500 \mu \mathrm{L}$ of each) was added on 1-cm-long sections of a sterilized fine bore LDPE tubing (Smiths Medical ASD, Minneapolis, MN) in 24well plates (Nunclon $\Delta$ surface, Nunc, Roskilde, Denmark). Fingolimod was also added to the wells at a concentration of $25 \mu \mathrm{M}(0.25 \%$ DMSO). Coculture controls with no added compound were included, as well as bacterial controls without differentiated HL-60 cells with and without fingolimod. The plates were incubated for $24 \mathrm{~h}$ in the same conditions as for cell maintenance. Then, the LDPE tubes were gently washed with TSB to remove adhering planktonic cells and transferred to Eppendorf tubes containing $1 \mathrm{~mL}$ of $0.5 \%(\mathrm{w} / \mathrm{v})$ Tween 20 TSB solution. Next, the tubes were sonicated in a water bath sonicator (Branson Ultrasonics, Danbury, CT) for $5 \mathrm{~min}$ at 35 $\mathrm{kHz}$. The tubes were vortexed for $20 \mathrm{~s}$ prior to and after the sonication step. Serial dilutions of the resulting bacterial suspensions were made from $10^{-1}$ up to $10^{-7}$ and plated on TSA plates.

Statistical Analysis. In the QS inhibition assay, statistical difference between the test compounds was calculated at each concentration using a one-way analysis of variance (ANOVA) with a Welch correction in the case of violation of the homogeneity of variance. A significant difference was observed against the wild-type strain at $10 \mu \mathrm{M}[\mathrm{F}(6,9.26)=10.71, p<$ $0.001], 15 \mu \mathrm{M}[\mathrm{F}(6,21)=5.87, p=0.001]$, and $25 \mu \mathrm{M}[\mathrm{F}(6$, $8.79)=9.51, p=0.002]$ as well as against the mutant strain at $10 \mu \mathrm{M}[\mathrm{F}(6,9.25)=12.64, p<0.001]$. A Dunnett's post hoc test was used to detect statistical differences between fingolimod and each of its derivatives. In the bacterianeutrophil coculture assay, significance was determined using unpaired $t$-tests.

\section{ASSOCIATED CONTENT}

\section{Supporting Information}

The Supporting Information is available free of charge at https://pubs.acs.org/doi/10.1021/acsomega.1c02591.

Molecular formula strings (XLSX)

Initial screening of fingolimod derivatives (Figure S1); viability inhibition of fingolimod derivatives against $C$. violaceum (Figure S2); aggregation data for fingolimod, 43, 45, 55, 62, 79, and 82 (Figure S3), NMR spectra (Figures S4-S59), additional tables providing inhibition data (Tables S1, S2, and S3) (PDF)

\section{AUTHOR INFORMATION}

\section{Corresponding Author}

Jari Yli-Kauhaluoma - Drug Research Program, Division of Pharmaceutical Chemistry and Technology, Faculty of Pharmacy, University of Helsinki, FI-00014 Helsinki, Finland; 이이이.org/0000-0003-0370-7653; Email: jari.yli-kauhaluoma@helsinki.fi

\section{Authors}

Matej Zore - Drug Research Program, Division of Pharmaceutical Chemistry and Technology, Faculty of Pharmacy, University of Helsinki, FI-00014 Helsinki,

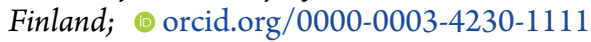


Shella Gilbert-Girard - Drug Research Program, Division of Pharmaceutical Biosciences, Faculty of Pharmacy, University of Helsinki, FI-00014 Helsinki, Finland

Inés Reigada - Drug Research Program, Division of Pharmaceutical Biosciences, Faculty of Pharmacy, University of Helsinki, FI-00014 Helsinki, Finland

Jayendra Z. Patel - Drug Research Program, Division of Pharmaceutical Chemistry and Technology, Faculty of Pharmacy, University of Helsinki, FI-00014 Helsinki, Finland

Kirsi Savijoki - Drug Research Program, Division of Pharmaceutical Biosciences, Faculty of Pharmacy, University of Helsinki, FI-00014 Helsinki, Finland

Adyary Fallarero - Drug Research Program, Division of Pharmaceutical Biosciences, Faculty of Pharmacy, University of Helsinki, FI-00014 Helsinki, Finland; (o orcid.org/00000003-4127-5476

Complete contact information is available at:

https://pubs.acs.org/10.1021/acsomega.1c02591

\section{Author Contributions}

${ }^{\S}$ M.Z. and S.G.-G. contributed equally. This manuscript was written through contributions of all authors. All authors have given approval to the final version of the manuscript.

\section{Funding}

This research was funded by the European Union's Horizon 2020 research and innovation program under the Marie Skłodowska-Curie grant agreement number 722467, the Academy of Finland (grant nos. 307464 and 324177), and the Finnish National Agency for Education (EDUFI Fellowship No. TM-18-11021). S.G.-G. was also supported by a personal full-time research grant from the Finnish Pharmaceutical Society.

\section{Notes}

The authors declare no competing financial interest.

\section{ACKNOWLEDGMENTS}

The authors are grateful to the collaborator Niklas Johansson for his help with the aggregation study. We would also like to thank Nina Sipari from Viikki Metabolomics Unit (Helsinki Institute of Life Science, University of Helsinki; Biocenter Finland) for her expertise with the LC-MS analyses.

\section{ABBREVIATIONS}

AHL, acyl-homoserine lactones; ATP, adenosine triphosphate; $\mathrm{CFU}$, colony-forming unit; DMSO, dimethyl sulfoxide; Fgd, fingolimod; LB, Lennox broth; LBA, Lennox broth agar; MIC, minimum inhibitory concentration; OD, optical density; PBS, phosphate-buffered saline; QS, quorum sensing; QSI, quorum sensing inhibitor; rt, room temperature; TSA, tryptic soy agar; TSB, tryptic soy broth

\section{REFERENCES}

(1) Ferri, M.; Ranucci, E.; Romagnoli, P.; Giaccone, V. Antimicrobial resistance: A global emerging threat to public health systems. Crit. Rev. Food Sci. Nutr. 2017, 57, 2857-2876.

(2) Omar, A.; Wright, J. B.; Schultz, G.; Burrell, R.; Nadworny, P. Microbial Biofilms and Chronic Wounds. Microorganisms 2017, 5, 9.

(3) Vestby, L. K.; Grønseth, T.; Simm, R.; Nesse, L. L. Bacterial Biofilm and its Role in the Pathogenesis of Disease. Antibiotics 2020, 9, 59.

(4) Olson, M. E.; Ceri, H.; Morck, D. W.; Buret, A. G.; Read, R. R. Biofilm bacteria: formation and comparative susceptibility to antibiotics. Can. J. Vet. Res. 2002, 66, 86-92.
(5) Arciola, C. R.; Campoccia, D.; Speziale, P.; Montanaro, L.; Costerton, J. W. Biofilm formation in Staphylococcus implant infections. A review of molecular mechanisms and implications for biofilm-resistant materials. Biomaterials 2012, 33, 5967-5982.

(6) Zimmerli, W.; Moser, C. Pathogenesis and treatment concepts of orthopaedic biofilm infections. FEMS Immunol. Med. Microbiol. 2012, $65,158-168$.

(7) Arikawa, J.; Ishibashi, M.; Kawashima, M.; Takagi, Y.; Ichikawa, Y.; Imokawa, G. Decreased levels of sphingosine, a natural antimicrobial agent, may be associated with vulnerability of the stratum corneum from patients with atopic dermatitis to colonization by Staphylococcus aureus. J. Invest. Dermatol. 2002, 119, 433-439.

(8) Tavakoli Tabazavareh, S.; Seitz, A.; Jernigan, P.; Sehl, C.; Keitsch, S.; Lang, S.; Kahl, B. C.; Edwards, M.; Grassmé, H.; Gulbins, E.; Becker, K. A. Lack of Sphingosine Causes Susceptibility to Pulmonary Staphylococcus Aureus Infections in Cystic Fibrosis. Cell. Physiol. Biochem. 2016, 38, 2094-2102.

(9) Martin, G. E.; Boudreau, R. M.; Couch, C.; Becker, K. A.; Edwards, M. J.; Caldwell, C. C.; Gulbins, E.; Seitz, A. Sphingosine's role in epithelial host defense: A natural antimicrobial and novel therapeutic. Biochimie 2017, 141, 91-96.

(10) Fischer, C. L.; Drake, D. R.; Dawson, D. V.; Blanchette, D. R.; Brogden, K. A.; Wertz, P. W. Antibacterial activity of sphingoid bases and fatty acids against Gram-positive and Gram-negative bacteria. Antimicrob. Agents Chemother. 2012, 56, 1157-1161.

(11) Cukkemane, N.; Bikker, F. J.; Nazmi, K.; Brand, H. S.; Sotres, J.; Lindh, L.; Arnebrant, T.; Veerman, E. C. Anti-adherence and bactericidal activity of sphingolipids against Streptococcus mutans. Eur. J. Oral Sci. 2015, 123, 221-227.

(12) Becam, J.; Walter, T.; Burgert, A.; Schlegel, J.; Sauer, M.; Seibel, J.; Schubert-Unkmeir, A. Antibacterial activity of ceramide and ceramide analogs against pathogenic Neisseria. Sci. Rep. 2017, 7, No. 17627.

(13) Verhaegh, R.; Becker, K. A.; Edwards, M. J.; Gulbins, E. Sphingosine kills bacteria by binding to cardiolipin. J. Biol. Chem. 2020, 295, 7686-7696.

(14) Pewzner-Jung, Y.; Tavakoli Tabazavareh, S.; Grassmé, H.; Becker, K. A.; Japtok, L.; Steinmann, J.; Joseph, T.; Lang, S.; Tuemmler, B.; Schuchman, E. H.; Lentsch, A. B.; Kleuser, B.; Edwards, M. J.; Futerman, A. H.; Gulbins, E. Sphingoid long chain bases prevent lung infection by Pseudomonas aeruginosa. EMBO Mol. Med. 2014, 6, 1205-1214.

(15) Seitz, A. P.; Schumacher, F.; Baker, J.; Soddemann, M.; Wilker, B.; Caldwell, C. C.; Gobble, R. M.; Kamler, M.; Becker, K. A.; Beck, S.; Kleuser, B.; Edwards, M. J.; Gulbins, E. Sphingosine-coating of plastic surfaces prevents ventilator-associated pneumonia. J. Mol. Med. 2019, 97, 1195-1211.

(16) Miró-Canturri, A.; Ayerbe-Algaba, R.; Smani, Y. Drug Repurposing for the Treatment of Bacterial and Fungal Infections. Front. Microbiol. 2019, 10, 41.

(17) Gilbert-Girard, S.; Savijoki, K.; Yli-Kauhaluoma, J.; Fallarero, A. Screening of FDA-Approved Drugs Using a 384-Well Plate-Based Biofilm Platform: The Case of Fingolimod. Microorganisms 2020, 8, 1834.

(18) Adachi, K.; Kohara, T.; Nakao, N.; Arita, M.; Chiba, K.; Mishina, T.; Sasaki, S.; Fujita, T. Design, synthesis, and structureactivity-relationships of 2-substituted-2-amino-1,3-propanediols discovery of a novel immunosuppressant, FTY720. Bioorg. Med. Chem. Lett. 1995, 5, 853-856.

(19) Brinkmann, V.; Chen, S.; Feng, L.; Pinschewer, D.; Nikolova, Z.; Hof, R. FTY720 alters lymphocyte homing and protects allografts without inducing general immunosuppression. Transplant. Proc. 2001, 33, 530-531.

(20) Rumah, K. R.; Vartanian, T. K.; Fischetti, V. A. Oral Multiple Sclerosis Drugs Inhibit the In vitro Growth of Epsilon Toxin Producing Gut Bacterium, Clostridium perfringens. Front. Cell. Infect. Microbiol. 2017, 7, 11.

(21) Lee, T.; Moon, H. S.; Kim, S. W.; Shrestha, J.; Shin, S. M.; Lee, J. Y.; Kim, S.; Park, E. Y.; Baek, D. J. Synthesis and Biological 
Evaluation of FTY720 (Fingolimod) Derivatives with Aromatic Head Group as Anticancer Agents. Chem. Pharm. Bull. 2018, 66, 10151018.

(22) Shrestha, J.; Ki, S. H.; Shin, S. M.; Kim, S. W.; Lee, J. Y.; Jun, H. S.; Lee, T.; Kim, S.; Baek, D. J.; Park, E. Y. Synthesis of Novel FTY720 Analogs with Anticancer Activity through PP2A Activation. Molecules 2018, 23, 2750.

(23) Kandagatla, B.; Prasada Raju, V. V. N. K. V.; Kumar, N. S.; Reddy, G. M.; Srinivas, K.; Iqbal, J.; Bandichhor, R.; Oruganti, S. Practical synthesis of fingolimod from diethyl acetamidomalonate. RSC Adv. 2013, 3, 9687-9689.

(24) Zivkovic, A.; Stark, H. Efficient chromatography-free synthesis of the oxy-analogue of fingolimod. Tetrahedron Lett. 2010, 51, 37693771.

(25) Rice, L. B. Federal funding for the study of antimicrobial resistance in nosocomial pathogens: no ESKAPE. J. Infect. Dis. 2008, 197, 1079-1081.

(26) Michiels, J. E.; Van den Bergh, B.; Fauvart, M.; Michiels, J. Draft genome sequence of Acinetobacter baumannii strain NCTC 13423, a multidrug-resistant clinical isolate. Stand. Genomic Sci. 2016, 11, No. 57.

(27) Grosso-Becerra, M. V.; González-Valdez, A.; GranadosMartínez, M. J.; Morales, E.; Servín-González, L.; Méndez, J. L.; Delgado, G.; Morales-Espinosa, R.; Ponce-Soto, G. Y.; Cocotl-Yañez, M.; Soberón-Chávez, G. Pseudomonas aeruginosa ATCC 9027 is a non-virulent strain suitable for mono-rhamnolipids production. Appl. Microbiol. Biotechnol. 2016, 100, 9995-10004.

(28) Waters, C. M.; Bassler, B. L. Quorum sensing: cell-to-cell communication in bacteria. Annu. Rev. Cell Dev. Biol. 2005, 21, 319346.

(29) Scutera, S.; Zucca, M.; Savoia, D. Novel approaches for the design and discovery of quorum-sensing inhibitors. Expert Opin. Drug Discovery 2014, 9, 353-366.

(30) McClean, K. H.; Winson, M. K.; Fish, L.; Taylor, A.; Chhabra, S. R.; Camara, M.; Daykin, M.; Lamb, J. H.; Swift, S.; Bycroft, B. W.; Stewart, G. S.; Williams, P. Quorum sensing and Chromobacterium violaceum: exploitation of violacein production and inhibition for the detection of $\mathrm{N}$-acylhomoserine lactones. Microbiology 1997, 143, 3703-3711.

(31) Skogman, M. E.; Kanerva, S.; Manner, S.; Vuorela, P. M.; Fallarero, A. Flavones as Quorum Sensing Inhibitors Identified by a Newly Optimized Screening Platform Using Chromobacterium violaceum as Reporter Bacteria. Molecules 2016, 21, 1211.

(32) Gopu, V.; Meena, C. K.; Shetty, P. H. Quercetin Influences Quorum Sensing in Food Borne Bacteria: In-Vitro and In-Silico Evidence. PLoS One 2015, 10, No. e0134684.

(33) White, C.; Alshaker, H.; Cooper, C.; Winkler, M.; Pchejetski, D. The emerging role of FTY720 (Fingolimod) in cancer treatment. Oncotarget 2016, 7, 23106-23127.

(34) Patmanathan, S. N.; Yap, L. F.; Murray, P. G.; Paterson, I. C. The antineoplastic properties of FTY720: evidence for the repurposing of fingolimod. J. Cell. Mol. Med. 2015, 19, 2329-2340.

(35) Yoshino, T.; Tabunoki, H.; Sugiyama, S.; Ishii, K.; Kim, S. U.; Satoh, J. Non-phosphorylated FTY720 induces apoptosis of human microglia by activating SREBP2. Cell. Mol. Neurobiol. 2011, 31, 10091020.

(36) Potteck, H.; Nieuwenhuis, B.; Lüth, A.; van der Giet, M.; Kleuser, B. Phosphorylation of the immunomodulator FTY720 inhibits programmed cell death of fibroblasts via the S1P3 receptor subtype and Bcl-2 activation. Cell. Physiol. Biochem. 2010, 26, 67-78.

(37) Puyo, C. A.; Dahms, T. E. Innate immunity mediating inflammation secondary to endotracheal intubation. Arch. Otolaryngol., Head Neck Surg. 2012, 138, 854-858.

(38) Puyo, C. A.; Peruzzi, D.; Earhart, A.; Roller, E.; Karanikolas, M.; Kollef, M. H.; Krupnick, A. S.; Kreisel, D.; Ibrahim, M.; Gelman, A. E. Endotracheal tube-induced sore throat pain and inflammation is coupled to the release of mitochondrial DNA. Mol. Pain 2017, 13, No. 174480691773169.
(39) Diaconu, O.; Siriopol, I.; Poloşanu, L. I.; Grigoraş, I. Endotracheal Tube Biofilm and its Impact on the Pathogenesis of Ventilator-Associated Pneumonia. J. Crit. Care Med. 2018, 4, 50-55.

(40) Reigada, I.; Guarch-Pérez, C.; Patel, J. Z.; Riool, M.; Savijoki, K.; Yli-Kauhaluoma, J.; Zaat, S. A. J.; Fallarero, A. Combined Effect of Naturally-Derived Biofilm Inhibitors and Differentiated HL-60 Cells in the Prevention of Staphylococcus aureus Biofilm Formation. Microorganisms 2020, 8, 1757.

(41) Mei, T.-W.; Luo, Y.; Feng, X.-J.; Lu, W.; Yang, B. Suzuki coupling based synthesis and in vitro cytotoxic evaluation of Fingolimod and analogues. Tetrahedron 2013, 69, 2927-2932.

(42) Hamada, M.; Nakamura, M.; Kiuchi, M.; Marukawa, K.; Tomatsu, A.; Shimano, K.; Sato, N.; Sugahara, K.; Asayama, M.; Takagi, K.; Adachi, K. Removal of sphingosine 1-phosphate receptor$3(\operatorname{S} 1 \mathrm{P}(3))$ agonism is essential, but inadequate to obtain immunomodulating 2-aminopropane-1,3-diol $\operatorname{S1P}(1)$ agonists with reduced effect on heart rate. J. Med. Chem. 2010, 53, 3154-3168.

(43) Kiuchi, M.; Adachi, K.; Kohara, T.; Minoguchi, M.; Hanano, T.; Aoki, Y.; Mishina, T.; Arita, M.; Nakao, N.; Ohtsuki, M.; Hoshino, Y.; Teshima, K.; Chiba, K.; Sasaki, S.; Fujita, T. Synthesis and immunosuppressive activity of 2-substituted 2-aminopropane-1,3diols and 2-aminoethanols. J. Med. Chem. 2000, 43, 2946-2961.

(44) Erdeljac, N.; Kehr, G.; Ahlqvist, M.; Knerr, L.; Gilmour, R. Exploring physicochemical space via a bioisostere of the trifluoromethyl and ethyl groups (BITE): attenuating lipophilicity in fluorinated analogues of Gilenya for multiple sclerosis. Chem. Commun. 2018, 54, 12002-12005.

(45) Shaikh, R. S.; Schilson, S. S.; Wagner, S.; Hermann, S.; Keul, P.; Levkau, B.; Schäfers, M.; Haufe, G. Synthesis and evaluation of fluorinated fingolimod (FTY720) analogues for sphingosine-1phosphate receptor molecular imaging by positron emission tomography. J. Med. Chem. 2015, 58, 3471-3484.

(46) Skogman, M. E.; Vuorela, P. M.; Fallarero, A. Combining biofilm matrix measurements with biomass and viability assays in susceptibility assessments of antimicrobials against Staphylococcus aureus biofilms. J. Antibiot. 2012, 65, 453-459.

(47) Beus, M.; Savijoki, K.; Z Patel, J.; Yli-Kauhaluoma, J.; Fallarero, A.; Zorca, B. Chloroquine fumardiamides as novel quorum sensing inhibitors. Bioorg. Med. Chem. Lett. 2020, 30, No. 127336.

(48) Collins, S. J.; Ruscetti, F. W.; Gallagher, R. E.; Gallo, R. C. Terminal differentiation of human promyelocytic leukemia cells induced by dimethyl sulfoxide and other polar compounds. Proc. Natl. Acad. Sci. U.S.A. 1978, 75, 2458-2462. 